Florida International University FIU Digital Commons

\title{
Through the Prisms of Gender and Power: Agency in International Courtship between Colombian Women and American Men
}

\author{
Jasney E. Cogua-Lopez
}

Florida International University, jasneycogua@gmail.com

DOI: $10.25148 /$ etd.FI10041606

Follow this and additional works at: https://digitalcommons.fiu.edu/etd

\section{Recommended Citation}

Cogua-Lopez, Jasney E., "Through the Prisms of Gender and Power: Agency in International Courtship between Colombian Women and American Men" (2010). FIU Electronic Theses and Dissertations. 146.

https://digitalcommons.fiu.edu/etd/146 


\section{FLORIDA INTERNATIONAL UNIVERSITY}

Miami, Florida

THROUGH THE PRISMS OF GENDER AND POWER: AGENCY IN INTERNATIONAL COURTSHIP BETWEEN COLOMBIAN WOMEN AND AMERICAN MEN

A dissertation submitted in partial fulfillment of the requirements for the degree of DOCTOR OF PHILOSOPHY in COMPARATIVE SOCIOLOGY

by

Jasney E. Cogua-Lopez

2010 
To: Dean Kenneth Furton

College of Arts and Sciences

This dissertation, written by Jasney E. Cogua-Lopez, and entitled Through the Prisms of Gender and Power: Agency in International Courtship between Colombian Women and American Men, having been approved in respect to style and intellectual content, is referred to you for judgment.

We have read this dissertation and recommend that it be approved.

$\begin{array}{r}\text { Alex Stepick } \\ \hline \text { Maria Aysa-Lastra }\end{array}$

Ana Maria Bidegain

Lourdes Gouveia

Sarah J. Mahler, Major Professor

Date of Defense: March 23, 2010

The dissertation of Jasney E. Cogua-Lopez is approved.

\begin{tabular}{r}
$\begin{array}{r}\text { Dean Kenneth Furton } \\
\text { College of Arts and Sciences }\end{array}$ \\
\hline Interim Dean Kevin O'Shea \\
University Graduate School
\end{tabular}

Florida International University, 2010 
CCopyright 2010 Jasney E. Cogua-Lopez

All rights reserved. 


\section{DEDICATION}

I would like to dedicate this dissertation to my family, whose confidence in my abilities and in me shaped the person I am today. All of you have been models for hard work, personal sacrifices and persistence. And to my husband, the always proud and supportive person whose unwavering love held me through the many uncertainties, challenges and sacrifices in graduate school. 


\section{ACKNOWLEDGMENTS}

I owe my gratitude to all those individuals who made this dissertation possible. To all those Colombian women and American men whom I interviewed I am grateful for opening their hearts and sharing their stories.

My deepest gratitude is to my advisor, Dr. Sarah J. Mahler. I am very fortunately to have her guidance, understanding and patience through the years, holding me to a high research level and teaching me to be a true social scientist. Her mentorship has been vital in providing me with a well rounded experience, opening my eyes to new opportunities and, showing me what I can really be professionally always trusting in my abilities without reservations.

To my committee members, Dr. Maria Aysa-Lastra, Dr. Ana Maria Bidegain, Dr. Lourdes Gouveia and Dr. Alex Stepick I am grateful for their continuous encouragement and guidance. Thanks for being always ready to listen and to give advice, and for being a true inspiration.

I am also indebted to the members of "Team Mahler," my friends, with whom I had the honor and the pleasure to share during the course of my graduate studies particularly for our valuable discussions that helped me create, understand and write this dissertation.

I gladly express my gratitude to Robert Broome, who was always readily available to edit all these pages, constantly challenging me to write to the best of my abilities and outdo my English as a second language limitations. 
Many friends walked with me in this graduate school path. Their support and care helped me to overcome setbacks and stay focused on my final goal. I do value their friendship and deeply appreciate their faith in me.

I am most importantly indebted to my husband. His love and patience, and his constant concern and support were the source of my strength. God opened all the doors and he held my hand while going thought them all, I hope to be at least half of what he has been for me through this process.

Finally, I need to acknowledge the financial support of the Florida International University Dissertation Year Fellowship that founded the data collection and writing stage of this dissertation. 


\section{ABSTRACT OF THE DISSERTATION}

THROUGH THE PRISMS OF GENDER AND POWER: AGENCY IN INTERNATIONAL COURTSHIP BETWEEN COLOMBIAN WOMEN AND AMERICAN MEN

by

Jasney E. Cogua-Lopez

Florida International University, 2010

Miami, Florida

Professor Sarah J. Mahler, Major Professor

Since 1999 Colombia has experienced dramatic increases in emigration, particularly the emigration of women towards the U.S. as fiancées of U.S. citizens or residents. Parallel to this trend is the increased number of websites facilitating these Colombian-American matches. This dissertation investigates the agency of Colombian women and American men who pursue romantic courtship through the services of International Marriage Brokers (IMBs) from the "Gendered Geographies of Power" (GGP) framework of analysis. It examines how both groups' social locations, their positioning in multiple axes of differentiation including gender, nationality and social class, affects how and why they exert their agency across and within different geographic scales. Most importantly, it investigates the role the imagination plays (imagination work) in both men and women's agency, an aspect of the GGP framework that has been under-researched and theorized to date. The research also finds that this 
imagination work is promoted and cultivated in deeply gendered ways by IMBs seeking to profit off this transnational courtship.

Employing data collected via interviews and content analysis of IMBs' websites, the dissertation analyzes comparatively the expectations each group (women, men and IMBs) bring to their imagination work and experiences of the courtship marketplace. A central question posed and answered in the dissertation is "What do women and men courting each other in cyberspace seek and do they find it?" The dissertation finds that the men seek "traditional" women and the women seek "liberated" less "macho" men. Ironically, the men find Colombian women who are among the most "liberated" women in their homeland but who downplay this aspect of themselves in order to strategically find a more modern man and migrate abroad where they expect to find greater personal and professional opportunities. 


\section{TABLE OF CONTENTS}

CHAPTER

PAGE

CHAPTER I - THROUGH THE PRISMS OF GENDER AND POWER: AGENCY IN INTERNATIONAL COURTSHIP BETWEEN COLOMBIAN WOMEN AND AMERICAN MEN .... 1

Colombo-American Matches: A case study ....................................................... 5

Framework of Analysis: Gender Geographies of Power (GGP) ........................... 6

Methodology and Data Analysis .................................................................. 9

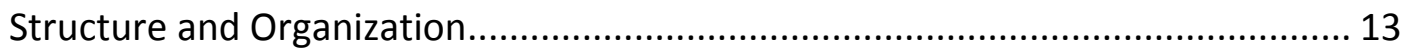

CHAPTER II - GENDERED IMMIGRATION SCHOLARSHIP ............................................... 16

Some early research studies touch upon males and females .............................. 16

WWII-1970s: Migration becomes a male only matter..................................... 19

Migration defined as male-only phenomenon ............................................. 19

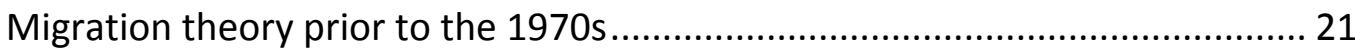

The feminist movement meets migration scholarship........................................ 23

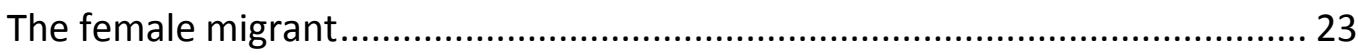

Gender as variable (male vs. female studies) ................................................ 24

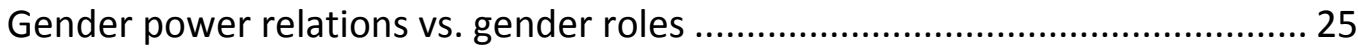

Bringing females into theory ...................................................................... 25

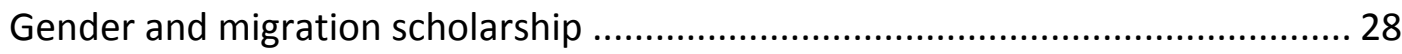

Gender as a central organizing principle of migration .................................. 28

Gender and transnational migration ........................................................... 30

Gender Geographies of Power ............................................................... 32

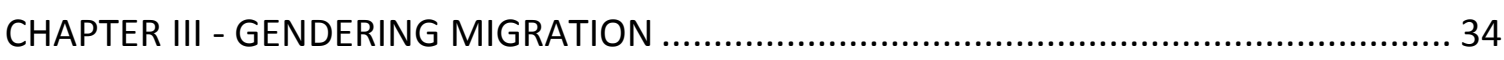

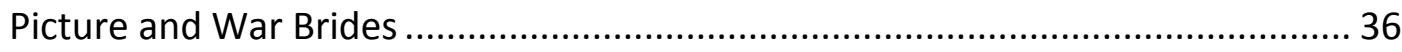

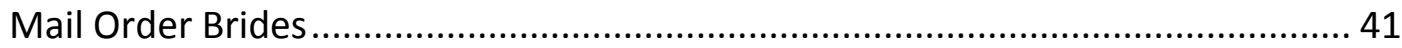

IMBs as part of the migration industry ......................................................... 44

International courting/marriage as migration strategy.................................... 46

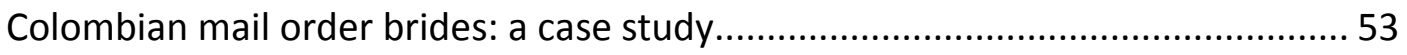

Colombo-American Courtship and Gender Relations ....................................... 55

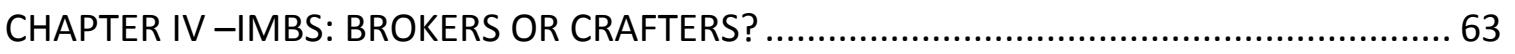

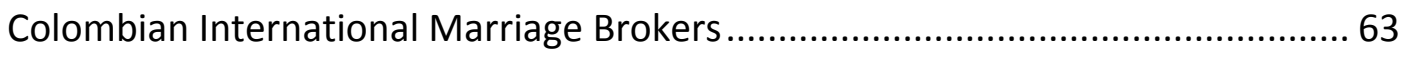

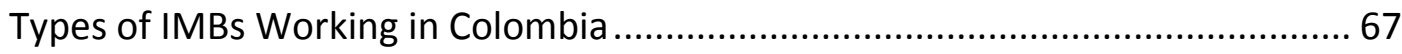

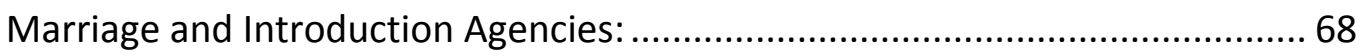

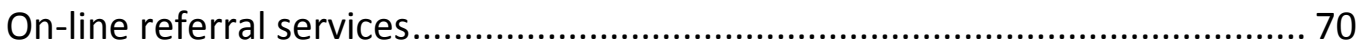

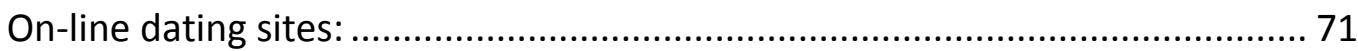

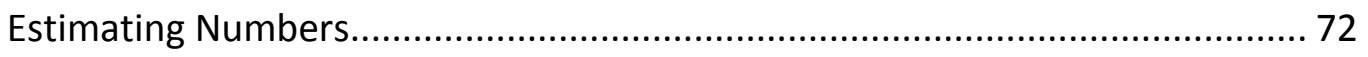

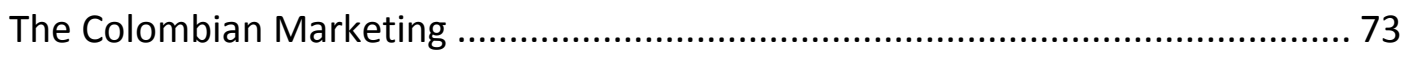

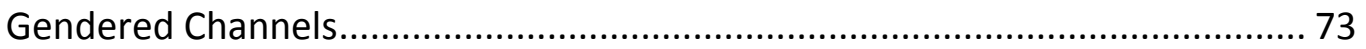

Gendered Content ............................................................................... 77 
Overcoming Colombians' Bad Image?

IMBs: crafters of international couples - Brokers of the International Migration Industry

CHAPTER V - GENDERED IMAGININGS 101

Shared Imaginings? - What Are Men And Women Expecting Of These

Relationships? 102

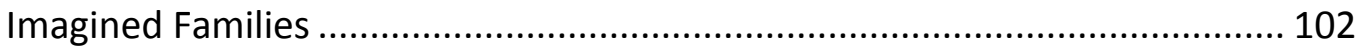

Imagined Adonises, Aphrodites and their Offspring .................................... 105

Gendered Motivations .................................................................................. 114

What Motivates Men To Use The Services Of International Marriage Brokers? ...

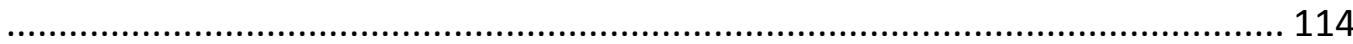

What Motivates Women To Use The Services Of International Marriage Brokers? 124

Recapitulating 139

CHAPTER VI - IMAGINATION INTO ACTION: THROUGH ROSE COLORED LENSES (THE EXPERIENCES OF COLOMBIAN WOMEN AND AMERICAN MEN). 141

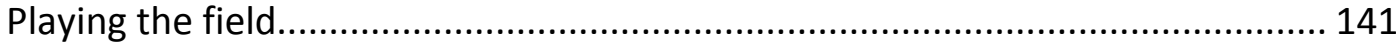

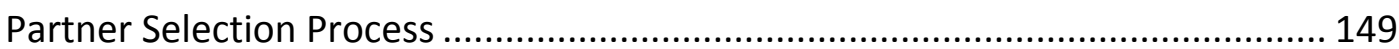

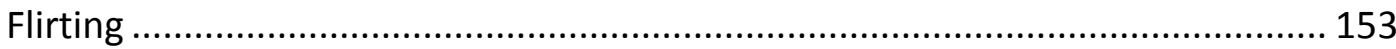

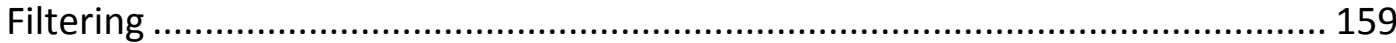

Cyber-chemistry and the not so rose colored lenses ...................................... 163

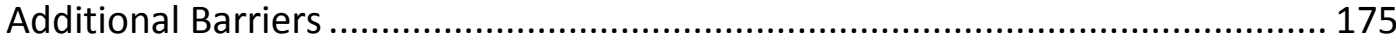

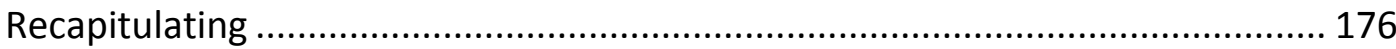

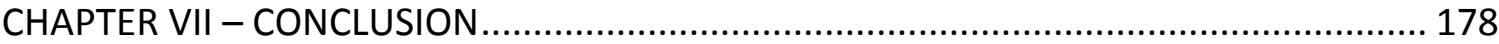

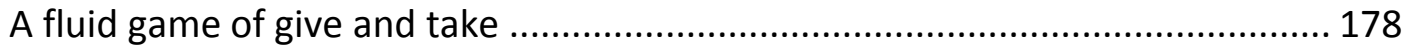

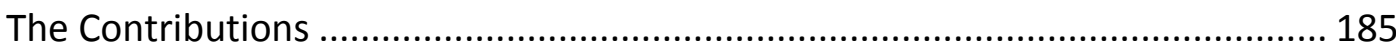

The future of gender international relations studies .................................... 187

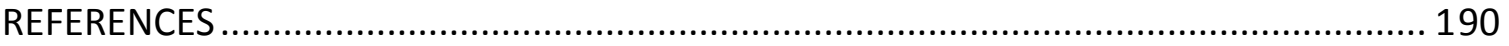

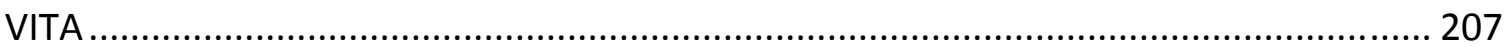




\section{LIST OF TABLES}

TABLE

PAGE

Table 1-1: Interviews distribution by source, location and language................................ 10

Table 3-1: South American non-immigrants admitted as fiancés of U.S. citizens

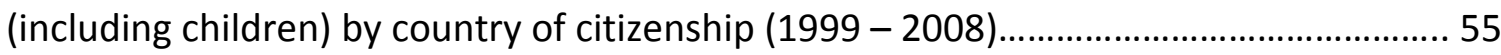

Table 4-1: List of attributes IMBs use to compare Colombian and American women..... 81

Table 4-2: General attributes IMBs use to compare Colombian and American men....... 90

Table 5-1: Motivational tendencies of enrollment in IMBs by gender........................... 113 


\section{CHAPTER I - THROUGH THE PRISMS OF GENDER AND POWER: AGENCY IN INTERNATIONAL COURTSHIP BETWEEN COLOMBIAN WOMEN AND AMERICAN MEN}

While conducting research in Bogotá for this study, I met Rosa Burgos by coincidence. That afternoon, after completing a long interview with a ColomboAmerican couple, a friend of mine asked me to accompany her to get the weekly followup treatment for her recently performed liposculpture. Rosa was the aesthetician with whom my friend had an appointment. When Rosa realized I lived in the U.S., she immediately started asking me questions about American men and life there. She was so interested in discussing this that she offered me a free massage if only I agreed to talk to her during the session. We ended up going to a nearby coffee shop where she told me her story. Rosa is a beautiful 33 year-old, certified full body aesthetician who has been working with a well known Colombian plastic surgeon for more than 10 years.

She is an attractive, soft spoken and amiable woman. She complained of having had bad luck with Colombian men since she started dating back in her teenage years, saying that they were always cheating on her, mistreating her and not taking her seriously. Four years ago she started a relationship with a Colombian man who she thought was very decent and serious. After almost a year of dating she realized she was pregnant, to which he reacted by disappearing. She decided to have the baby and raise him alone. Two years ago, Rosa joined a high-end marriage agency after seeing an ad in a very exclusive magazine a client of hers had left in her treatment room. Aided by the 
manager of the agency, Rosa was able to write a "winning" profile and even got a discount on the photo studio. Many of her clients come from the States (what is known as "plastic surgery tourism") and she had always been curious about what her life would be like if she had the opportunity to meet a nice American man and live in the U.S. She decided to join the agency because she believed American men were different than Colombian men, because the manager of the agency made things easier for her and because many of her clients had explained how much more profitable her occupation could be in the States. Six months ago, after talking, meeting and dating several Americans online and face-to-face, she finally met Kenneth Healy, who she believed was different from all Colombians and from other Americans who were only interested in sex.

Kenneth lives in San Jose, California. He is a 56 year-old retired marine and business owner who has been divorced twice and has no children. I had the opportunity to interview Kenneth over the phone right after I came back from Colombia. He joined the same marriage agency as Rosa eight months before they met. Kenneth was disillusioned and disheartened about American and Colombian women but out of his bad experiences he met Rosa, with whom he professed to be in love and ready to marry. Kenneth had gone to Colombia the first time and met a woman that lied and cheated on him while he was completing the paperwork for her fiancée visa. He realized she was being unfaithful the day he flew to Bogotá to surprise her and to celebrate their six month anniversary. Upon arrival he checked into the agency's hotel and to his surprise he found his "girlfriend" holding hands and smiling at another American man in the 
agency's computer lab, showing everyone her big new diamond ring. But the second part of his trip was better: thanks to the support and encouragement of the agency's representatives he met Rosa and her baby. Immediately he thought of her as a very loving person. He remembered how he watched the way that she treated her child and was impressed by her loving spirit. At the beginning they understood their relationship as one simply of friendship as he was very heartbroken and not interested in a woman with children and she was looking for someone younger, taller, better looking and willing to commit for life. Kenneth stayed in Bogotá for ten days, out of which he spent seven with Rosa and the baby. After he returned to San Jose, they continued to talk to each other over the Internet and in a matter of a month they realized they were meant for each other and have been courting ever since.

At the coffee shop Rosa asked me if what she was feeling was normal, and wanted some assurance about American men and about whether all the things he had promised her could be true, since the only source of information she had were the people at the agency. She said Kenneth wanted to get married and help her obtain the licenses she needed to work in the States. I asked her why she had changed her mind, since in the beginning she was not really interested in him since he was short, old, not particularly good looking and not ready for a relationship. She explained that after talking to him regularly she came to realize that he was all she had dreamed of but in a different "container." She could sacrifice her ideal of the "perfect American man" for what she saw in front of her: a very committed, loving and responsible person, who not only loved her but also her son, and offered them a solid future. When I asked Kenneth 
if it was not too soon (after what he had been through) to start another relationship, he stated that Rosa was not only gorgeous but was also a very nice person, exactly what he had envisioned he would find in Colombia since the moment he joined the agency. Even though initially he was not looking for a woman with a child, he stated that Rosa's son was a good baby and that the child seemed to like him. Almost a year after our initial conversation at the coffee shop, while preparing to write these lines, I emailed Rosa. She responded, telling me that she is now living in San Jose with Kenneth, although she has not yet married him as she is in the middle of a legal dispute with her child's father, who is not allowing the baby to leave Colombia. They realized that finding the right person through the agency was not easy. She knows that what their respective images of the "dreamed of partner" was very important in their relationship. At the same time it was only one component of what would lead to a successful relationship and that they would have to surpass this and many other difficulties while courting, when engaged and when they become married.

The purpose of this study is to examine the motivations and expectations of both women and men using the services of marriage agencies to facilitate their search for love, migration or both. The story of Rosa and Kenneth serves as a condensed illustration of the multiple challenges that these individuals face while in the process. This study also aims to analyze the role International Marriage Brokers play in the development of these relationships. Rosa and Kenneth's story shows how the agency's personnel often play a key role in these kinds of relationships, not only in the process of enrollment and matching, but also when their clients face very difficult emotional and legal situations. 


\section{Colombo-American Matches: A case study}

Most of the literature and studies of international courtship and marriagerelated migration focuses on Asian and South Pacific countries and women. Little is known about these situations in other countries, particularly in Latin America, with the exception of the works of Felicity Schaeffer-Grabiel (2004) and Denise Brennan (2003). Their seminal work gives us reason to believe that some of the rationale for participating in international marriages is not the same around the world, and the factors affecting people in diverse circumstances cannot be assumed to be entirely similar. Economic, social, political and geographic differences contribute to creating different social environments for women and men in different parts of the world, and Colombian women are not an exception.

Colombian women and American men were chosen as the case study for this work for a myriad of reasons. According to U.S. Homeland Security immigration statistics, Colombians have increased their admission into the U.S. as fiancées of American men (including children) by 321\% from $1999(447)$ to $2008(1,433)$ (Yearbooks of Immigration Statistics 1999 - 2008). Fiancée visas are offered by American men to Colombian women who perceive this as an easier way to immigrate to the U.S., when compared to other options, because of the tightening of the borders after the events of September 11, 2001 and the prejudices to entry based on stereotyping Colombians as drug-traffickers. However, more relevant are the particular, culturally based gender relations and migration patterns (both to be developed in Chapter 3 ) that make relationships between Colombian women and American men such a good case study. 
Each individual's social location and geographic scale brings in resources that yield strong agency and imaginative processes. For women these images are of professional and married lives in a different country, for men these images are of traditional wives; both express distinctive cultural and social norms.

Framework of Analysis: Gender Geographies of Power (GGP)

The predominant literature on international marriage and courtship has focused on power differentials in which men are usually perceived as powerful and women as powerless. This study, in contrast, demonstrates how the use of imagination, social changes and the role of technology and communication systems have aided the leveling and shifting of power. It also includes the notion of the ideal of an international partner: to find a traditional loving partner by American men and to pursue love, a better life and migration by Colombian women. Sarah Mahler and Patricia Pessar (2001, 2003, and 2006) developed a comprehensive framework for the analysis of gender termed "Gender Geographies of Power." I am using this framework as the foundation for the analysis of the data collected and the overall development of the present study. In their own words it is a:

Framework for analyzing people's gendered social agency - corporal and cognitive - given their own initiative as well as their positioning within multiple hierarchies of power operative within and across many terrains...The gendered geographies of power framework is intended to aid case and comparative study research and analysis of gender across transnational spaces. [Pessar and Mahler, 2003:818] 
This framework is composed of three key components:

1. Geographic Scales: This spatial term recognizes that gender operates simultaneously across multiple spatial and social measures and institutions. It is within those institutions (body, family, state, workplace, etc.) and between and among them that gender ideologies and relations are stated, shaped or both.

2. Social Locations: This component refers to the individual's positions within interconnected power relations created by multiple stratifying factors (history, politics, economics, geography, kinship relations, etc.). Social locations are not only ascribed by birth but are also acquired through life circumstances and opportunities, leading to different advantages and disadvantages. This means that social locations are not fixed or singular; on the contrary, they may be fluid, changeable and multiple. Thus, the proponents of this framework comprehend "social locations" as a continuum from most disadvantaged to most privileged and locate people by class, race, sexuality, ethnicity, nationality, age, etc., along it with the possibility of relocation within the continuum if perceived as necessary. For instance, one can be privileged vis-à-vis gender but not vis-à-vis class, race, etc.

3. Agency: Using Doreen Massey's (1994) power geometry concept, Mahler and Pessar include in this component the different types and degrees of agency that people exercise according to their social locations within different time-space compressions, promoting or constraining mobility as a whole. Additionally such agency places people in different positions regarding access to different degrees 
Additionally the authors recognized the role of imagination, defined as specific cognitive characteristics (initiative, creativity, etc.) that affect someone's social location and power geometries. These individual characteristics are akin to Appadurai's ideoscapes ${ }^{1}$ that create, shape and renovate general understandings and ideologies of gender, consumption, modernity, place, "the family," etc.

It is precisely this part of the framework that I develop most extensively. I have termed it "imagination work" representing the ability of individuals to visualize their future in terms of dreams, expectations, beliefs, and overall fantasies nourished by the experiences of others and the influence of "accredited" institutions, cultural myths, etc. More than the recognition of the imaginative work that individuals perform, it should be considered a critical tool that each individual exploits in order to achieve goals that they would otherwise find difficult to achieve due to the multiple barriers (social, cultural, geographic, etc.) they face.

In this study, imagination work represents the important role that imagination play in the development of Colombo-American courting relationships, including a better understanding of what the participants hoped for compared to what reality yields. I also

1 "Ideoscapes are a concatenation of images, often related to ways of life, many times political and frequently have to do with ideologies of states or economies and the counter-ideologies of movements explicitly oriented to capturing state/economic power or a piece of it." (Appadurai, 2003: 34) 
believe that this is a concept that contributes to the study of gender and agency in general, beyond its contribution to this particular case study.

Overall, the GGP framework, including the development of "imagination work" and the use of diverse methodological approaches, is very useful for the development of gender, agency, transnational and migration studies. GGP also considers elements and concerns of both agency and structure that allow the possibility of its use within a more fluid and continuous conceptualization of the courting and migration process. Thus, this study uses the GGP framework to examine and understand the stories of these men and women who try to surpass constraints they find locally in searching for suitable partners and better futures. I believe that this study provides the audience with a firsthand, empirically-based perspective that goes beyond geographical borders and sheds light on the ongoing processes of international gender relations, power distributions and agency, particularly in the form of imagination processes that yield novel strategies of courtship and migration.

\section{Methodology and Data Analysis}

The data collection for this study consisted of two types of data. First, openended, semi-structured interviews with a) Colombian women and American men participating in international courtship and b) IMB leaders/organizers in Colombia and the U.S. Most of these interviews were conducted in Bogotá, Colombia in the offices of several IMBs and other locations of the participants' choosing. Other interviews were conducted over the phone. Based on a snowball sampling technique, I was able to interview a total of forty (40) subjects (Table 1-1). 
Table 1-1: Interviews distribution by source, location and language

\begin{tabular}{|l|c|c|c|c|c|}
\hline \multirow{2}{*}{ Subject } & Number of & \multicolumn{2}{c|}{ LOCATION } & \multicolumn{2}{c|}{ LANGUAGE } \\
\cline { 3 - 6 } & Interviews & Colombia & U.S & Spanish & English \\
\hline Female & 19 & 15 & 4 & 19 & 0 \\
\hline Male & 13 & 10 & 3 & 1 & 12 \\
\hline $\begin{array}{l}\text { IMB } \\
\text { Representatives }\end{array}$ & 8 & 5 & 3 & 5 & 3 \\
\hline TOTAL & 40 & 30 & 10 & 25 & 15 \\
\hline
\end{tabular}

These interviews lasted from 75 to 120 minutes and were recorded only when permission by the interviewee was granted. Five participants did not grant permission for recording, so detailed notes were taken for these interviews. As all interviewees were promised complete confidentiality, special care was taken to remove any explicit or implicit identifiers. Thus names and other identifying details have been changed throughout the text. All the interviews with women, one with men and five with IMB representatives were conducted in Spanish; all the rest were conducted in English. All interviews were translated and the ones conducted in English reviewed to assure grammatical correctness for all.

The second data collection technique consisted of content analysis of the information contained in the web pages and advertising material of eight of the main IMBs that arrange matches between Colombian women and American men. Although a total of 69 IMB websites were reviewed, a indepth analysis was performed on eight of them. Bulletins, updates, publications, etc. from the agencies to their clients and participants were also reviewed. A major concern in the development of this study was the ability of the researcher to access the private spheres of IMB organizations. To 
counter this limitation I made initial contacts with individuals in IMB organizations through my own established networks in Colombia. The fact that I am a Colombian immigrant myself who is married to an American citizen allowed me to be identified as part of their clientele and served to open the door to conversations and further exploration of these courtship, marriage and migration processes.

By using MAXQDA, the qualitative data analysis software, the data analysis was developed in a systematic manner. Transcripts of all the interviews were imported into the program making two different text groups of data (individuals and IMBs). Sociodemographic data were recorded using the attributes option of the program as a way to create a comprehensive (as far as possible) database of the demographic descriptors of the subjects interviewed and to facilitate the quantification of relevant variables for further exploration and reporting. The table of attributes contains information on individuals' gender, age, marital status, education, occupation, language proficiency, number of children, exploratory trips to the U.S. or Colombia, household size, house and car ownership, etc. The table also contains information on the IMB's location, ownership structure, type, size, and success rates.

Once all the transcripts were imported, a process of pre-coding each interview was developed based on the basic cognitive elements of the project (i.e., motivations, expectations and experiences) in addition to key questions contained in the interview protocols (personal stories, overall process, history of IMBs, types of clients, strategies of marketing, etc.). The pre-coding step was essential in the understanding of the data and the specific identification of patterns and themes within each initial code, which in 
turn were further explored by distinctive attributes (e.g., gender, age, education, etc.). As the analysis was being performed, most of the sample quotes were selected and assigned weight scores to facilitate their retrieval later in the reporting process. Once those main patterns and themes were identified, the elements of the resulting code trees were revised to eliminate replication, merged when needed and further examined using the MAXQDA activation principle by attributes to complete the analysis. Using the visualization tool (table of coded segments) I was able to convert selected code frequencies into attributes that allowed me to quantify qualitative data and obtain valid and reliable statistics in terms of the determination of percentages of different patterns observed (e.g., motivational tendencies, picture posting behavior, commitment levels, relationship fluidity and pace, etc.).

As stated before, the analysis of IMBs was complemented with the content analysis of their websites. Such analysis was also supported by the use of MAXQDA. The entire content of 8 websites was coded (with respect to company profile, pricing, marketing strategies, gender stereotypes, matching process, graphic content/representations). These data were supplemented (in some cases triangulated) with the content from other 61 additional websites, to make sure the information was accurate and conclusions were accurately drawn. Another important tool used was the "external link" feature that allowed me to easily access the sites and maintain an organized record of the pictures and graphic representations of each site that were part of the analysis. 
In general, the data collected provided original data for describing the processes, motivations, and expectations of Colombian women and American men participating in and using IMB services. Additionally, the interviews and content analysis of the IMBS provided me with another perspective of the process including their recruitment efforts and their perpetuation of gender ideologies. These tools helped to measure attitudes and orientations of this specific population which allowed the development of refined descriptive and quantitative assertions about international courtship and marriagebased migration through the use of IMB services.

It is important to note two main limitations of the project. First is the insufficient data collected to explore issues of race that these courting relationships might imply. Second, because of the depth and presumed long-term character of these international romantic matches, this study only focuses on the courting stage. Future studies need to focus on the actual development of their marriages, and possible influences of race in their matches.

\section{Structure and Organization}

The organization of this study is straightforward. Chapter Two contains a comprehensive study of the migration scholarship history, particularly focusing on the development and inclusion of gender as central to the study of migration. It contains a thorough explanation of the Gendered Geographies of Power framework used for the data analysis and development of the study. The chapter highlights the need for considering gendered aspects, particularly the idealizing, longing and imaginings that create and perpetuate migration flows when studying migratory processes. 
Chapter Three addresses cross-border relationships, particularly the specific definitions and descriptions of three types of these relationships: picture brides, war brides and mail order brides. This section highlights the strong levels of agency exerted by men in these types of relationships as presented in the literature and will also discuss the role of women, who are often portrayed as victims and/or submissive individuals with little or no agency. Such agency and power differentials are challenged by my focal case and are explained in the context of the GGP. Special emphasis is placed on crossborder relationships constituted between Colombian women and American men with the intermediation of International Marriage Brokers (IMBs) and on the role of IMBs in the migratory process.

Chapter Four presents the history of the Colombian IMB business from its timid beginning in the 1960s to today's expanded presence; it describes the characteristics of the different types of IMBs functioning in Colombia and their marketing and gendered strategies. It includes the analysis of IMBs as crafters of specific messages and ideals of future partners and relationships. International Marriage Brokers then are presented as suppliers of "ideals" that feed the imagination of both men and women and allow their active participation in the process of transnational courting, marriage and migration.

Chapter Five contains detailed explanations of the different motivations that people expressed as key to use the services of IMBs. It includes the expectations that women and men have for the future in terms of their family structure, physical appearance and children, as well as descriptions of particular motivational factors by gender. The chapter emphasizes the important role of imagination in the processes of 
international courtship through the services of IMBs. Such imagination is presented as gendered and within specific idealizations of the other that creates conflict between genders, at least in theory. Chapter five also includes an analysis of the geographic and social locations of the participants as complementary forces shaping their imagination and willingness to migrate.

Chapter Six illustrates the reality of interviewed women and men participating in international courtship through the services of IMBs. Divided by different processes (partner selection, flirting, filtering) it contains detailed explanations of the ups and downs participants face in their effort to find the imagined partner. It also includes stories that portray a long journey with some disillusionment, some success but in general a combination of experiences and strategies within the context of gender and power. This chapter thus contains the stories and explanations of the distinctive ways these individuals exert power and shows how the crafting and commitment in these relationships really provides a space for agency and for different strategies for courtship and migration to blossom. This chapter accentuates the consistencies or inconsistencies between women and men in their behaviors and their imagination work. 


\section{CHAPTER II - GENDERED IMMIGRATION SCHOLARSHIP}

While in the process of researching the basic literature for the development of this project, I realized that there was the lack of a concise description of the literature about gender and migration, considering that I was reading different pieces of the puzzle at different historical periods. I considered (and it was part of the requirements for my degree) that a consolidation of such literature was needed as of the foundation for the study of international courtship and marriages. This chapter, then is the [consolidation] of such material from a historical perspective. It contains a description of the historical progression of migration scholarship starting from a) an analysis of early studies that differentiated the experiences of male and female migrants, to b) the study of the migration scholarship that progressively defined migration as either a male-only or female-only phenomena and that c) finally arrives at a more comprehensive study of gender migration.

\section{Some early research studies touch upon males and females}

The large migration of people during the late 19th and early 20th centuries included movements of both women and men. However, early studies of migration cannot be considered to be gender-driven, nor even gender-aware. However, at least some of them described gender differences and did not merge the experiences of immigrants into a gender-absent perspective. Although a significant study of the experiences of female immigrants was still lacking, those early studies of migration 
sometimes mentioned, though not extensively, female experiences and family dynamics in descriptive terms.

Among the most important of this early research was that generated by The Chicago School of Sociology, especially research produced before the 1940s. Through various methodologies (participant observation, life histories (e.g., diaries, letters) direct interviews, etc.) researchers chronicled the different experiences of female and male migrants, and of entire migrant families. They documented various strategies each of those groups used in order to accommodate themselves to their new environments (Simon, 1992). Some of the key works produced at the time that included both females and males as subjects include: Italian Immigration into the United States by di Palma Castiglione (1905); The Jewish Girl in Chicago by Viola Paradise (1913); The Polish Peasant in Europe and in America by Thomas and Znaniecki (1919), among others. Additionally, the publication of autobiographies and life stories at the time recognized the differences between the migratory experiences of women and men as in the case of The Promised Land by Mary Antin (1912) and Living my Life by Emma Goldman (1931). The compilation of life stories at settlement houses, such as the Jane Addams Hull House in Chicago, allowed also for the uncovering of the diverse experiences of male and female immigrants that were then used by the Chicago School authors and more recently by some feminist writers (see Elizabeth Ewen: Immigrant Women in the Land of Dollars [1989]; and Baxandall and Gordon: America's Working Women [1995]).

Although historians at that time also tended to summarize migration history without mentioning much about the differences between male and female migrants, 
they did not exclude either group. However, there were biases. For example, female migrants were mentioned specifically only in those short chapters or sections related to household activities. They were also mentioned in the context of public/job related issues such as joining unions, participating in strikes, fighting for suffrage rights, etc. (Weinberg, 1992; Pedraza, 1991). A good example of these types of accounts is The Huddled Masses: the Immigrant in American Society, 1880 -1921 (1982) where women are mentioned in small sections on households or unions of one of the chapters of the book.

Women are also mentioned in the earlier studies of migration specifically with respect to the effect of their sex on public policy and migratory status. Women were discriminated against within the migration process based on assumptions of prostitution, sexual preferences, illiteracy, marriage fraud, fears of miscegenation, etc., particularly if they were Chinese, Japanese, Indians, or Filipino (Gardner, 2005; Hing, 2004; Luibhéid, 2002; Joppke, 1999).

Early attempts at theorizing also paid some attention to gender/sex, when attempting to produce migration theory, as epitomized by Ernest Ravenstein's 1889 essay "The Laws of Migration." He mentioned as one of his laws for example, the predominance of females among short distance migrants and the need to further study such a tendency. However, later, when Ravenstein's work is mentioned by many of the pioneers of today's migration theory (i.e., Lee, 1966), his gendered approach was muted. Subsequently almost all theorizing has been done without regard to gender until very recently. This will be discussed later in detail. 
In contrast to the earliest studies of migration which were inclusive of male and female migrants (though again, not exhaustively so), studies of migration produced between the 1940s and 1970s muted, if not excluded altogether, the contributions and experiences of female migrants, either by coincidence, or as a direct outcome of World War II. Consequently, the next section contains a description of the inconsistent development of migration studies and theories and the strong polarization of such studies towards an analysis of male-only migration.

\section{WWII- 1970s: Migration becomes a male only matter}

\section{Migration defined as male-only phenomenon}

World War II marked a new era for migration scholars; immigration studies became focused on the issue of labor supply and demand which was needed in order to reconstruct and reactivate the wounded economies of the world. Migration scholars tended to share the common image of international migrants as young breadwinning men. This consequently led to the stereotypical perception of migration as a male strategy (Houstoun, et all, 1984; Leeds, 1976; Pedraza, 1991; Simmon and Brettel, 1986). Because of the importance of these migrations (primarily based on the large numbers of people that it mobilized), the majority of scholars up to the 1970s essentially failed to see immigration as gendered. They ignored the differences in experiences of immigrant women and shortsightedly condensed the experiences of all immigrants. They assumed that the male experience sufficed to explain migration. Those same authors habitually portrayed female immigrants (if discussed at all) as 
passive beneficiaries of migrant men - the "real migrants" (Pedraza, 1991; Lee, 1996;

Grieco and Boyd, 1998; Hondagneu-Sotelo and Cranford, 1999; Hondagneu-Sotelo, 1999; Mahler, 1999; Pessar and Mahler, 2003, Zlotnik, 2003).

The Bracero Program (1942 - 1964) is exemplary of this male bias both in policy and in research. The Bracero Program was a labor importation treaty between the U.S. and Mexico in which Mexican workers were allowed to work temporarily in U.S. agriculture. This program only permitted males to participate, thus effectively creating male dominance in Mexican migration. But this fact has rarely been highlighted, let alone recognized. As Mexican migration became the stereotypical migration in the post WWII U.S., so did the unstated assumption of migration as a male phenomenon. A similar process characterizes the "gender neutral" research on post-war experiences of guest workers and guest worker programs in Europe. The classic work by Castles and Kosack (1973) on migration in the Western European countries of Great Britain, France, Germany and Switzerland centered on male workers. This study of migration and many others produced in Europe failed to investigate female migrants, thereby eliminating the possibility of comparing male vs. female barriers and opportunities faced by immigrants within and across Europe.

In sum, after WWII, and prior to the late 1970s, immigrant women were almost invisible in academic discussions and publications examining the large movements of people around the globe. Nevertheless, it was during the same post-war period that female immigrants started to move more often and more independently than they did previously. Predominantly as a response to labor demands, and also given their post- 
war marital condition (widow/single) or their fresh awareness of existing opportunities for a better life in other places on the planet, the rate of female migration rose (Morokvasic, 1984; Pedraza, 1991; Gabaccia, 1992; Lee, 1996; Hondagneu-Sotelo, 1999; Zlotnik, 1995). Once again, in evident contradiction to the large participation of females in migratory movements, few studies or publications were produced which took into consideration the particular experiences of female migrants.

\section{Migration theory prior to the 1970s}

Migration theories reflect the academic thought and assumptions about the world operative at the time of their creation and under the historical circumstances of that time. Although the migration experiences of men and women can be fundamentally different, migration research has developed theoretical approaches that typically fail to address and therefore to explain the specific interactions between gender and migration (Oishi, 2002). One reason for these limitations in theory is the use of research methodologies (whether quantitative, qualitative or a combination of both), that assume migrants to be male (and thus are gender biased) or treat gender as a male/female dichotomous variable. For instance, Everett Lee in 1966, although using Ravenstein's work as the foundation for his analysis (which had addressed gender to a degree), failed to formulate a gender aware framework. Instead he focused on the volume of migration, the establishment of streams and counterstreams, and general characteristics of migration without considering women as strong, independent and 
specific participants of the migratory process and, once again, portrayed migration as a male-defined process.

Of those migration theories produced in the post-WWII period, the Neoclassical Economic Theory is a typical example of a theory that does not consider gender. This theory has been used very heavily and is still the leading lay if not scholarly view on migration. This theory explains international migration as being caused by economic factors, whether at the macro or micro level. From a macro perspective, migration is caused by geographic differences in the supply and demand for labor (Todaro and Maruszko 1987 in Massey, 1999). The macro perspective emphasizes the importance of migration to the equilibrium needed in the process of global economic development, and involves the movement of people in response to different wage systems and the availability of jobs in different parts of the world (Massey, 1999). A micro perspective recognizes the role of individuals in the decision-making process; however, deciding to migrate or not is presented as merely the cost-benefit analysis of migration and settlement without taking into account the more complex dynamics of gender, family, etc. (Massey, 1999).

Neoclassical economic theory emphasizes supra-individual economic factors while socio-cultural characteristics (e.g., ethnicity, gender, etc.) play a silent role. Microeconomic perspectives also ignore gender completely, these two (macro - micro economic analyses) help to explain the overall pre-1980s omission of gender in migration analysis. Additionally, this neoclassical theory presents women, when mentioned at all, primarily as wives or dependents of migrants and not as independent 
migrants due in part to their perceived low qualifications for the labor market in developed countries and to the prevailing assumption that men were breadwinners (Grieco and Boyd, 1998). Correctives to genderless theorizing on migration would begin as females and then gender would be brought in to migration research beginning in the 1970s.

\section{The feminist movement meets migration scholarship}

Up to this point I have outlined and analyzed the early history of gendered migration scholarship, highlighting the shift from the earliest studies that were inclusive of men and women as particular participants in migration movements up to the postWWII migration scholarship that ignored the experiences of women and defined migration as a male matter. I have shown the development of migration theory as following a similar history. What follows is a review of a substantial transformation of migration scholarship - the history of bringing female migrants, then male vs. female analysis and ultimately gender into migration scholarship.

The female migrant

The emergence of the women's movement in the late 1960s and early 1970s in the U.S. and the consequent increased interest in topics directly related to women stimulated a rejuvenation of the study of migration and the reinsertion of females into it (Morokvasic, 1984; Pedraza, 1991; Brettell and deBerjeois, 1992; Weinberg, 1992; Hondagneu-Sotelo and Cranford, 1999). However, is important to note that most of these new studies adopted a "women only" framework (Hondagneu-Sotelo, 1999; Hondagneu-Sotelo and Cranford, 1999; Pessar and Mahler, 2003). They tended to omit 
the study and analysis of men and boys as part of the migration sequence. Female-only studies replace male-only studies as normative during this time (Pessar and Mahler, 2003). In retrospect, the transition from a "male only" to a "female only" perspective in the analysis of migration substituted one bias for another - albeit the second was intended to be a corrective to the original. The move to a focus on the female ultimately laid the foundation for later seeing gender as an inclusive and centralizing concept in the study of migration (Hondagneu-Sotelo, 1999; Hondagneu-Sotelo and Cranford, 1999).

$\underline{\text { Gender as variable (male vs. female studies) }}$

While many feminist migration researchers were busy focusing on female migrants, some authors opted to develop migration studies employing "gender" not as a concept but as the variable "sex." This led to the production of male vs. female comparisons, which were common among researchers utilizing quantitative data, particularly surveys and census materials, with sex as one of many independent variables of the analysis (Massey, 1987; Fawcett and Arnold, 1987; Weinberg, 1992; Zlotnik, 1997; Hondagneu-Sotelo, 1999; Hondagneu-Sotelo and Cranford, 1999; Foner, 2003; Hondagneu-Sotelo, 2003a; Pessar and Mahler, 2003). The reduction of the complex concept of "gender" to the variable "sex" generated important statistical analyses and comparisons between male and female migrants. They were a far cry from understanding gender but were an improvement over ignoring male and female differences. "Women only" and "gender as variable" studies also largely lacked historical depth, overall contextual awareness and recognition of the dynamics of everyday life 
(Fawcett and Arnold, 1987; Massey, 1987). Although these studies served to balance the hitherto male-only studies, there was still the need to develop a more comprehensive study of gender and migration.

\section{Gender power relations vs. gender roles}

Another "solution" to the earlier male bias in migration research was developed via studies that focused on rigid sex role models that depicted men as strong leaders in the public sphere while women were portrayed almost exclusively in motherhood and other domestic, private sphere roles. These role-based models helped explain why men migrate and women remain passive followers or do not migrate at all. The emphasis on static sex "roles," common outside migration research as well, would later be criticized in favor of more process-oriented as opposed to structure-oriented views. Structureoriented "roles" were criticized in favor of dynamic "power" analyses including the examination of gendered power relations, social change and the significance of women as active decision-makers and change generators (Weinberg, 1992; Hondagneu-Sotelo and Cranford, 1999; Pessar and Mahler, 2003, Pessar, 2005).

\section{Bringing females into theory}

With the inclusion of women in the analysis of migration, developments in theory also started to incorporate females. One of the most notable theories that includes women and located them centrally is the Household Theory $(\mathrm{HH})$ or the New Economics of Migration. This theory places the migration decision-making into larger units of analysis such as the family or the household. The decision to migrate is thus taken as the result of an economic analysis that allows the migrants to maximize their 
expected total income and hierarchical status and also to minimize their potential risks through the diversification of income (Massey, 1999). The proponents of this theory argue that migration cannot be understood based solely on individuals weighing economic and political pros and cons as the microeconomic theory argues. Rather, they emphasize the analysis of socio-cultural processes developed within the household unit. Therefore, within this theory the focus is shifted to the entire household, where women are seen as key participants in economic strategies and decision-making processes (Pessar, 1982, George, 1992).

Although in principle $\mathrm{HH}$ theory encompasses life experiences, values, gender differences and identities of the different subjects, these are limited to the household level of analysis and thus do not capture or analyze supra- $\mathrm{HH}$, multi level power structures that affect migrations. Given that gendered differentials of power, knowledge and access to resources are not fully considered in the HH theory, analyses focus on the dominant actors--predominantly men--at the expense of the subordinated ones-predominantly women (Grieco and Boyd, 1998).

Other theories, such as World Systems Theory and Segmented Labor Market Theory, also include gender to some degree, certainly more than the micro-economic theory had. World Systems Theory, as proposed by Emanuel Wallerstein, states that the capitalist expansion from core (developed) to peripheral (undeveloped) countries creates changes in the economies of peripheral countries and that those inequalities generate internal and international migration (Massey, 1999; Wallerstein, 2004). Under this theory, structural forces that propel migration do not include gendered 
particularities of people migrating and/or their differential access to the resources to be able to consider and decide to migrate. Segmented Labor Market Theory, on the other hand, claims that migration is stimulated by wage systems and labor demands of the developed economies (Massey, 1999). The proponents of this theory (Michael Piore and others) focused on the labor demanding economies and examined gendered labor markets and the role of immigrants in these economies; however they were less interested in the local circumstances of the economy of sending economies (Grieco and Boyd, 1998; Oishi, 2002).

World Systems Theory and Segmented Labor Market Theory are explicitly related to socio-economic mechanisms of the macro-level economic and political order, but the explanation of the origin of labor migration is given in socio-economic terms only. However, since 1) capitalist wage labor views men and women differently (not only in terms of wage structures but also in the determination of occupations, access to employment and power differentials within it) and 2) migration does not respond uniquely to the search for waged employment, these theories were considered to be gender-insensitive (Pedraza, 1991; Grieco and Boyd, 1998; Oishi, 2002). Responding to criticism and to the realities in the different socio-economic structures and their gendered relations, both theories have been transformed and currently their supporters include analyses of direct gendered patterns such as labor recruitment, wage differentials, network compositions and relations along with the global macro-economic and political circumstances. Gender is not theorized by the original authors of these theories, however, later revisions often included gendered perspectives in their 
analyses. Such are the cases of Castro (1999), Ehrenreich and Hochschild (2002), Levitt (2003, 2001) and Saskia Sassen $(1988,1999,2000,2002,2007)$ among others. Sassen's work for instance uses the household theoretical framework but she incorporates gender analyses to see how economic changes, particularly the process of globalization has created gendered flows of migration, occupations, etc.

To summarize this section, the inclusion of females into studies of migration began in the 1970 s and marked a qualified improvement. Although such inclusions (female only studies, using gender as a variable, using gender roles as the basis for understanding female participation in migration and mostly the inclusion of gender in theorizing) can be seen as steps towards a more comprehensive inclusion of gender as a key analytical tool for understanding migrations. In the next section I will discuss the next advances, namely, 1) an elaboration of the study of gender as a central organizing principle of migration, 2) a discussion of the study of transnational migration and 3) an analysis of how scholars have brought gender tools to transnational analyses of migration.

\section{Gender and migration scholarship}

\section{Gender as a central organizing principle of migration}

The various steps and missteps in the research on female and male migrants have motivated a more comprehensive view, spearheaded by Pierrette HondagneuSotelo, toward seeing gender as a central organizing principle of migrations. To be precise, the importance of gender in the study of migration is that it is much more complex than the simple inclusion of both sexes in an analysis. Since gender is 
historically situated and socially constructed it becomes what Hondagneu-Sotelo first termed a "central organizing principle of migration." As such, gender both transforms and is transformed by migration processes (Hondagneu-Sotelo, 1999; Hondagneu-Sotelo and Cranford, 1999, Oishi, 2002; Hondagneu-Sotelo, 2003a; Pessar and Mahler, 2003; Pessar, 2005; Mahler and Pessar, 2006).

When studying migration, one needs to consider the uneven relations of power among females and males, which are reproduced and transformed within institutions such as the family, schools, the economy, local laws and politics, etc. (HondagneuSotelo, 2003a; Pessar and Mahler, 2003; Boyd, 2006). It is important to notice that these uneven relations of power are then continually negotiated at all stages of migration (i.e., entry, exit and general experiences). In general, these gendered power inequalities disfavor females, who tend to enjoy reduced access to resources, reduced social and economic power, higher vulnerability to violence and abuse, and overall reduced life chances compared to males. Migration is many times viewed as a channel to "escape" these types of relations and inequalities in the countries of origin, mostly when referring to south to north movements (Constable, 2003). However, one must consider and analyze similar conditions in destination countries and thus also the constant negotiation of gender relations and gendered opportunities (Hondagneu-Sotelo, 2003a; Boyd, 2006).

Because many aspects of immigrant life are influenced by the dynamics of gender, gender relations, identities and ideologies cannot be analyzed in isolation. On the contrary, it is through the mutual constitution of gender with other axes of 
difference such as race, class, generation, sexual orientation, ethnicity, nationality, etc., as well as with social, economic and cultural institutions, that gender relations are negotiated and modified. A clear example of this is offered in Yen Le Espiritu's work in which Filipino immigrants employ a particularly gendered idea of morality as one of their strategies to overcome central ideas of whiteness and being able to position themselves above the "white" dominant group. Thus, gender relations, identities and ideologies are constantly changing to adapt to different socio-cultural and socioeconomic conditions. At the same time they are constantly shaping the circumstances and chances of humans in the processes of migration and settlement (HondagneuSotelo, 1999; Hondagneu-Sotelo and Cranford, 1999, Oishi, 2002; Hondagneu-Sotelo, 2003a-b; Pessar and Mahler, 2003; Espiritu, 2003; Zlotnik, 2003; Pessar, 2005; Boyd, 2006; Mahler and Pessar, 2006).

\section{$\underline{\text { Gender and transnational migration }}$}

During the late 1980s migration scholarship was not only being transformed by the inclusion of gender perspectives, but was also awakening to the study of the crossborder events and consequences of migration processes (Glick Schiller et all, 1992; George, 1992; Mahler, 1999; Mahler and Pessar, 2006). The transnational perspective on migration developed in the 1990s, examining transnational subjects and developing methodologies to research migrations in both home and host societies. Transnational migration is in general defined as "a social process in which migrants establish social fields that cross geographic, cultural, and political borders" (Glick Schiller et all 1992: ix). Migrants therefore are permanently creating and maintaining social relations and ties 
and renegotiating their own gender relations and ideologies among their communities of origin and destination despite physical or geographical distances (Glick Schiller et all, 1992; Glick Schiller et all, 1992[b]; Georges, 1992; Sutton, 1992; Wiltshire, 1992, Mahler, 1999, Mahler and Pessar, 2006).

Although in the early years of transnational migration gender was not specifically considered as a central principle for understanding transnational migrations, some authors strove to include gendered analyses as part of the transnational migration scholarship. Such is the case of the articles by Rosina Wiltshire (1992), Constance Sutton (1992) and Eugenia Georges (1992) in which they describe some of the effects of different and unequal gender relations across borders that affect other instances of everyday life, such as access to resources, breaking "traditional gender roles," political involvement and nationalistic sentiments, among others, in both origin and destination communities. Additionally, in 1996 several authors (including Sarah Mahler and Patricia Pessar) started a concrete process of academic involvement and production that culminated in a special volume of the journal Identities: Global Studies in Culture and Power in 2001 which contained what could be called the first attempt to directly combine studies of gender and transnationalism as key characteristics of migration (Pessar, 2001; Hondagneu-Sotelo, 2003a-b; Pessar and Mahler, 2003). Slowly but steadily, gendered analysis of transnational migration evolved to be a key element in the understanding of human movements. To better understand such multilayered and complex subjects, these scholars argued for the development of a particular theoretical framework to assist in this endeavor. 


\section{Gender Geographies of Power}

To help elucidate the fundamental added value derived from a gendered analysis of the experiences of migration, Grieco and Boyd (1998) developed the first gendersensitive theoretical framework for the study of international migration. Their framework addresses three very different structural stages of migration: a) A premigration stage that includes many aspects of the migration motivation and happenings within the country of origin that influence the propensities of people to migrate. These aspects include concepts such as gender relations, status and gender roles and structural characteristics of the country of origin; b) the act of migrating as the intermediate stage between leaving the country of origin and entering the country of destination. This stage includes policy issues in both countries, as well as the role of intermediary organizations; and c) A post-migration stage that accounts for the factors influencing adaptation/integration of immigrants into the receiving society. This stage takes into account the impact of entry status, as determined by the receiving state, on the ability of immigrants to integrate and settle as well as on the patterns of incorporation into the labor market. Although this framework covers the overall process and key elements for the understanding of migration, it does focus primarily on structural determinants and fails to locate the different ways in which people act (agency) given these structural determinants.

A still more comprehensive framework for the analysis of gender was developed by Sarah Mahler and Patricia Pessar (2003 and 2006) called "Gendered Geographies of Power" (GGP). Such framework of analysis includes people's gendered social agency 
and their diverse power, social and geographical positioning and hierarchies. This framework and the use of diverse methodological approaches are very useful for the development of gender, transnational and migration studies. In contrast to the framework proposed by Boyd and Grieco, GGP considers elements and concerns of both agency and structure, as well as the possibility to be used within a more fluid and continuous conceptualization of the migration process.

It is important to note, as GGP serves as the methodological framework for the development of this project, its the three major components of the GGP (Geographic Scales, Social Locations and Agency) are complemented in this study by the further development of the role of imagination in what I have termed "Imagination Work" as previously explained in Chapter 1. Thus, considering gender as a central organizing principle of transnational migration and using the Gendered Geographies of Power framework, I now move forward toward the discussion of international marriage shaped by gender strategies of migration initiation and legalization. 


\section{CHAPTER III - GENDERING MIGRATION}

This chapter pertains directly to the description and analysis of three most noticeable types of marital relationships across borders in the history of the United States. This chapter explores: picture brides, war brides, and mail-order brides. The first two instances are presented as a historical background for the chapter, and are not comprehensive of the extensive literature written about the topic. The title of the chapter makes evident that this analysis is centered on a gendered perspective of migration that considers the strong influence of recruitment factors and the amalgamation of agency and power in the overall patterns of relations across borders. Thus, this chapter is primarily dedicated to the understanding of relations across borders as a form of gendered migration, making special emphasis on the Colombian case - one of the current non-traditional and most visible sources of international brides.

Given that marriage is a fundamental human institution, it is not surprising that marriages and migrations go hand in glove. That is not to say that all migrations are characterized by marriage; there are numerous examples of migrations where single men or single women (e.g., nineteenth century Irish and German migration) constitute a large proportion or even the majority of the migration flows. However, marriage as an institution has always held a privileged position in society. Marriage, especially for the purposes of family formation and reunification, is considered one of the primary motivators for and means of international migration (after labor) around the world. 
Consequently, migrations resulting from marriage are supported by the majority of the traditional receiving countries (Australia, Canada, France, Germany, the United States and the United Kingdom, among others) through immigration policies and agreements (UN, 2005; Luibhéid, 2002). In general, the institution of marriage is strongly supported by international human rights law in which the family is considered the "natural and fundamental group unit of society and is entitled to protection by society and the State" (UN, 1948: Article 16 [3]).

Therefore, relations across borders are not new to the American society and have evidently evolved parallel to the development of communication technologies, the economy and politics. Since the beginning of the 20th century reports about picture brides have been widely exposed (Ichioka, 1980; Chai, 1992; Gabaccia, 1994; Constable, 2003). Later on in history and due to socio-political circumstances, a large development of what is now known as war-brides was evident particularly after WWI and WWII (Strauss 1954; Kimura 1957; Barnett, 1963; Chin, 1994; Gabaccia, 1994; Saenz, 1994: Luibhéid, 2002; Constable, 2003). More recent developments and transformations of the mail-order bride systems are becoming much more common as a result of the rapid advancement of communication technologies (Cohen 1986; Tucker, 1989; INS, 1999; Scholes and Phataralaoha, 1999; Bunagan, 2002; Thai, 2002; Constable, 2003; Pehar, 2003; Pessar, 2003; Brennan, 2004; Hing, 2004; Gordon, 2006).

These relationships are very much framed within gendered structures (self, family, society, nation, etc.) and are constantly gendered results, meaning that women are predominately migrating within these structures, men are usually searching and 
contracting matchmakers or middle-persons to facilitate the arrangements and power differentials play roles that empower one or the other in a variety of ways. It will become evident that most of the literature (with clear exceptions made by some like Nicole Constable and Schaeffer-Grabiel) reflects on the different levels of agency exerted by men while portraying women as passive victims of their future husbands and/or families and unable to actively participate on the decision making process of these arrangements.

\section{Picture and War Brides}

Picture brides was the name given to the marriage arrangements developed particularly between 1900 and 1920 based on the exchange of pictures and short accounts of the whereabouts of the interested parties through the intermediation of matchmakers across borders. These arrangements were particularly developed between immigrant workers of Asian decent living in the United States (mostly in Hawaii and the West Coast) and the families of Asian brides-to-be living in their countries of origin (Ichioka, 1980; Chai, 1992; Gabaccia, 1992; Constable, 2003).

This practice was considered as an extension of the original marriage tradition in Asian countries where the partner selection was achieved through the intermediation of the family members. The picture exchange is seen as the alternative to the family screening process and the short accounts that accompanied these photographs make up for the interest in the other's family genealogy, wealth and other aspects such as education, health, etc. (Chai, 1992; Luibhéid, 2002). 
This somehow convenient alternative for single Asian men, to get married while saving money and time, was considered to be very harsh on women. Not only had they entered into these arrangements as the way to respond to their parents' commitment but also they were required to obey their husbands and to not disappoint their families or jeopardize the family's name. Usually these arrangements contained an additional economic component in which the brides were supposed to send money back home to help their parents in difficult times and/or support the education of younger members of the family (Chai, 1992; Gabaccia, 1994). Additionally they had to go through an official registration under the husband's family name, strict medical examinations, and physical inspections at the ports of exit and entry, among other conditions to be accepted in the U.S. (Gabaccia, 1994; Luibhéid, 2002).

As there was no way to verify the information provided by the matchmaker about the candidates or future husbands, women and their families were often deceived. Frequently the pictures did not correspond to the actual reality, as men used altered pictures that make them looked much younger, and the accounts of their occupation, habits (drinking, gambling), education, age gaps, etc. were regularly fictitious and misleading. Unfortunately, upon arriving to their destination, deceived picture-brides had no options of nullifying their contracts (Chai, 1992; Luibhéid, 2002; Constable, 2003).

This practice was discouraged by the measures taken and movements lead by the U.S. nativists who demanded exclusion based on race, particularly against Asians. As a result the Asian governments tightened their own emigration laws and procedures 
reducing the number of brides traveling abroad. Also by the passage of the Immigration Act of 1924, this controlled and prohibited immigration from Asian countries to the U.S. (Chai, 1992; Luibhéid, 2002).

As an aftermath of the World and Korean Wars, large numbers of U.S. soldiers became engaged to or married foreign women, particularly European and Asian, as a result of the long presence of American troops in these regions that followed these wars (Kimura 1957; Barnett, 1963; Saenz et. all, 1994). As the servicemen returned to America, they did not do it alone; they were accompanied by their wives to establish themselves in America and enjoy the all that this land offered. These women of interracial relationships became known as War Brides as they moved to the U.S.

In general, servicemen engaged in these relationships, many times against the will of superiors and/or family members. By the time they had stayed the average length of time of four years in foreign countries, these couples comprised people who did not have specific obligations, family responsibilities, institutional or occupational careers that would explicitly block or dissuade them from engaging in these interracial relationships (Strauss 1954; Kimura 1957). Although there was minimal parental opposition from the bride's side, it was clear that the American servicemen were actively seeking partners that would meet their own expectations, and the women would be have to accommodate themselves to the American society after migration. The fact that most of these couples migrated back to America shows a tendency of these servicemen to return and implicitly request that their wives assimilate and incorporate into the American society. These couples moved to the States and in 
general complied with the "expected" roles of a couple at the time in which wives accepted their domestic tasks while men were the primary manager and decision-maker in the relationship based on assumptions of familiarity with American customs and laws (Schenepp and Yui, 1955).

These interracial marriages were severely discouraged in America. Initially, based on racial grounds and specific anti-Japanese sentiments reflected in immigration laws, Asian women were prevented from marrying American soldiers and to enter the U.S. (Saenz et. all, 1994). The 1945 War Brides Act was established in order to facilitate the admission of foreign spouses of American servicemen to the U.S. without having to wait for visa availability. However the Act did not explicitly include Asian women. The long history of racial discrimination against Asians influenced the Act and thus, the admission of Asian wives was still very much proscribed. It was only until the 1947-1948 Amendments to the migration law which included specific issues of race discrimination that Asian women were allowed to enter and stay in the U.S. (Strauss 1954; Chin, 1994; Luibhéid, 2002; Ota, 2002). The War Brides Act expired in December 1948. Therefore, Asian spouses had to wait for visa eligibility under the quota system until 1952 when racial exclusions for children and spouses of American citizens were eliminated through the McCarran-Walter Act (Luibhéid, 2002; Ota, 2002).

In addition to the legal requirements and obstacles, these foreign women particularly Asian- also faced great levels of opposition from society. This opposition was not only based on the differences of religion, language, race prejudice, class, age, education, etc., but also due to the difficulty of American citizens to overcome their 
hostilities against the Japanese enemy during WWII. Women from Japan were still seen as the enemy and thus treated as such for many years. These circumstances allowed the development of enclaves, particularly in Hawaii and some areas on the West Coast (Strauss, 1954; Schenepp and Yui, 1955; Kimura, 1957; Saenz et. all, 1994; Ota, 2002) It is important to examine how the literature on U.S. migration history has portrayed the men and women participating in these marriages. From the descriptions above it is not difficult to consider how Picture Brides were perceived as victims and passive individuals. Picture brides and their families were fooled into marriage by pictures of their prospective spouses that depicted them as much younger and more handsome than the aged, work-exhausted men the women would find upon arrival into the U.S. (Ichioka, 1980; Chai, 1992; Gabaccia, 1994; Constable, 2003). Clearly, the brides' families and grooms were portrayed as the main agents in these connections and relationships. It was the groom and the bride's families the ones initiating the communication and deciding on the bride-to-be through a matchmaker. It was the bride the one who had to submit to their arrangement and fulfill her part of the agreement to ensure her own future and the future of her family. Similarly, War Brides are seen as passive in terms of their submission to men-dominated decision making processes and expected fulfillment of "traditional" female roles. War Brides are portrayed as women migrating at the behest of their men to fulfill their expected domestic and motherhood roles in America. Most of the literature does not engage this content as "agency analysis" but continuously includes explanations of the structural and power 
circumstances that allowed these relations to happen in favor/disfavor of the people involved.

\section{Mail Order Brides}

A more recent and common development on the constitution of marriages across borders is the system of Mail Order Brides. It refers to those marriages constituted with the intermediation of matchmaking organizations or International Marriage Brokers (IMBs).

Significant changes in the use of technology, specifically the wider use of the Internet, have altered the formation of international marriages, specifically the proliferation of web-based matchmaking businesses (Constable, 2003; Pehar, 2003 Schaeffer-Grabiel, 2004). This type of international marriage is facilitated through these services first as online/phone introductions and then usually by face-to-face encounters, after which many couples decide to get married and open themselves to the legal process of filing for a fiancée visa or the family sponsored permanent residence permit. International Marriage Brokers are officially defined under the United States International Marriage Broker Regulation Act of 2005 - Bill H.R. 3657 as:

Corporations, partnerships, business, individual, or other legal entity, whether or not organized under any law of the United States, that charges fees for providing dating, matrimonial, matchmaking services, or social referrals between United States citizens or nationals or aliens lawfully admitted to the United States as lawful permanent residents and foreign national clients by providing personal contact information or otherwise facilitating communication between individuals. [IMBRA, 2005] 
Historically, the "classic" marriage broker or mail-order bride enterprise worked through printed catalogs of women's pictures and provided short biographies that were mailed to all the interested men that were willing to pay for such catalogs and could obtain contact information when desired (Scholes and Phataralaoha, 1999; Constable, 2003; Pessar, 2003; Taraban, n.d.). The "modern" international marriage brokers or international matchmaking organizations shifted to the use of the Internet for the dissemination of their listings of women and to promote international multi-cultural marriages. Through the web-based programs of these IMBs, women, typically from Asia and increasingly from Latin America, "make themselves available" to the possibility of marrying men primarily from developed nations (Constable, 2003; Pehar, 2003; Schaeffer-Grabiel, 2004; Taraban, n.d.). These are men who own the economic means for searching for marriageable foreign women and are willing to pay to obtain their contact information. As per the official definition, these multi-million dollar industries often charge interested parties to access their databases (which typically include name, age, occupation, education, religion, height and weight, marital status, and some comments on the prospective mate's hobbies and general interests) and in most cases to provide basic contact information. In addition to the actual transmission of contact information, these enterprises typically offer translation, advisory and consulting services for a fee and promote tours and travel services to men so they can visit large numbers of interested women in different countries around the world, (INS, 1999; Scholes and Phataralaoha, 1999; Bunagan, 2002; Constable, 2003; Pehar, 2003). There are also very specialized - personalized matchmaking services that cater to specific 
clients such as in the case of Jewish communities, successful professional and/or millionaire singles (Scholes and Phataralaoha, 1999; Pehar, 2003; Gordon, 2006).

It is vital to state that some literature on human trafficking suggests that IMBs may act as trafficking agencies: "[w]hile many companies have a legitimate interest in matchmaking spouses, some of the businesses use the lure of immigration as a pretext for trafficking the women into prostitution" (UN, 2005:30). In fact, there are illegal recruitment organizations that present themselves as mediators between the women and false work placement agencies, matchmaking organization, etc., misleading and manipulating the potential migrant into illegal systems of human trafficking. They are very vulnerable to being trapped within trafficking organizations that offer job opportunities or marital relationships. Once they arrive in the receiving country the conditions of their recruitment and the extent of abuse and bondage become evident (Bales, 2003; Brennan, 2003; UN 2006). Additionally, international marriages, specifically the immigrant's legal status in many cases hinders the ability of these women to seek help from the local authorities, in addition to the precarious circumstances in which they are forced to live (Bales, 2003; Brennan, 2003; Sassen, 2003; UN 2006).

Once more, most of the literature on U.S. history of migration and mail order brides tends to replicate these kind of explanations and determinations of roles and expectations of each partner that were given to Picture and War Brides (i.e., male control - female subordination). The critical point is that by characterizing migrations as male-led, women and children become derivative migrants-dependents. Agency clearly lies with males as breadwinners (even when females also earn wages) and heads 
of households. Few authors (e.g., Denise Brennan, Nicole Constable and Felicity Schaeffer-Grabiel) have explored the actual process of international relations through the use of IMBs and showed how women also have a big role in this "romantic" transactions overcoming images of passive followers and victims.

\section{IMBs as part of the migration industry}

Undoubtedly, international courtships are the result of a dual effort. On one hand there are individuals acting as their own agents (using a combination of the GGP elements) constantly leveraging their participation in these arrangements. However, on the other hand there is the strong participation of international matchmaking organizations leading on-line introductions, face to face interviews, etc. and attracting people on both ends of the relationship.

Using Hernandez-Leon (2008) definition of migration industry as "the assemble of entrepreneurs who motivated by the pursuit of financial gain, provide a variety of services facilitating human mobility across international borders "(154) I argue that IMBs are part of such industry acting as migration entrepreneurs.

As part of the migration industry, IMBs ultimately encourage migration through marriage by providing personal introductions and matchmaking expertise and articulating infrastructural resources (websites, electronic communication services, physical locations, tours, events, legal advice access, etc.). Thus, IMBs facilitate the mobility of people and the realization of their goals (e.g., love, traditional marriage, migration) increasingly perceived as easily attainable through the experience of migration. 
The establishment of IMBs has economic profit as the core of their existence. Most of these businesses are owned by international couples who met through an IMB, used the services of a matchmaker and one of them actually migrated. Such experience allows them as entrepreneurs to identify needs of fellow "marriage seekers" and to detect the opportunity to make money as these individuals seeking love at the international level are willing to join an IMB, travel and migrate (whether to the US or Colombia). However not all the owners of IMB are/were part of the IMBs circle (i.e., exclients, successful and unsuccessful couples/individuals); some of them are just entering the business in Colombia influenced by the increasing popularity of Colombian women and American men as good marriage partners. Thus, this migration industry seems not to be based on close ethnic networks (as in the case of remittances or clandestine migration) but an open opportunity of making money through the promotion of migration at the international level.

Owners of these businesses often refer to "personal satisfaction in bringing couples together" as part of their motivations to establish such businesses. Most agencies claim (through the interviews and/or their websites) to be in business because of the need they see of connecting their people, the need of helping Colombian women and American men to find true and committed love, surpassing limitations of age, physical appearance and contested gender roles. I interpret this "personal satisfaction" as relating to ethnic affinities between the owners of IMBs and their clients. Using specific marketing techniques in which American salesmen are directly talking to potential American male clients while Colombian saleswomen are talking to potential 
Colombian female clients. Thus, I contend that these businesses are not necessarily coethnic networks but based on a co-ethnic affinity associated with experienced-based knowledge and expertise provided by IMB representatives and demanded by potential clients.

\section{International courting/marriage as migration strategy}

Marriage as a gendered institution is being constantly transformed through migratory processes. Although traditionally marriage-based constructions of migration are very much identified by the oppressive forces (to women) of patrilocality and hypergamy, I argue that women are using those same factors to their favor and moving along the spheres of courting and marriage (through pragmatic visions of legitimate partners) and migration (achieving positive migratory status) for their own

improvement. Hence, women are actively seeing and using gender as a facilitating tool that could help them to achieve successful and more egalitarian incorporation into other societies while obtaining legitimate and viable courting/marital relationships as opposed to the opportunities and expectations to be found in their home countries.

Gendered agency via migration and the internet means how men and women utilize websites for international courtship leading to marriage that enable them to capitalize upon migration laws that favor family unification (i.e., marriage). Although their choices are constrained by the asymmetrical power relations between women and men, and between people living in developing and developed countries, they exert their agency through facilitating their own marriages. 
Gender and power inequalities are related to the possibility to control or influence others on the basis of access, or lack of thereof, to meaningful material (money, technology, etc.), social (networks, traditions, etc.) and intellectual (information, education, skills, etc.) resources. Gendered power differences are shaped by the merging and interaction of different social structures and by what individuals can achieve through their navigation within those structures using their own basic means. Thus conditions like poverty, lack of information, low education attainment, isolation, unsafe and repressive living arrangements, lack of physical safety, affect and/or enable men and women differently. In general, gender inequalities disfavor females, who tend to enjoy reduced access to resources, reduced social and economic power, higher vulnerability to violence and abuse and overall reduced life chances compared to males. These inequalities are constantly defined, performed, reproduced, re-enforced and transformed within institutions such as the family, schools, the economy, local laws and politics, etc. (Lim, 1990; Grieco and Boyd, 1999; Hondagneu-Sotelo and Cranford, 1999; Pessar and Mahler, 2003; Hondagneu-Sotelo, 2003; Boyd, 2006).

Regardless of the multiple legal and societal obstacles that international marriages have to overcome, it is still migration through courting and marriage, particularly to the U.S., which is considered to be the relatively easier form of migration because the fairly simple process of obtaining a fiancé visa or the family sponsored permanent residence permit, as compared to the difficulties found in obtaining any other type of visa and/or permanent residency status (INS, 1999; Thai, 2002; Gouveia, 2005). International courting and marriages thus, can be seen and analyzed as 
gendered strategies for migration, in this specific case to generate the initial migration through the use of IMBs.

Migration itself does not facilitate the reduction or perpetuation of gender inequalities. Structural forces create a basic environment that individuals may be able to use in their favor or not to better position themselves within these structures and the power differentials they contain. Considering that power differentials are not static, and that on the contrary they are fluid over time and space, migratory movements become catalyzers to the continued changes produced over gender identities, relations, and ideologies. Agency as the different strategies and forms in which individual act according to their circumstances and resources is also gendered. Men can use traditional structures to subdue women, but women are increasingly using the same structures from an international perspective to change their role within the family. Agency, exerted through the utilization of the few immigration policies favoring women, is important. Family reunification processes imply the direct migration of women to join their "working" husband - a much gendered perspective. The relative easiness of the process facilitates the migration of women through positive migratory legal results, without having to risk their personal safety or infringing the law compared to the alternative of undocumented migration. Women are constantly using their very own femininity to engage into international courtship/marriages that provides them with positive migratory status and the option to level gender disparities compared to those in their home country. Sometimes the different relations of power and inequalities after migration are unaffected because of legal restrictions 
(visa/dependency), no labor access, and limited contact with society, etc. These marital arrangements vary in legality and form, and not all of them are guaranteed to benefit women, however women are continually accessing and navigating these strategies (Parreñas, 2001; Luibhéid, 2002; Brennan, 2003; Constable, 2003; Constable, 2005;

Davis, 2006)

At the same time, on the basis of imaginary constructions of marriage, men and women envision their futures and engage in these relationships that could be seen as changing this traditional social institution's ideas of love and romance for more pragmatic views of companionship, spatial location, and migratory status, among others.

Some might look at the activities of women who seek mates abroad to migrate as a purely instrumental use of the institution of marriage. Such marriages are easily disapproved and interpreted as plain manipulations or schemes using womanly charms (gendered terms) to hook men into "green card" marriages. It is important to note that while in the West notions of romance as the basis for marriage are normative (Simpson et al., 1986; Allgeier and Wiederman, 1991; Sprecher et al., 1994; Levine et al., 1995), anthropologists have long understood marriage as much less about romance between the spouses than about building alliances between families (Obeyesekere, 1967; Yalman, 1967; Tambiah, 1973; Lee and Stone, 1980; Moore, 1981; Dumont, 1983; Simmons et al., 1986). That is, marriage has a long instrumental history and men seeking carnal satisfactions by bringing women-particularly women who they imagine 
as their ideals-closer to themselves should also be seen as instrumental (Cohen, 1986;

Thai, 2002; Constable, 2003; Brennan, 2004; Gouveia, n.d.).

The reality of marriages involving migration and migrants, however, is frequently different than the image. One reason is changes to immigration policy. Previous to 1986, a foreign spouse was able to receive permanent residency in the U.S. once the paperwork was submitted and approved. However, in 1986 the Immigration Marriage Fraud Amendments (IMFA - Public Law 99-639 - Act of 11/10/86) were adopted as a measure to address legislative concerns about "increasing" incidents of marriage fraud (Hing, 2004; Tucker, 1989). The IMFA basically changed the status of immigrants who marry citizens or legal permanent residents (LPR), from a direct residence status to a conditional one. Procedurally, the couple has to file paperwork on behalf of the foreign spouse after marriage in order to obtain a "conditional resident status" valid for a period of two years during which the couple must remain married. After those two years, the couple must file paperwork again in order to remove the conditions on permanent residency and might be called for an individual or a joint interview conducted by a U.S. Citizen and Immigration Services (USCIS) staff to verify the validity of the marriage. Because of administrative delays on visa processing, the conditional status could last up to three years or more. During this time, the couple must remain married. In response to these requirements, spouses must adapt their expectations and motives to accommodate to these fundamental legal restrictions.

General descriptions of international marriages portray men as "buyers" not only of brides, but of "traditional" women who can be controlled and subjugated and women 
as submissive and sexual compliant beings who will uncomplainingly perform domestic labor instead of gaining personal satisfaction through their own careers, parental responsibilities and own interests (Cohen, 1986; INS, 1999; Scholes and Phataralaoha, 1999; Thai, 2002; Constable, 2003; Pehar, 2003; Rossiter, 2004; Davis, 2006). There are many incidents of women staying in abusive relationships to preserve their right to permanent residency only to have the abusive husband not show up to the second and definitive interview causing the woman to lose her status despite the history. Such cases helped spur a change in policy allowing women who can document the abuse to stay and receive permanent resident status, but the standard of proof is high (Violence Against Women Act of 1994 and Violence Against Women Act of 2000).

Is marriage through migration always a narrative of female victimization? There certainly is an abundance of data to suggest that many marriages continue a long legacy of inequality in spousal relations beginning at the courtship stage. However, there is also growing evidence of some women's ability to enter into relationships from various positions of power. Perhaps their social locations and geographic scales, their positions within a variety of status hierarchies including income, race, gender, education, occupation and their actual geographic locations, are not equivalent to the social locations and geographic scales of the men they engage with, however, the woman continuously exert agency, juggle their power and are not mere victims (Thai, 2002; Constable, 2003; Pehar, 2003; Gouveia, n.d.; Schaeffer-Grabiel, 2004). Power relations are central to a gendered analysis of international migration. Currently, most of the literature on international marriages and immigration that incorporates gender analysis 
does not focus on agency, specifically on the different levels and forms of agency that women develop while involved in courtship leading to marriage. On the contrary, as argued above such literature tends to focus on men as the active agents in these marriages. Individuals (both of women and men) participating in international courtship and marriages are constantly exercising different forms and levels of agency, negotiating their access and use of power, being creative and marshaling different types of initiative. They do so by selecting different IMB agencies, by submitting their names and strategically introducing themselves, representing themselves in different ways whether online or face-to-face, carefully selecting which men or women deserve attention, and deciding whether or not to marry them (Constable, 2003; Gouveia, 2005).

Once again, such levels of agency do not imply that we should ignore issues of universal gender inequality, the "traffic" of women and the idea of marriage as an oppressive patriarchal institution. But they allow us to see how individuals claim dignity, express strength and in doing so resist and transform the images of passive sex object/submissive wives or sexually demanding/controlling husbands. Thus, it is vital to consider and analyze the complex and often understated articulations of power, specifically the active role of these women questioning their characterization as passive and naïve participants of these arrangements. Many women use (conscious or unconsciously) international marriage as a strategy, within the limits of their social locations, to achieve or continue the migration processes.

In the next chapters I will look more closely at the conditions, locations and motivations of individuals that influence their participation in these types of 
relationships and also to the role played by important external forces such as recruitment organizations and the nation's policies and laws.

\section{Colombian mail order brides: a case study}

Most of the information presented above is related to studies of female familyrelated migration mostly developed in Asian and South Pacific countries. Little is known about these situations in other countries. There is reason to believe that some of the rationale for participation in international marriages is the same around the world, but the factors affecting people in such diverse circumstances cannot be assumed to be entirely similar. Economic, social, political and geographic differences contribute to creating different social environments for women and men in different parts of the world. For instance, South American countries for which the U.S. alone represented an estimated $10 \%$ of the total visas approved for fiancés of citizens in 2007 and those have been much understudied. This project contains as a case study, the particulars about the experiences of American men and Colombian women engaged in international marriages through the use of IMBs.

Colombians are an appropriate population to present as case study for a variety of reasons. According to U.S. Homeland Security immigration statistics, Colombia has ranked into the top 10 fiancée sending countries since 1999; the same statistics show that Colombians have increased their admission into the U.S. using fiancé visas (including children) by 321\% from 1999 to 2008 (Yearbooks of Immigration Statistics $1999-2008)$. As it is, Colombians represent an estimated $4 \%$ of the total visas 
approved for fiancés of U.S. citizens in 2008. No other South American nationality is similarly represented in this fiancée category (Table 3-1).

Colombian women are increasingly "portrayed and advertised" as the beautiful and perfect South American women willing to marry foreign men as declared on a large number of the websites of the IMBs (e.g., colombianbride.com;

allcolombianwomen.com; latindreamwife.com; barranquillasbest.com). The question asked and investigated was why Colombian women have captured such an important position in the U.S. male imaginary in recent years? Different explanations exploring structural constraints, individual characteristics and the development of a market (geographic proximity, drug/war related international images, increased establishment of Colombian IMBs, apparent higher educational and socio-economic status) will become evident in the next chapters as motivators for engaging in international courtship with eligible partners overseas and for exercising agency.

Consequently, the study of the increasing numbers of marriage-based migration of Colombian women merits some attention, even more when considering the different strategies that men and women apply not only to the initial constitution of international marriages but also to the migration process itself. This study is centered on the analysis of the increasing movement of Colombian women, through the use of online marriage agencies. As a marriage-based form of migration, these marriages are transforming not only the image and constitutions of marriages but also creating new strategies of migration. 
Table 3-1 South American non-immigrants admitted as fiancés of U.S. citizens (including children) by country of citizenship (1999 - 2008)

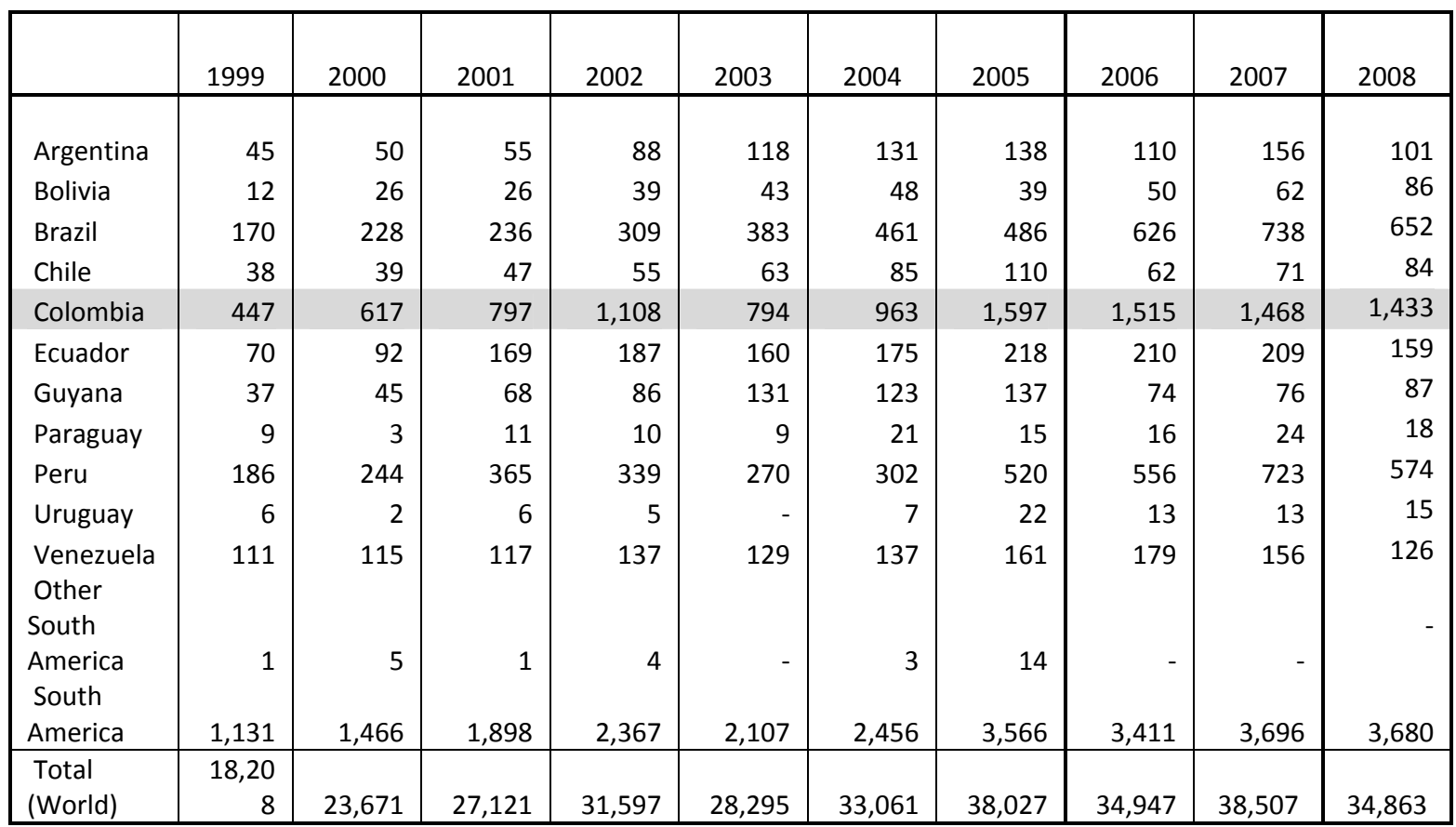

Source: Homeland Security Department, Yearbooks of Immigration Statistics (1999 - 2008) http://www.dhs.gov/ximgtn/statistics. Retrieved on October 10, 2009

\section{Colombo-American Courtship and Gender Relations}

The story of Rosa and Kenneth from the introductory chapter epitomizes a deeper level of culturally rooted and differing gender relations across borders. The idea that an international partner becomes a response to the socio-cultural differences between the two societies in terms of traditions, expectations and overall relationships that each individual is confronted with in their own location.

In Colombia, according to Milagros Palma (1986) even before colonial times, indigenous traditions passed on through legendary stories embodied fundamental values that exemplify, legitimize and perpetuate "machista" behavior. Traditional myths and legends constantly reinforced the concept of dependency of women on men. 
Because of the constant need for physical and emotional protection that men provide to their women, women are expected to maintain their purity and chastity so as not to elicit violent reactions from men, while men are allowed to explore and learn of the world without restrictions. With the Conquest and throughout the Colonial period, the power white men had over indigenous and black slave women granted special rights to male 'mestizo' children and denied any privilege to females either as mothers, daughters, or wives.

Until the early twentieth century, Colombia was legally and culturally a highly patriarchal society in which women were denied civil and political rights and were defined within the limits of housekeeping and motherhood. No large-scale women's movement arose in Colombia in the $19^{\text {th }}$ century as in other countries. However, since the early 1900s a group of influential women started efforts to improve women's lives and to end their oppression in the country's social, economic and political life (Cañizares Molina, 1995). During the 1930s, Colombian women earned greater civil rights (such as the ability to testify at trials, to handle their own money and property, to legally contract with anyone, and to accept inheritances or endorse any economic contract or agreement), and the opportunity to receive higher education. Before then women were only allowed to receive schooling until middle school, and the academic programs were different from those of men (Velasquez, 1986; Cohen, 2001). These achievements were met despite much male opposition alleging that the higher exposure of women to life outside the home increased the possibilities of sexual promiscuity and marital difficulties (Cohen, 2001). In 1945, a constitutional reform recognized women as equal 
citizens. However, women still could not vote, women leaders fought ten more years for that "privilege." Colombia was nearly the last country in Latin America to grant women the right of suffrage. Since the late 1950s educated women openly and broadly started to criticize the patriarchal power visible in all social and political arenas of the nation (Velasquez Toro and Reyes Cardenas, 1995; Gonzales, 1995; Garcés de Eder, 2002; Murdock, 2008). They sought equal access to positions of power whether at the public as the private sectors, healthcare access, housework and childcare loads, and resolution to issues of family violence.

Colombian political violence has also been a key factor influencing the lack of recognition of gender equality not only on paper but also in practice. Violence and patriarchy cannot be separated as the combination of them, ideologically and within the distribution of power, focuses on dominance and control that create a multiplying effect on the manifold issues of violence, socio-political injustice and overall welfare of women (Meertens, 2001). Violence and its different manifestations tend to highlight the public and to overlook the private. Violence in Colombia has been predominantly analyzed and dealt with from the "public" sphere particularly by producing stronger State structures and conflicts that harmed (directly, by omission, or as a side effect) women's interests. Correlated to that analysis is the need to recognize that violence has also affected women in the "private" sphere: the family, its internal relations, assigned sex roles and power differentials (Uribe, 1995). Faced by changes in the way of living men, in this case Colombian men, tend to revert to the perceived stability that "tradition" provides and insist in maintaining structures that allow them to maintain their power and control. 
The constitutional reform of 1991 created an "official" culture of nondiscrimination based on gender, race and class, as well as multiple other measures that have been taking place to ratify the rights and obligations of all Colombian citizens regardless of gender, race, and class. Although reliable statistics are scarce, to date women's status in Colombia is undergoing important changes, as reflected by multiple studies (DNP, 2000; Cabal, et al, 2001; CEPAL, 2001; UNICEF, 2003; Garcés de Eder and Marulanda Herrán, 2005). Specifically concerning the increasing numbers of women joining the labor force, their higher literacy rate, an increased number of reproductive health services and the passage of legislation intended to address significant gendered inequalities in the legal system.

More specifically in terms of gender relations, contemporary history also helps to explain how unbalanced Colombian laws were until very recently with regards to gender behavior particularly on sexuality, divorce and separation. For instance, it was not until 1980 that the right to uxoricide (killing one's wife) was abolished completely although since the 1890 Colombian Constitution (Art 591) uxoricide was not considered a form of homicide, particularly in cases of adultery. In 1936, adultery was abolished as a crime. However, the right to kill women that were found in adultery was extended to other male relatives (brothers, fathers, etc.) of the adulterous woman, as it was seen as a correct and honorable thing to do. Women were seen as the only depositories of family honor. They were the guardians of the home; only wives could bear legitimate children, children born out of wedlock were considered bastards and their mothers were rejected and isolated (Velasquez Toro, 1986). 
In terms of divorce and separation based on unfaithfulness and according to Law 8, Article 153 of 1922, a factual cause of separation or divorce was women's adultery. However, male extramarital relationships were allowed as long as he was not living with the other woman. In these cases, women would lose their parental rights and access to economic resources while men did not lose any rights and kept control over monetary and other type of family resources (Velasquez Toro, 1995). Several changes to the Colombian Civil Code and the laws regarding marriage, divorce and separation have, to a certain degree, equalized the consequences of unfaithful partners and the legal consequences should the couple seek legal divorce or separation.

Thus, the idea of gender and honor is central to an explanation of the deeply rooted concept and tradition of machista behavior in Colombia. It is not that Latin men exhibit machista characteristics for no reason but that legal and cultural practices have empowered them to assume different levels of understanding and practices that tend to boost their dominant role and behaviors and that lead to worse conditions for women while decreasing their rights. Historically, for Colombian men, and to a greater extent in patriarchal societies in general, honor is defined as men's ability to protect all of that they consider their own, which includes the women in their family (Garcés, 2008; Sigal and Nally, 2004; DeSouza, et.al, 2004). This part of Colombian gender history and reality has been famously described by Gabriel Garcia Marques in his novella Chronicles of a Death Foretold (1981). In that novella, the honor of the Vicario family is defended (by the Vicario brothers) with the death of Santiago Nasar, due to the unproved accusation by Angela Vicario of Santiago's deflowering her. On her wedding night, Angela is 
returned to the house of her parents after her husband (Bayardo San Roman)

discovered that she was not a virgin. The two brothers, with the entire town as their tacit accomplices, kill Santiago as a way of making him pay for the shame he inflicted on their family through the robbery of their sister's virginity. Honor, then, is a mechanism of revenge to which men resort to clean a collective moral order. This novella was inspired by a true story, happening in a small town of the Caribbean region of Colombia in 1951.

Garcia Marques' illustration of the strong patriarchal society, specifically how the honor of a man and his entire family was based on the purity of his female relatives, is a clear example of how Colombians have justified under the idea of "honor" the highest levels of control and dominance of men over women. The expectation of protecting their women comes with exaggerated masculine behaviors and expectations such as sexual expertise or dominance, higher alcohol consumption, physical aggressiveness and verbal coldness. Women, on the other hand are expected to be passive, nurturing, pure, forgiving, and compliant to male requirements and expectations (Garcés, 2008;

DeSouza, et. al., 2004).

Many changes have been made, however many individuals remain propatriarchal and most institutions remain male-dominated in Colombia. General ideas of equality have been embraced by governments, institutions and individuals. However, there is still a significant gap between the acceptance of equality and the actual behavior of individuals, the government and social institutions. Consequently, Colombian women continue fighting for equal rights, particularly for the true exercise of 
political and civil rights; for the freedom of election and decision in personal affective matters (love, sexuality, pregnancy); for the construction of a new image beyond roles of personal dependence, abnegation, passivity and subjection; and for equitable working conditions-including housework (Gonzales, 1995; Garcés de Eder, 2002; Fuentes Vasquez, 2002; Murdock, 2008).

Cultural traditions and legal constraints have limited the possibilities of Colombian women through the years to express themselves and demand better partners, better lives and better futures. The same traditions and structural constraints that Colombian women have to face are then motivators for imagining and engaging in international courtship with eligible partners overseas and for exercising agency over victimization. Unquestionably, the work of International Marriage Brokers (IMBs) has aided them in their pursuit of better partners, lives and futures. Such aid comes in the increasing portrayal and advertisement of Colombian women as beautiful and suitable women willing to marry foreign men in their websites and printed material. Colombian women are described not only as beautiful and exotic but also as having higher educational levels and socioeconomic status than the ones of women from other geographic locations participating in the international marriage business. These IMBs operate to serve men, in this case American men who are searching for "traditional" wives overseas.

In traditional patriarchal societies power is tacitly given to men within the economic, political, social, and religious structures. Traditional men's roles in society are based on their ability to exercise power and control (Kaufman, 1999). Men's power and 
privilege is based on a range of social positions and relations. That is to say that not all men enjoy the same power and privileges as race, class, age, sexual orientation, etc., are key determinants of the different levels of power men might exert and enjoy.

It is no secret that the "traditional family" has been transformed during the past 60 years in the U.S., and the rest of the world. Socioeconomic changes and the increase in the number of women acquiring higher levels of education and participating in the labor force has produced fundamental changes within the patriarchal society of Colombia, its inherent "traditional" gender roles and thus, the family structure (breadwinner husband/homemaker wife). Such changes included a shift in the power relations and roles performed by each partner within the family and the expectations of each partner towards each other as part of it.

The rapidly changing American society embodied a great challenge not only to American women to step up and assume an "equitable" role in the family and society as a whole, but also to men who needed to redefine themselves within the shifting social structure for which some of them were (and still are not) willing to handle. As some men find little tangible rewards in accepting these social and cultural changes, many of them find in the IMBS an alternative to avoid having to completely accept these changes by seeking women they imagine being traditional and family-oriented overseas. 


\section{CHAPTER IV -IMBS: BROKERS OR CRAFTERS?}

In this chapter, I discuss the history of the Colombian International Marriage Brokers (IMB) from its modest beginnings in the 1960s to today's highly profitable business. Then I will discuss what I have termed the "Colombian Marketing." This section describes in detail the strategy employed by IMBs to cater to clients in both Colombia and North America. This section is broken down into three facets: The Gendered Channels, the Gendered Content and the Overcoming of Colombia's bad image. The chapter closes with an analysis of the role of IMBs within the matchmaking and migration industries. As mentioned previously, the data used to assemble this chapter come from face-to-face and phone interviews with representatives of IMBs and content analysis and review of IMB websites and their advertising materials.

\section{Colombian International Marriage Brokers}

The history of Colombian International Marriage Brokers starts with the establishment of the "Agencia Matrimonial VOGULYS" [matrimonial agency VOGULYS] (AMV) in 1966. Jonas Vogulys Ramirez, the son of the agency's founders, who since his childhood has been immersed in the business, described to me its modest beginnings saying that: "...everything started at the moment my parents meet each other, here in Colombia in a bus that was going to Zipaquirá. They started to talk, they liked each other and after a while they got married." After getting married, they realized that they 
had many friends they could play matchmaker for, including "my dad's Lithuanian compatriots and friends, and my mom's single and educated friends. I said educated because this was in the late fifties and you know that women at that time did not study, they were more homemakers..." Jonas explained how after different attempts through parties and social events their friends were liking each other but not starting any sort of relationship, so that is when his mother decided to introduce all of her friends in a more formal way. "After a while, they realized it was already a real need people had. You see people they did not even know will come to my mother and say 'Elisa, why don't you do me a favor, look, I know that you have helped many to get married, why don't you help me?' When my mother told them that it was just a hobby, something she did for her friends, these people insisted. However the real reason they asked my mother for help was because they wanted to marry a foreigner not a Colombian." That realization helped them to reflect on the possibility of opening a matrimonial agency. "So with the help of my mother's friends from the Colombian Academy of History, the National Library and the Luis Angel Arango Library where she worked, and the support from one of the owners of 'El Tiempo,' one of the most important newspapers in the country, they started the agency. That was in 1966, the newspaper headline said 'Vogulys, the first marriage agency in Colombia and Latin America' and that marked the real beginning of the agency." Jonas continued explaining that his father traveled often to Europe and the United States searching for new contacts and other agencies to partner with and make their growing business successful, "because other newspapers and magazines interviewed them more people started to go to the offices, we were the only ones for 
about twelve years, until competitors emerged." Vogulys has been in business for the last 43 years claiming a $70 \%$ successful match rate, Jonas states it is not an easy business. "As a matter of fact you can see how a new agency opens here, and another there... many had to close because this business is not likely to say 'I am going to open a bakery, I will sell good bread here and that is how I am going to succeed!' No, this business is not that easy..."

What started accidentally and as a "hobby" for Elisa Vogulys filled a real need and thus took off into a very profitable business until the idea was copied by too many competitors. The demand still exists, however; in fact, it has grown with the evolution of communication technologies. Most of the IMBs that were established in the $1980 \mathrm{~s}$ and 1990s replicated the advertisement strategies of established marriage agencies in the U.S. and Asian countries. The Colombian agencies started producing printed catalogues from which predominantly foreign men would select a couple of "interesting" women and would communicate through the IMB by way of postal mail (i.e., letters, tape-recorded messages and, later on, homemade videos) or by phone. Jonas illustrated this point by saying "we have been the pioneers in using many of the advanced technologies to help our clients. For instance one tool that changed our business a lot was the fax... They would write a letter we would put it into the fax and poof! It was already in the States! That was amazing... and we were the only agency that had that for many years... Then it was the computer, not yet the internet but the computer, I am talking about the late 80 s and it was a big machine, very slow compared to what we have now. It was the beginning of a new era for our business..." 
However, the real and drastic change in the business was produced by the use of the World Wide Web, that is, the change from printed catalogues to on-line services. When talking with one of the representatives from Latin Life Mates (LLM) an agency established in 1990 she stated that the Internet brought about remarkable differences in the way they do business and the way people communicate: "We changed from the books to the web probably five or six years ago, and we are currently changing our webpage again, we are transforming the page completely. The internet changed everything in this business, it made the process faster, and the couples could meet in advance, before we always needed to be in the middle, do you understand? Before, to form a couple it took a lot of time. But now it is completely different...It is faster! Before we did not have email, so all the ladies had to wait for a letter or a phone call, but those (phone calls) were too expensive so they were not frequent. In most of the cases we had to wait until the gentleman decided to travel but now we can help them to talk in no time. They can hear and see each other perfectly on the screen, through the computer and all of this with almost no cost for us. The Internet has really, really changed our business. It has helped it grow so we get more business..."

Clearly, the Internet revolutionized the IMBs' modus operandi. The change from catalogues to websites not only decreased the costs of production, transportation and distribution of the catalogues but also made it possible to reach a wider audience and to update their content more frequently. With the use of the Internet, IMBs are not only reaching a larger number of customers and facilitating their communication, which as we will see later has represented and increase on the opportunities for men and women 
to actively strategize and interact in what may be considered a more level playing field. Catalogues were specifically created to be viewed by men, but the Internet also allows the agencies to contact and attract many of their female clients in a more open and direct way. Through the Internet women have, in some cases, the opportunity of not only being searched for by a large number of males but, for the first time, the ability to search for men and select those in whom they are interested. The playing field has been leveled in some ways; the agencies are creating spaces for women to express their desires in the process of finding a partner.

Presently, the legal process for establishing a marriage and introduction agency in Colombia is fairly simple. The owner(s) only need a permit from the city's office of the Department of Commerce; they operate under the general classification of being "providers of Internet services" and there is no governmental or non-governmental entity controlling or supervising their operations. Though several agency owners mentioned the existence of an association called the "Asociación Colombiana de Agencias Matrimoniales -ACAM" (Colombian Association of Marriage Agencies) that was constituted during the 1980s by some of the owners of the early agencies. The ACAM served to protect the good name of established agencies from the wrongdoings of emerging ones. However the association was terminated in the mid-1990s because of the lack of support of new agencies and of people willing to volunteer as a member or to pay the association fees.

\section{Types of IMBs Working in Colombia}


While reviewing websites and talking with IMB representatives I recognized three very specific types of IMBs functioning in Colombia: 1) marriage and introduction agencies, 2) on-line referral services and 3) on-line dating sites. The primary differences are based on the type of services they provide and the strategies they use to promote international romantic connections.

Marriage and Introduction Agencies:

Marriage and introduction agencies are those IMBs that have, in addition to a website, a specific physical location where women and men can meet and interact through the services of the agency's personnel. These agencies target female clients through local advertisement and male clients through web-based sites detailing female contact information and travel tours in Colombia. Examples of this type of IMB are: LatinLifeMates.com, IntroductionsbyConsuelo.com, Vogulys.net.

Marriage and introduction agencies offer a wide-ranging set of services to both female and male clients. As the core of their services, they offer on-line and face-to-face introductions and individual matchmaking to all clients. This, of course, requires very personalized service and attention, corresponding to specific paid fees. In order to alleviate common clients' concerns particularly about personal safety most of these agencies offer security and background checks on all clients, as well as constant monitoring of on-line behavior, postings and communications among all clients. Nearly all agencies offer translation services and different types of advice: posting advice, which includes recommendations on how to present themselves through their profile 
and selection of pictures to upload; personal image advice meaning recommendation on overall appearance, clothing selections, dental work, plastic surgery, etc; and marriage and migration related legal advice in terms of visa request, passports, embassy interviews, etc.

In addition to the above mentioned services, agencies offer to their client access to the Internet, free international calls and the possibility to participate, free of (additional) charge to the women, in social events that are usually scheduled either before or after business hours and during the weekends. To men coming from overseas, the agencies offer tours. These tours are billed as a risk-free travel experience, as a simple way to travel to the country. Tours are seen as particularly important in order to meet in person the women they are interested in and getting to know those that might be "their perfect match" as recommended by paid professional matchmakers. Tours are offered at different locations; each location is publicized based on weather, cultural and geographic characteristics, as well as by generalized socio-cultural distinctiveness of women from the specific location. Tours are generally offered during American holidays (St. Patrick's Day, Easter Weekend, Independence Day, Thanksgiving, etc.) so that men can maximize their stay in Colombia without too much disruption of their working obligations. Usually agencies offer unlimited introductions in their office, the offer of accommodation in hotels (usually owned by the same agency owners'), social events such as pool or beach parties, breakfast socials, evening get-togethers, and happy hours.

Tour packages offer varying scales of services according to the level of membership that an individual holds. In general, women are "standard" members, 
which mean that the same kinds of services are offered to all of them equally. A few agencies charge women a membership fee (one time only, annual, semi-annual), while many offer free memberships, free photo-studios, prices and even raffles. In contrast, men are most likely required to become members of an agency. The level of membership depends on the services they are interested in. Memberships are represented by different ranks of precious metals (i.e., silver, gold, and platinum) or gemstones (i.e., diamond, emerald, and pearl) which vary by price and signify the different services offered. Many agencies use different strategies to sign up new male members such as lifetime memberships, free standard membership, free subscription/initial periods, free three first contacts, military and buddy membership's discounts, etc. As of 2010 the prices ranged from $\$ 45$ per month to $\$ 1700$ lifetime memberships.

On-line referral services

On-line referral services are commission-based companies that provide few, if any, services themselves. Examples include "Barranquillasbest.com" and "Adventureromancetours.com". They work as affiliates of national and international well-established marriage and introduction agencies and their goal is to link clients to an affiliate agency's website or general services (primarily traveling tours) to earn a commission. Though in many cases these sites charge clients to gain access to tour discounts, general information and to access to the databases of women, they do not offer any personalized services, they simply redirect the clients. In many cases, the 
referring agency even offers to create the affiliate's website which includes all the information about the local women as well as tour availability, prices and dates.

On-line referral sites commonly target male clients offering services such as access to the databases of female members, video profiles, detailed biographic data, exclusive and priority access to "new girls' information," helpful dating and traveling advice, and tour, hotel and airline discounts, etc. Their main goal is to persuade men to travel to Colombia using the services of the referral agency. On-line referral sites do not necessarily target women as clients or members since that task is an undertaking of the affiliate marriage and introduction agency.

On-line dating sites:

On-line dating sites are virtual spaces created with the purpose of having men and women, in this case at the international level, search for a partner based on their own requirements and personality traits. On-line dating sites such as "Colombiancupid.com" and "LatinGirls4You.com" make the search for a partner a very individual task, meaning that through these sites men and women do not require a matchmaking agent but instead rely on their own initiative and judgment. These are virtual spaces that facilitate the interaction of people and attempt to overcome geographic barriers. These services are very much like those developed in the U.S. (e.g., Match.com, Eharmony.com, etc.). However, they do not yet provide tools for compatibility, personality tests, and the like.

On-line dating sites generally charge men and sometimes women to be able to communicate freely with other members of the site. Such communication includes 
different combinations of private email networks, instant messaging, chat with video and audio support, video greeting, video mail, automatic translation of text messages and emails, etc.

\section{Estimating Numbers}

It is difficult to determine the exact number of on-line based referral and dating sites working to match Colombian women and American men let alone marriage and introduction agencies duly organized in Colombia because of their general classification as "providers of Internet services" which also include companies offering the services of internet connections, café internet services, and online based businesses. Despite this circumstance, in an effort to estimate the increase of IMBs established in Colombia or with Colombians in mind, a newspaper (The Miami Herald) article reports that there were approximately a dozen agencies doing business connecting American men and Colombian women by 1997 (Laughlin, 1997). Yet, as of February of 2009, I was able to identify 68 Colombian IMBs, of which 49 were marriage and introduction agencies, 13 were on-line referral services and 6 were on-line dating services (Figure 4-1). The marriage and introduction agencies are primarily located in Cali, Bogotá, Medellin, and Barranquilla. In general, these IMBs are owned and operated by international couples who had been internationally matched by an IMB, although there are many owned and operated by experienced ex-employees of well-established agencies that decided to branch out on their own. Others are run by entrepreneurs. 
Figure 4-1: Percentage of IMBs in Colombia by type as of February $2009(\mathrm{~N}=68)$

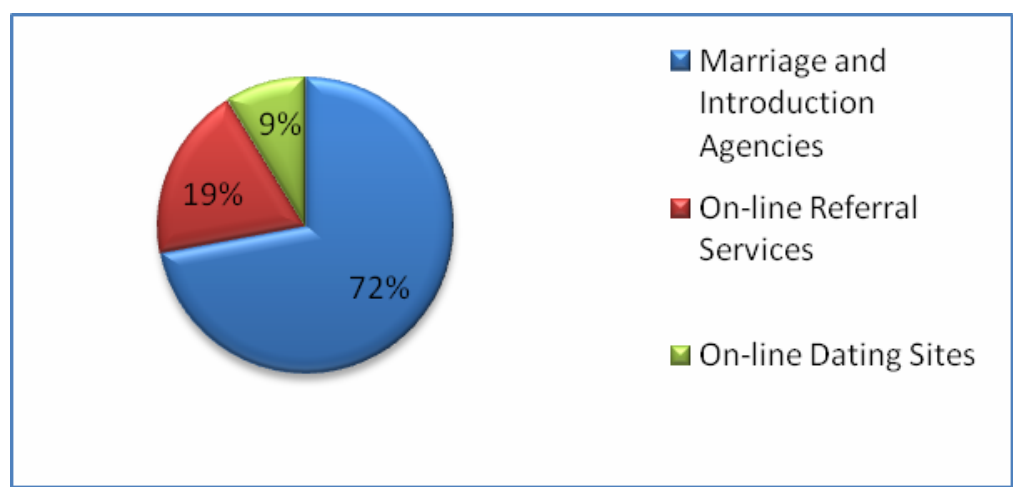

\section{The Colombian Marketing}

International Marriage Brokers compete among themselves and around the globe. They offer connections among people from many different countries, and many become "specialized" by region or country. Such specialization implies the development of specific content and strategies that allow them to effectively target their clientele and succeed. With that in mind, the study of Colombian IMBs merits a deeper analysis into what they do in terms of targeting their clients and facilitating their connections, while at the same time creating and propagating stereotypes and stimulating imaginaries and representations of gender and perhaps culture and nationality.

\section{Gendered Channels}

As with any other business, IMBs heavily rely on different strategies to publicize their services and increase the numbers of potential clients. Colombian IMBs, use three main resources for the purpose of disseminating their services and expressing the 
unique characteristics that allow them to compete in the Colombian IMB market. Those sources are: printed advertisement, on-line marketing and personal referrals.

Printed advertisement is largely used in the form of magazines and newspaper ads. Recruitment of female "clients" through printed advertisement is done through the "personals" section of classified ads in the largest newspapers in Colombia (Graphic 41). Some IMBs that target women from the upper social classes advertise in high-end and very exclusive magazines through "unique" interviews and articles. Recruitment for male clients through printed advertisement in newspapers and magazines seems to be less common. Other forms of printed advertisements are brochures and informative promotional material.

Graphic 4-1: Sample of ads posted by IMBs in Colombian newspapers to attract female clients

www.contactosteune.com Encuentra amistad noviazgo, matrimonio y mucho más... Chat 24 horas, web cam, teléfonos y fotos. Mas de 15.000 afiliados de todo Colombia y el mundo.

TU FELICIDAD puede estar aqui www.casatebien.com

Animate, inscribete 2458274.
CONVOCATORIA PARA MUJERES A NIVEL NACIONAL Busca tu pareja en la mejor agencia matrimonial y de amigos a nivel internacional, inscripción $\$ 22.000$ incluye estudio fotográfico, iinscribete! 7580791 6123626. Celular: $317-4994302$ asesora@mimujerlatina.com

On-line marketing in the form of advertisement and availability through search engines is very common as well. Online advertisement for IMBs is frequently found in the form of banners and side bars, email messaging and email spam. Additionally, many 
IMBs are very strategic in the way they present themselves on their websites in order to take advantage of the keyword tools and sponsored searches offered by popular search engines (e.g., Yahoo, Google, etc.). These tools increase their chances of appearing within the first search results or at sponsored search ads. Thus, this is a very effective way for IMBs to be able to maximize their exposure on the web and reach potential customers at the moment the customers are looking for the services the IMBs offer. Although these tools are designed to reach both female and male clients, IMBs specially target the male population by increasing their advertising, particularly on male oriented sites.

However, the most common and effective tool of advertisement used by IMBs is the highly influential person-to-person passing of information: personal referrals. This transfer of information is largely based on knowledge of "successful" stories- the alluring possibility of meeting that 'special someone.' Such is the case of Rita Mendez, one of the women I interviewed, and who at the time of the interview had been married to an American man for almost a year. She stated that she "liked the agencies so much that I have invited many, many friends. Some are already married... I have recommended the agency to so many people, I cannot tell you how many. (She laughs). But look, two of my closest friends are married, like me, to a 'gringo' and they are living in the U.S. Many others of my close friends are talking with Americans through the agency. In fact, they [American men] have come to Colombia to visit my friends... you know sometimes it is not that easy. I mean these relationships are not easy, but yes, I recommend it all the time." 
An agency owner explained to me how "typically women are so much better about sharing information than men. Once women join our website or use our services typically they send us their friends, sisters, nieces, etc. to join..." And the representative from LLM told me that "for instance, from a group of 20 men that come to Colombia, 10 get engaged. When the gal gets married she brings her cousin, her sister, her neighbor, her best friend and so on. When that new one gets married then she brings other 5 or 6 gals, and that keeps it going. That is what happens; most of the gals here have been referred by someone else. It is very unusual to receive a gal here in the office, saying that she saw the classified ad or the sign in front of our offices. No, here it is always that someone tells them to come..."

Men do recommend to each other the services of IMBs, whether face to face or in the web. In fact there are online communities such as "Gringo Talk" (Graphic 4-2) and "The Good Wife. Com" dedicated to men sharing their dating and traveling experiences with foreign women whether from Latin America or other parts of the globe, particularly their opinions about the services of different agencies, do's and don'ts, the characteristics of women from different countries, cities, etc. 


\section{Graphic 4-2: Gringo Talk banner often posted in the web-pages of Colombian}

IMBs.

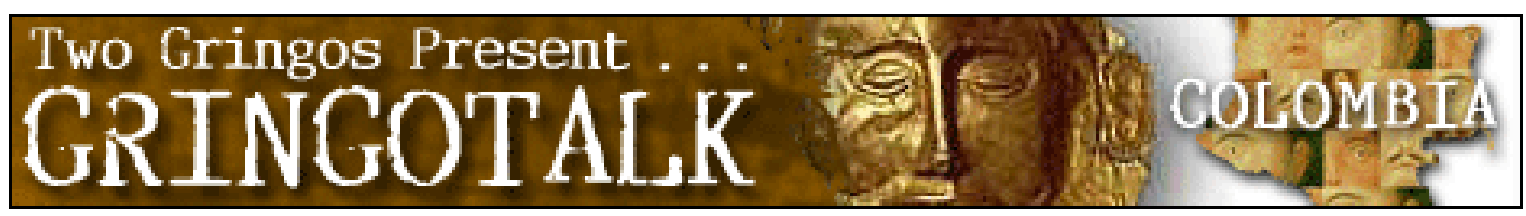

The recommendations done at the personal level are best described by the

words of Alexander Rodgers an American I had the opportunity to interview and who proudly shared with me how he had "helped over 200 to get married or engaged. You can call me Cupid! (Laughs) Mr. Cupid! That was good; I did it for three years. I am not doing it anymore, it was not my business, my business is in finances, then I used to spend $90 \%$ of my time helping and counseling people and believe me I didn't get paid for doing it..."

\section{Gendered Content}

The general content of the IMBs' websites and advertisement material is clearly targeted to persuade men and women to join their sites and use as many of the services offered to them as possible. The central idea revolves around the effectiveness of IMBs as the means to find the "imagined" foreign partner, as a way of taking charge of one's future and as a way of making one's dreams come true. Websites are the virtual shop windows of these businesses (Chow-White, 2006), in which not only pictures and videos of their clients are displayed but also the testimonies of "successful couples," large colorful pictures of seemingly happy couples, tour events, happy hours, bachelor's 
parties, etc. Thus, the content of these websites are very much crafted according to the clientele the IMBs want to reach.

The analysis of websites and interviews with different IMB representatives consistently showed the representation of the potential mate as the holder of values and behaviors that are "lost" in the cultures of their clients. Thus, Colombian and American women are constantly compared and the Colombian woman portrayed as a more ideal mate. The same is true, albeit in reverse, for women seeking mates. International Marriage Brokers present meticulously assembled images of the women and men that feed and stimulate the imagination work of their clients. They do this, of course, to increase their chances of acquiring more clients and increasing their business. Because women and men are presented differently by the IMBs, I will provide detailed explanations of how their clients are presented in their websites, brochures and through personal interactions.

\section{How are Colombian women presented?}

Colombian IMBs compete aggressively against well established Asian and Russian IMBs. In contrast to the stereotypical perception and portrayal of Asian, and to some extent Russian women, as timid, quiet, servile and immersed in traditional structures of courting and marriage (Constable, 2005; Johnson, 2007), Latin women are portrayed within an image of being as spontaneous, talkative, cheerful and very sensual:

We have visited Russia and Asia and nothing compares to the beauty and sincerity of Barranquilla women and Colombian women... We have the prettiest and sweetest Latin ladies. Latin Women and Colombian women in South America and are here to help you find your lifetime companion. 
I have been to Russia, Ukraine and Costa Rica looking for a bride. I didn't have any luck. A number of the men on the trip with me got engaged but NONE of them got married. AFA boasts over 700 engagements this year but I only know of one person that actually got married... The success rate [in Colombia] is very good, over $50 \%$ [of the clients] have connected with someone and are now in a long-term relationship. Many of the men have rented apartments or have purchased condos or homes because this area is so beautiful and tranquil. (www.loveme-colombia.com)

We don't want to imply that only Colombian ladies would make great wives but we know for sure that they do. The Colombian culture is based on family and marriage and the girls here still hold onto those beliefs, unlike so many cultures in the world today.

Besides being beautiful, educated, and interesting, the Colombian woman is very devoted and faithful. We call that the whole package. So if you want to travel all over the world and meet girls from every culture that sounds like a fun thing to do, but if you want the whole package, then do what thousands of men have already done... come to Colombia. (http://www.latinintro.com)

Colombian IMBs seize upon and further cultivate the deeply embedded image of "Latina Women" in the minds of American men. The term "Hispanic" or "Latino" was recognized as an ethnic category in the 1980 U.S. census. It is frequently used to refer to Spanish-speaking people in the U.S. as an ethnic identifier (Flores, 1999). Accordingly, "Latina women" is becoming an all encompassing category that represents a mixture of races (black, indigenous and European) without reference to a particular Spanish speaking country.

As a strategy IMBs' representation of Latin women is then constructed from a dual context: one refers to the sexuality/sensuality embodied by public characters such as the entertainers Adriana Lima (model), Eva Longoria (actress), Jennifer Lopez (actress and singer), Jessica Alba (actress), Karen Carreno (model), Paz Vega (actress), Salma 
Hayek (actress), Shakira (singer), Sofia Vergara (actress), and others. The other refers to individual traits associated with traditional customs and moral and religious principles, perhaps inherited from the European influence (Navarrete, 2006). Consequently, IMBs apply a deliberate strategy in which the general classification of Colombian women as "Latinas" attracts male clients, but they also compete over other websites by adding in a seductive "Colombian identity" in which alluring personal and physical characteristics of Colombian women are highly recognized and consistently highlighted:

While the women you meet Online and In-Person may not look, dance or sing like the Barranquilla native Shakira, they will take your breath away none the less! (http://www.thecolombianconnection.com)

Meet Beautiful Latin Women, Colombian Women and Latin Ladies for online dating... We feature 100's of beautiful, single, latin ladies, Colombian women and Latin Women seeking love, friendship and marriage with serious minded men from all over the world. (http://www.latindreamtours.com)

Come to Bogotá, Colombia to meet Beautiful Latin Women. Latina women and international dating sounds exotic, but the magic of the blend of Latin American cultures is real. Experience it for yourself. (http://www.mylatinadventure.com)

Engage The Exotic - Latin Women of Colombia. International Introductions is your opportunity to meet and marry Latin women significantly younger and more beautiful than what is locally available.

(www.latin-wife.com)

Latin women are, on occasion, marketed as diametrically opposed to their American counterparts (Gabriel-Schaefer, 2004; Chow-White, 2006). By exalting the specific characteristics of Colombian women, many agencies present, although many 
times tacitly, American women as being completely opposite to Colombian women. The "FAQ" section of the allcolombianwomen.com website, for instance, reassures men that "Colombian women are not as materialistic as American women" and further explains that men "will be pleasantly surprised with their [Colombian women's] honest appreciation of all small gifts, attention and affection they receive." Another particular example can be found at the ColombianConnection.com website where it is explained that "Colombian women are extremely feminine, romantic and faithful, with high morals and family values... truly interested in you [American men] and not your checkbook and credit cards."

Such comparisons are based on stereotypes of the behaviors and qualities of both Colombian and American women. International Marriage Brokers use particular women's characteristics that they perceive as desired by men and consequently "offered" and "advertised" within their sites and printed advertisement. After analyzing the content of more than twenty IMBs websites, the following is a summary of the core stereotypical characteristics presented by those IMBs (Table 4-1). It provides an overview of characteristics by which Colombian and American women are explicitly or implicitly compared and contrasted within these businesses.

Table 4-1 List of attributes IMBs use to compare Colombian and American women

\begin{tabular}{|c|c|}
\hline Colombian Women & American Women \\
\hline Exotic/Gorgeous & Common \\
\hline Faithful & Unreliable \\
\hline Family-Home Oriented & Career Oriented \\
\hline Feminine & Tomboyish/Unkempt \\
\hline Honest & Deceitful \\
\hline
\end{tabular}




\begin{tabular}{|c|c|}
\hline Humble & Over-confident \\
\hline Passionate & Indifferent \\
\hline Sexually Available & Sexually Liberated \\
\hline Strong traditional values/Conservative & Lacking values \\
\hline Submissive & Dominant \\
\hline Subservient & Demanding \\
\hline Supportive & Competitive \\
\hline Tactful & Outspoken \\
\hline Unselfish/Caring & Self-centered \\
\hline
\end{tabular}

Overall, IMBs craft the presentation of women based on an ideal combination of four basic "qualities." They are thus portrayed as being: a) extremely attractive, b) family/home oriented, c) highly educated/ successful and d) open to establishing relationships with older men. The first characteristic corresponds directly to the graphic content which supports the descriptions of Colombian women as beautiful and attractive women. The home pages and photo galleries of the IMBs' websites are filled with pictures of beautiful young women.

The general concept of Colombian women is represented by pictures of women in flattering and alluring poses, wearing tiny swimsuits or especially revealing outfits (Graphic 4-3). Likewise, the written descriptions of services include intense accounts of the physical and interior beauty of Colombian women. This can also be seen in the repetitive mention of Colombian women being highly noticed and awarded in beauty contest such as Miss Universe, and Miss World.

Strategically, most pictures are located in the home page of the websites, where male clients will form their first impression of the site and decide whether or not to join 
and use the services of the IMB. As explained by three different IMB representatives, in many cases the pictures from the home page are not necessarily of active members of the IMB. On the contrary, many times they are pictures of paid models, not clients or possible matches. The large majority of on-line referral services present this type of content in their websites; in fact, many of them charge their members to view the pictures only for their "viewing pleasure." On-line dating sites and marriage and 
Graphic 4-3: Examples of the sexualized representation of Colombian women in IMB websites

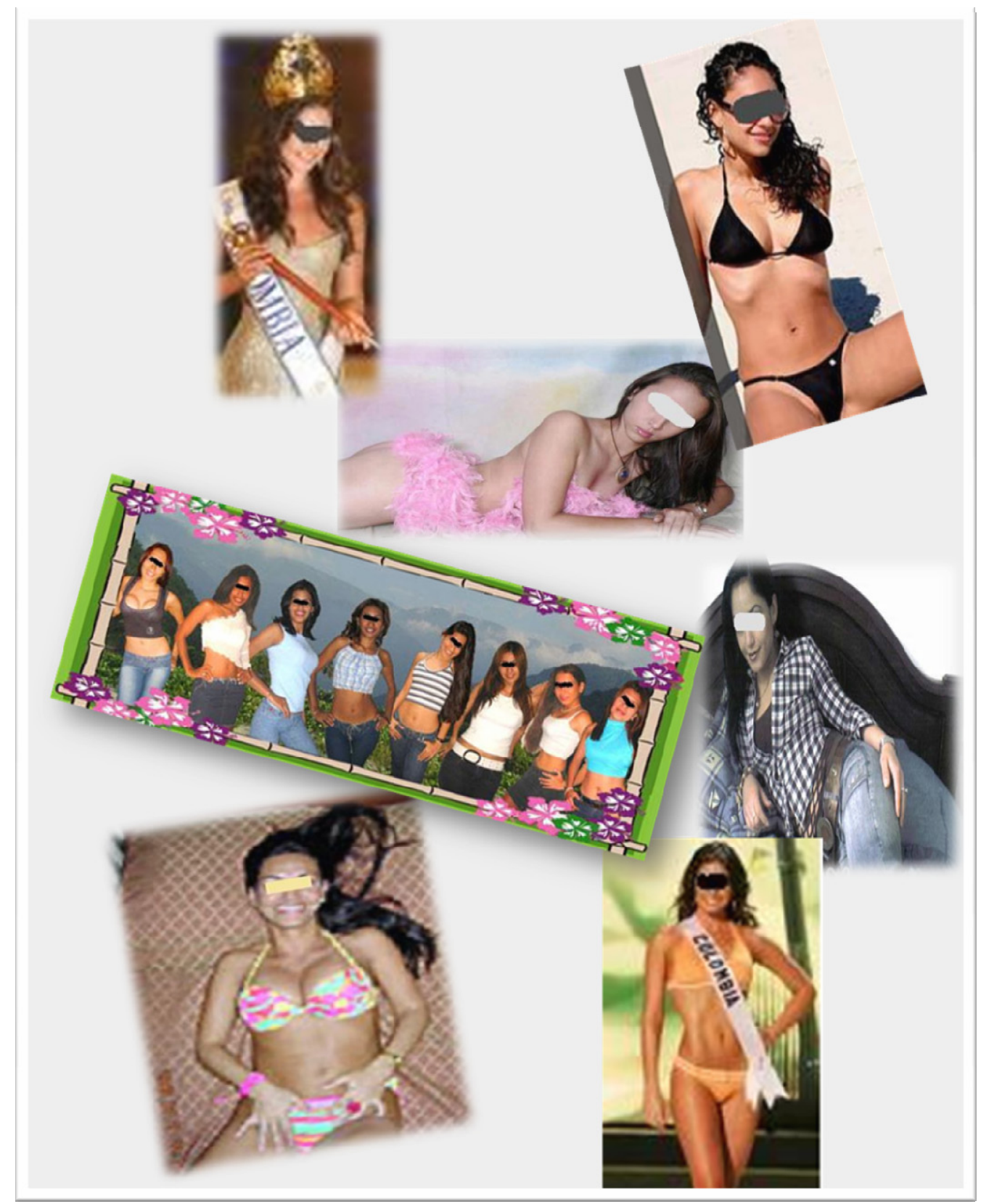

introduction agencies tend to present more toned down, neutral and realistic images of Colombian women. However this does not necessarily mean that the women are fully dressed, less alluring or are portrayed less suggestively. 
Some IMBs allow women to upload pictures of themselves in casual poses and regular clothes. Other IMBs, because of the nature of their business, provide free photo studios or request photo studio-like pictures of female members. In these cases, the pictures are taken by the IMB photographer and women are advised by the IMB staff on clothing and postures. Regardless, the graphic content of these IMBs' websites is designed to please men interested in the premise of the beauty of Colombian women.

The second "quality" repetitively marketed by IMBs is Colombian women's values of the traditional family and spousal relations (stay-at-home wives, breadwinner husbands). Many sites advertise their services stating that today's American men cannot find the type of woman perfect for them locally so they need to use the services of IMBs to find a true companion. In fact, the brochure for agency Latin American Introductions explains how "Back in the 50's things were simpler, you [American men] could date and marry someone and expect a happy traditional marriage, divorce was down and people were happy together. Today we [American Men] must to look to other locations throughout the world like Colombia to find women with the same attitudes about dating and marriages as those women from the 50 's." The idea of traditional marriage, low divorce rates, understanding, undemanding and dazzling women has certainly contributed to the success of IMBs catering to American men. Such emphasis is given in what American men see as a contrast to the high numbers of American women joining the labor force, choosing to pursue professional careers, and delaying motherhood.

The women of Cali are considered some of the most beautiful Latinas in the world. They are meticulous in their appearance and enjoy dressing themselves appropriately for a tropical climate. Skirts and heels add to their sensuous appeal. Add to this their 
warm hearted nature and family orientation, and you have a delightful mixture of the best of femininity. With so many to choose from, the choice can sometimes be difficult.

(www.latinbest.com)

All Colombian girls are the most beautiful girls in the world. They are sexy, sensual, loyal, romantic, sensitive, caring, and make good family-oriented wife with moral values.

This girls [sic] are responsible and hard working.

(www.allcolombiangirls.com)

Not only are these women beautiful but they are genetically (sic) and socially family oriented. This means that they make excellent wives and mothers as the family is THE most important thing in their lives. (www.loveme-colombia.com)

It is common knowledge that Latin American women are faithful, loyal, and devoted wives. There is a reason why Colombia has the lowest divorce rate in the world. Their world revolves around the family. Colombian women stay with their first family until marriage and then the tradition continues with their new family. They have been raised to complement, nurture and respect their men.

(www.latin-wife.com)

Colombian women are extremely feminine, romantic and faithful, with high morals and family values. Statistically speaking, Colombian Women are the best women to marry!

(www.thecolombianconnection.com)

In Latin culture, family life, traditional values, and fidelity in females are part of the social structure. In many cases, these women still live at home with their parents until married and believe marriage should be forever.

(www.latinmatch.com)

If you are interested in marrying a traditional girl, who is attractive, youthful, honest, and sweet, then we believe that this will be your best opportunity.

(www.latinintro.com)

Colombia provides the greatest opportunity to meet the most beautiful and family oriented women in South America (www.colombianwomenonline.com)

Although Colombian women are described as being family and home oriented, the messages do not imply that these women are not hard working and/or highly 
educated. Quite the opposite, the third "quality" of Colombian women is based on their own willingness to work and in their higher levels of education. Colombian women are shown as versatile women who, unlike their American counterparts, "choose" to devote their lives to their families' welfare over careers. Colombian women are certainly not portrayed as "underprivileged" women, in need of being rescued from extreme poverty. They are described in the websites and on individual consultations with IMB representatives as educated and economically stable women in search of committed, long term relationships. International Marriage Brokers claim that their female Colombian clients are searching for husbands, not for bank accounts or green cards; they claim that Colombian women are used to supporting themselves economically in very difficult circumstances. They do not need men to support them, but men to love and respect them. Nonetheless, IMBs warn male clients of the possibility of having "some" women who seek a green card or money, but clearly state that they are a very small minority of their clientele.

These women are not looking to escape their countries since many of them are professionals or have good jobs. They are also likely to have very close family ties; however, upon finding the right personal match, they would follow their life partner anywhere.

Are these women looking to escape economic conditions in their countries? No. Many of these ladies are very well educated, have good jobs or careers and some even own their own businesses. They also have extremely close family ties, which is a strong part of the Latin culture. (www.latinmatch.com)

The answer is, some are looking for love and some are looking for a visa. It's unrealistic to think that every girl is $100 \%$ honest and has only good intentions, and anyone who would promise that is not being honest themselves. The good news is that vast majority of the ladies in Colombia are good and honest girls and looking for love. Common sense always prevails, if you use clear headed observation, good and timely 
questions, and at times trust our judgement [sic], then can easily sort out the rest. We have been at this a long time and can certainly help you out in this area, all you have to do is ask (www.latinintro.com)

C'MON AREN'T THEY JUST AFTER A GREEN CARD? Colombian people are very family oriented. There first loyalty is to their families this includes their husbands. It is a very difficult thing to do to just pack up and leave your job, family, and friends for someone you barely know. All of these women are very open to coming to the U.S. but will not make that decision without serious consideration, and unless their sure that the person their going back with is right for them.

ARE THEY JUST AFTER MY MONEY? No. You only ask this question because your [sic] used to American women! While stability is important to everyone they are not preoccupied with their husbands [sic] financial recourses [sic]. Because no matter what you have it is still 9 times out of 10 better than what their [sic] used to. And since their [sic] used to a lower standard of living, they are very content with just the slightest improvement in their lifestyle. (www.latindreamtours.com)

One last "quality" of Colombian women that seems to address specific needs of American men is the purported "openness" of Colombian women to establish relationships with older - average looking men. Almost all IMB's web pages contain some explanation and comforting messages about the age differences between couples that men can expect. This is a response to the common desire of American men to seek younger women. International Marriage Brokers explain their websites that Colombian women are willing to commit to these types of relationships because they base their decisions on the internal qualities of a partner rather than the age. Other IMBs do explain that the better/younger you look the better but that in general a man will be able to find a much younger and attracting women compared to what they could find in the U.S. Two IMB representatives explained how women are looking for stable men 
that are serious about a commitment, a characteristic they perceive as very scarce

within Colombian men and abundant within American ones.

What is true is you can generally knock about ten years off the minimum age you could attract at home... If you are 40 and able to date local women as young as 32 years old then you should have no problem finding an even better looking 22 year old Latin

bride.

(www.latin-wife.com)

Many Colombian women consider age to be a sign of maturity and stability. As a result, they are more interested in you as a person than they are your age and appearance! They seek the more important qualities such as honesty, stability, and sincerity. Give them that and you will be richly rewarded!

(www.thecolombianconnection.com)

How are American men presented?

Quite in contrast to the marketing of females to male clients, the IMB marketing of men to female clients is not done primarily through the web pages of IMBs. Rather, this marketing is included in parallel websites, strategic language, and/or general descriptions in the sections describing American men either to attract female clients or to reassure American men of what Colombian women are looking for in a partner. Based on their perceptions about what Colombian women are looking for, IMBs present American men as qualified, attractive men with goals and expectations of partners in structured and committed relationships.

Contrary to the marketing directed to American men, very few IMBs have "Men Photo Galleries," or facilitate women's ability to actually search and contact men to initiate conversations (with the exception of on-line dating sites). Pictures of men across the sites can be found on the different sections such as "Testimonials," "Tours," "About 
Us," etc. However, unlike the representation of women, men are systematically shown surrounded by many women, in pictures of couples, or in groups (Graphic 4-4)

In general, what IMBs offer to women in their American male clients are, once again, stereotypical qualities that fit hand in glove with what Colombian women are looking for as their imagined "ideal." Four basic themes recur: American men are a) emotionally stable, b) economically stable, c) have non-macho attitudes and d) are very attractive (Table 4-2). As explained before, these characteristics are constantly contrasted against Colombian men's qualities. Colombian men are portrayed as the "bad guys" (Gabriel-Schaefer, 2004; Chow-White, 2006) who are not emotionally or economically stable, who demonstrate macho attitudes and behaviors in everyday life situations and not being as attractive, not necessarily in looks but in the behaviors, as their American counterpart. Consuelo Romero, the owner of IntroductionsbyConsuelo.com explained to me some of the differences by saying that "American men have life goals, they are very clear in knowing what they want, and it is a life mate, a family and a good life. Unlike Colombian men they are faithful, hard working and always put their family first; here in Colombia, men are thinking in how to have fun today, in partying and met as many women even if they are engage or already married, that does not happen with American men, they really value their women and their family."

International Marriage Brokers steadily assure their female clients that American men enjoy high enough socio-economic status to meet the women's criterion of financially stable. For instance, one of the representatives of Latin American 
Introductions agency told me that "most of our clients are professionals, they have their careers, houses, cars, and good money, at the end of the day to come all the way to Colombia shows that they have the money to come, and they do just because they want to find a 'good wife."' International Marriage Brokers representatives explain to their clients that American men have easier access to resources such as money to use the services of IMBs, having limited restrictions to travel (visa) and personal traits that will make any "good" woman of the world happy.

Table 4-2 General attributes IMBs use to compare Colombian and American men

\begin{tabular}{|c|c|}
\hline \multicolumn{2}{|c|}{ American Man } \\
\hline Emotionally Stable & $\begin{array}{c}\text { Confident } \\
\text { Faithful } \\
\text { Wanting to establish lifelong } \\
\text { relationships }\end{array}$ \\
\hline Economically Stable & $\begin{array}{l}\text { Hard Workers } \\
\text { Generous } \\
\text { Good providers } \\
\text { Professionals }\end{array}$ \\
\hline Non-Macho Attitudes & $\begin{array}{l}\text { Help with household tasks } \\
\text { Help with Child care } \\
\text { Believe in equal gender rights } \\
\text { Emotive, Expressive } \\
\text { Independent }\end{array}$ \\
\hline Attractive & $\begin{array}{c}\text { Charming } \\
\text { Gentlemanly } \\
\text { Healthy habits (exercise, food, etc.) } \\
\text { Good looking }\end{array}$ \\
\hline
\end{tabular}

As most of the recruitment of women is done through personal interactions and the stories told are the basis for such recruitment, the inevitable negative stories or bad experiences of women marrying foreign men need to be neutralized. For that purpose, women are constantly assured that all male clients have been screened, gone through 
Graphic 4-4: Examples of the graphic representation of man in IMB websites

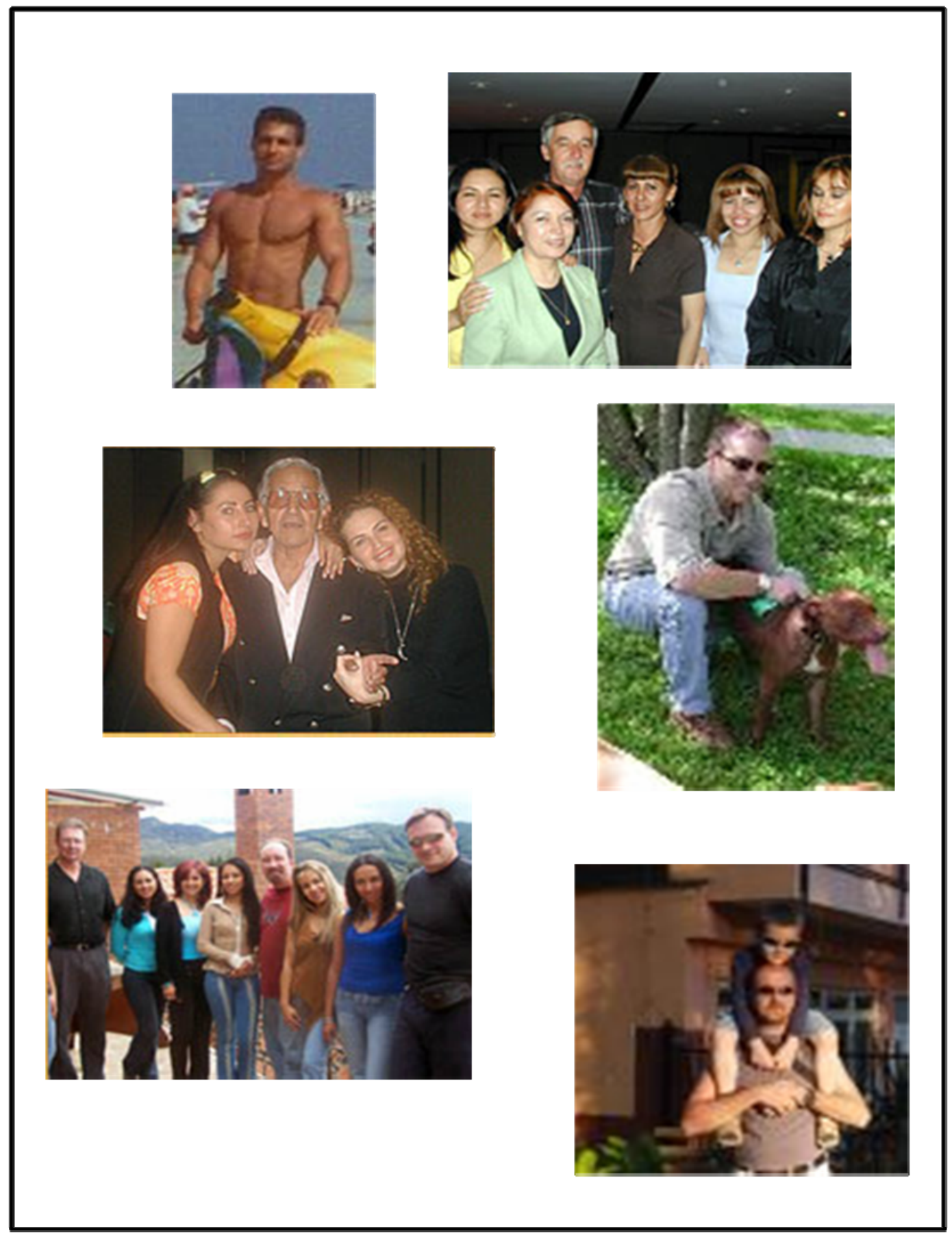


criminal background checks as required by the American law (International Marriage

Broker Regulation Act of 2005) and that IMBs do this in order to protect them from

having to experience those not so positive stories themselves.

Approximately, $90 \%$ of our male clients are professional, executives, entrepreneurs, and technicians that have decorous lives without economic struggles and wanting to establish a family in the short future. They are men of different ages, activities, cultures, customs and socioeconomic levels that reach to our agency in the search of a place to change their lives, share friendship, company through the establishment of committed relationships. (www.solitos.com)

Let me invite you to meet the most exclusive, educated and successful foreign gentlemen looking for someone special like you! ... Open your eyes to a different world, the world where men are faithful, thoughtful, generous, and anxious to love you and propose marriage. (www.introductionsbyconsuelo.com)

Our gentlemen are searching for traditional women for romance and serious relationships aiming to marriage.... All of them have stable jobs and many of them are professionals. (www.tlcworldwide.com)

\section{Overcoming Colombians' Bad Image?}

As part of what I have termed "Colombian Marketing," IMBs have also been very resourceful in trying to overcome Colombias' negative images, dangerous news, stereotypes and misconceptions, while at the same time trying to influence or persuade clients of the comparative advantages of Colombian women as related to the women from other countries. Through specific remarks, mostly in the form of "FAQs" or "Why Colombia?," IMBs intend to reassure male clients about their concerns for personal safety and possible abductions when traveling there, in addition to providing concrete descriptions of Colombian people's goodness and Colombia as a tourist destination. 
Several IMBs do use the official Colombian government's image campaign and the official tourism portal videos and multimedia tools (i.e., Colombia is Passion, The Only Risk is Wanting to Stay) to show a very positive side of Colombia to their clients who perhaps only know about negative aspects of the country.

As a single man looking for a girlfriend or wife, Colombia is the country for you! Explore Colombia and enjoy its great weather, its beaches, mountains, etc. and do so in the company of exotic, exciting and INTERESTED Latin Women! (http://www.thecolombianconnection.com)

It is also important to know that culturally and politically, Colombia is a modern democracy with close relations with the United States. Considering that Latins [sic] are the fastest growing minority in the US, Colombians do not have the difficulty assimilating to our culture as do women from many other countries.

(http://latinlifemates.com)

There are so many reasons to come to Colombia: Bogotá is only 3 hours from Miami, it is relatively inexpensive to travel here and you can make several trips per year if you wish. How easy is it going to Russia or the Orient three times a year? Colombian ladies share the same alphabet as we do and learn English more easily. More importantly Colombian women come from a strong family culture but at the same time they have a modern life in Bogota and assimilate very easily to western life. Plus the weather is always pleasant here and the people of Colombia are some of the friendliest people in the world. (http://www.latinintro.com)

The marketing campaign of Colombian IMBs has worked so well that it has overcome most of the negative press that Colombia has had over the past 50 years. Indeed, many IMBs traditionally focused on other parts of the globe have been trying to break into the Colombian "market." Such is that case of the "Colombianbrides.com" website, which seemed to work with Colombian women by its name, but only served the owners to increase traffic in their other sites. When I contacted their representative he explained that as a business they were exploring the possibility of contacting 
Colombian women through their website responding to the increasing demand for Latin - Colombian women in particular by their male clientele. The representative specifically stated that "Well, yes the 'colombianbrides.com' is one of our websites, but we are not actively working with Colombian women. You see we do primarily concentrate on the Asian market (Asian brides) so we are more strategic in Asia, we have much expertise in Asia. Our expertise is not so much in Latin America per say or Colombians for that matter, while we have the website, unfortunately we do not have many women from Latin America signed in probably it is our problem because we do not speak Spanish... but the pages gets a lot of traffic so we keep it. You need to understand that we always allow women to basically find us and to send their application to us directly, so in our case we don't have representative offices in Latin America, we don't have recruiters women find us, but definitively we... we have a better exposure in Asia than we do in Latin America." Evidently, the owners of this website use the growing popularity of Colombian women within the IMB business to attract more clients and serve them not necessarily within the Colombian context.

In general, this Colombian marketing (channels, content and the overcoming of bad images) shows how the work and strategies of IMBs are gendered. Perhaps, this is the result of the dual clientele involved and the mutually constituted factors and expectations that are part of the general ideals and realities of the participating women and men. The overall messages and graphic representations used by IMBs in their pursuit of "business" are basically framed by what they perceive and recreate as being demanded by their clients (women and men) while in the process of courting. 


\section{IMBs: crafters of international couples - Brokers of the International Migration Industry}

After reviewing the history of Colombian IMBs and their most important characteristics and procedures it becomes evident that IMBs are agents that act as brokers of the international migration industry: they craft ideals of international men and women and promise to assist them in marriage/courting systems which, although they do not state so explicitly, are oriented toward facilitating women's migration.

Although, by the American law definition, IMBs are considered "brokers" of international marriages, in reality they act as the crafters of specific dreams of love, company and the future, that influence their clients both female and male. As these IMBs market women and men differently in their websites and advertisement material, such marketing enhances the very messages and desires that those same men and women are transmitting in the first place to IMBs representatives. Thus, IMBs craft into a strong fit the different messages of stereotypical expectations of clients using their services. Starting at two opposite perspectives IMBs craft a specific message oriented toward satisfying clients of both sexes. The IMBs craft these messages around two seemingly competitive theories of partner relationships and marriages: the "traditional" and "modern". International Marriage Brokers exploit these messages and, in so doing, reinforce these desires and stereotypes.

The "traditional" view of relationships and marriage characterizes women as seeking men by offering physical attractiveness, family oriented values and love based services (e.g., childbearing, childcare, housekeeping, etc). In return, they want men who 
are good providers. Today, that largely means men holding an above average income associated with high levels of education and intellectual characteristics, and a real commitment to establish a stable relationship. In addition, and this is a critical addition, the Colombian women seek men from a geographic location that could open opportunities related to stability, security and status which Colombia does not offer them. Under the traditional view, men are cast as the family heads and financial providers of the home while women are cast as submissive companions and in charge of household/family maintenance.

The "modern" view, on the other hand, represents the idea of both women and men joining the labor force, possessing similar educational and intellectual statuses, and offering committed love, physical attractiveness, family oriented values and love based services in a more equitable manner. This view is often referred to in the literature as companionate marriage (Hirsch, 1998; Sweeney, 2002; Cherlin, 2004). Under this view, men and women are expected to share leadership and to bestow to the household/family maintenance and economic provision in equal proportions.

What I contend is that IMBs are promoting ideals of partners and relationships that satisfy both women and men expectations and correspond to their very basic motivations (which will be further described in the following chapters). International courtship and marriages, whether traditional or companionate, were considered by my informants as less dominant and more distinctive than the types of courtships and marriages they would confront courting and marrying a conational in their own cultures. American men seek traditional marriages in which there is a clear division of roles and 
responsibilities of each individual. Women on the other hand want companionate marriages, particularly those women that have similar occupational, educational and intellectual status compared to the one of their partners. However at some point of the courtship process men become open to negotiate roles and tasks within the family (husband, wife, parents) while women are choosing to assume a traditional role whether for love, migration, economic circumstances or other motivations.

Thus, taking those forces and ideals that shape gender roles within marriages, IMBs have been able to craft a specific message that combines those specific traits that men and women are looking for in a marital/partner relationship and the expected roles that each of them anticipate the other to fulfill. International Marriage Brokers are creating a particular definition of marriage, in which a more egalitarian attitude is present but gender roles are still defined based on the expectations of traditional marriage roles.

International Marriage Brokers are constantly creating and/or perpetuating stereotypes and different forms of representations not only using strategic images of men and women but also words that (re)create imaginaries of close to "ideal" partners. Thus, IMBs act as specific agents that craft a concise message that satisfies all their clients, female and male, while being able to grow as a business and achieve economic profit. Such crafting is facilitated by the unknown aspect of foreign individuals' behaviors and idiosyncrasies. Foreign partners are offered by the IMBs as a clear process of "otherization", suggesting a foreign spouse as the opposite of what they, both women and men, would be able to find as a partner within their own societies. In this 
case the other becomes the "better" option. Such process of "otherization" supports the constant generation of ideals and imagination work as of envisioning that perfect mate each individual dreams of having. At the same time they are reinforcing stereotypes and using a priori negative feelings and experiences that each individual might had with conational partners. Consequently, international marriages and thus, migration of one of the spouses is increasingly common and thought of as an alternative to overcome local socio-cultural constraints and difficulties and creating the "ideals" of a more egalitarian though somehow traditional form of marriage.

Nevertheless, the message created by IMBs contains what to the outsider eye could interpret as evident contradictions. Some of those contradictions are a) the promotion of women as "traditional" through written elaboration on the characteristics and expected roles of women though portraying them using graphic representations of women that contradict the written message and portray them as very sexually liberated. That is, the language IMBs include on their websites stresses Colombian women's traditional family values while the websites' pictures of them market the oppositewomen as Latin vixens. Meanwhile, the IMBs market American men as loyal, good providers while, simultaneously, depicting them in website photos surrounded by many women or as part of a "success story," success stories which also characterize them as womanizers. The IMBs also cultivate companionate ideals among the women while simultaneously exploiting the men's greater economic power by providing very uneven access to client databases. 
However, such apparent contradictions are used by women and men as tools to represent themselves and acquire "comparative" advantages in their representations of physical attractiveness, behaviors and to access potential matches. Thus, women and men are not agents that participate in these systems passively. On the contrary, using the messages created by the IMBs women and men have been able to strategize and use such messages to their advantage. Whether or not men and women are or become what the IMBs offer in their sites will be examined in the following chapters. What cannot be denied to this point is the role of IMBs as crafters of ideals of courting, marriage and to a degree of partner behavior. 


\section{CHAPTER V - GENDERED IMAGININGS}

As demonstrated by the immigration data detailed in Chapter III and the increase in the number of Colombian IMBs discussed in Chapter IV, it is clear that there is a growing number of men and women using the services of international matchmakers. But why? What is motivating these individuals to join the IMBs? What are they expecting to achieve through these relationships? Are these motivations and expectations the same for women and men?

Colombian women and American men are using the services of IMBs as the channels to find "suitable" lifelong committed partners overseas. They hope to find love. However, finding love not only means the strong unselfish, loyal, compassionate affection and concern for the good of the other person, as any dictionary might say; it also includes other expectations, particularly those involved with imagining ideal mates and relationships with them. These expectations include the possibility of having a family, attraction based on sexual desire, the performance of traditional sex roles both for males and females, legal migration and the availability of resources (economic support, professional development, social status, etc.).

This chapter contains detailed explanations behind the gendered motivations and expectations of my informants. It also includes theoretical analyses as well as relevant socio-cultural and structural factors affecting these motivations and expectations. Although the expectations and motivations are related, the chapter starts 
with detailed descriptions of two sets of expectations within the imaginative process that were found across genders in an effort to explain the dynamics, agency and power differentials of the participants.

\section{Shared Imaginings? - What Are Men And Women Expecting Of These Relationships?}

There are some important commonalities in IMB clients' motivations to seek a

mate overseas. Though each individual had specific "requirements," many of them agreed on a few key qualities. They anticipated the establishment of a specific type of family which included detailed descriptions of the expected gender roles each partner would assume, and they also wanted to find partners with specific physical characteristics, age ranges, partners wanting children. Imagined Families

While interviewing the women using the services of IMBs, it was clear to me that they were imagining their futures framed within an "ideal" marital relationship. Such is the case of Rita Mendez, the 31 year-old, divorced business administrator, who was willing to give up her successful professional career to live a family life with her daughter and her soon-to-be- husband in the U.S. Rita recalls that she "always wanted a family, I wanted a husband. At the beginning [of her involvement with IMBs] I didn't want to admit it," she told me. "I said that I only wanted to meet new friends, but deep inside I wanted my own family, to get back the family I lost when my marriage fell apart. I like to be the mother and the wife. I really like that lifestyle... It is not like I would stay at home all day cooking and cleaning, but I like the idea of a family, to come back from work to a place where you feel complete." Rita imagined a husband 
with specific characteristics like "a faithful man, a hardworking, respectful and committed man" who would not expect her to do all the home chores, who would help her raise her 9 year-old daughter and who "would encourage me and support me to achieve all I wanted to achieve in life." Rita believes she found such a man; he lives in California and she is waiting for a fiancée visa to be able to travel and get married. However, she realized that she needed to "forget about my career there is no way I can get the same kind of job I have here in Colombia. But that is OK, because I will have my family. I will probably stay home for a while, but after a while I will find a part time job or something like that, so I can feel that I am doing something outside of the house."

Women using the services of an IMB, expect to establish marital relationships with a shared distribution of responsibilities, an ideal they cannot find with a Colombian man. Thus, they want to find a "companionate" husband, one who would share housework and childbearing tasks, to be supporting and to help them, if she so chooses, to develop professionally. They are expecting to get married and to be acquiescent to a more "traditional" division of roles and responsibilities (assuming wife and motherly tasks) yet within a more open and equitable relationship in terms of negotiation, flexibility, communication, security and stability.

American men have "traditional" expectations in the wives they seek; they want to find a family-oriented wife. Their common imaginings of this wife, the key to the family life they desire, are found in the expectations of Alex Silverman a 58 year-old 
astrophysicists and Tom Connor a 43 year-old, self employed publicist. Alex is the

more liberal end of the range I found in American men's search for traditional wives:

One thing that attracted me about this is that Colombian women and Latinas in general seem to be more old fashioned... I am not for the idea of having a woman in the house all the time. On the contrary I think women should be paid equally for doing the same job and there should be equal opportunity for women as there is for men. But the problem is that the women in Europe and the U.S. have lost the idea of being mothers, wives and home people. And on top of it all they have lost their femininity. In Colombia, women are very feminine, and I like that... I am hoping to find a feminine, intelligent and beautiful Colombian. If it is her desire to work I am OK with that, but I don't want it to be her priority. Family should always be first... For what I know, most of the women in the agency [IMB] are working, independent women; that is very attractive... [But] you know I am here [in Colombia] again because the women I have dated before had not forgotten that family is first...

In the words of Tom Connor the idealized notion of the "traditional"

woman moves to a much more conservative end of the continuum:

I like Colombian women because they are more sensitive, more submissive, submissive to the man I mean. I am looking for a woman who would take care of the home, a woman who knows that her place is in the home and my place as the man of the house is at work... I understand if she feels that that is sacrificing a lot to do that, that she's not reaching her working potential, but she needs to understand that family comes first. Men are good at working away from the home. The nicest thing is that Colombian women get it; they know how important family is, so they sacrifice and devote themselves to it, to their husbands and their kids.

It is clear that although American men's expectations for finding a "traditional" wife vary, they seek women deeply rooted in traditional gender roles (those of stay-athome mothers) and who prefer family over personal or professional achievements. Ideally the men hope to find an unselfish and giving woman who would display her 
"womanliness" through the care she provides as a wife and as a mother. Some men, like Tom, are resistant to wives in the work place, considering it a male space. However, most of them are not looking for a foreign maid or a nanny; they want a companion who understands the value of a family and acts as the backbone of it, even if they are working.

These expectations of a family, whether "traditional" or "companionate," are clearly responding to the ideals marketed by IMBs. Marrying a foreign partner is perceived as the opportunity to find a partner whom they cannot attain locally. Successful and educated women want to marry and migrate in search of a dreamed-for family and a better future, while men are willing to lead Colombian women to fall in love with them and follow them to their home country to establish a family-first type of relationship.

Imagined Adonises, Aphrodites and their Offspring

The explicit physical characteristics, age ranges and the willingness of people to have children or take care of existing children that these men and women are expecting to find in a potential partner are, by definition, very personal and subjective. However, there are some underlying qualities worth mentioning. Contrary to the IMBs' message that Colombian women "would not care about men's appearance," I found that the women do hold expectations for the men's physical appearance and attractiveness. The men make physical attractiveness a more explicit expectation, however women also expect a good-looking partner. 
Both female and male interviewees asserted that physical appearances are very important to them; they do expect to find a good-looking partner, and disapprove of those who "do not take care of themselves." For men this might seem "normal" as they have been portrayed as "filtering" their potential matches based on the pictures posted on the women's profiles (Constable, 2003; Schaeffer-Grabiel, 2006; Kabeer, 2007;

Plambech, 2008; Thai, 2008). Likewise, yet contrary to the IMB's rhetoric, women are deciding on their dates and future partners using physical characteristics as part of their selection criteria, not just accepting opportunities or offerings out of their wish of finding a foreign man. Rita for instance, explained that "I was not looking for an extragood looking guy. I mean I did not have a specific image in my head. Well, the physical aspect was important but let's say that I was being flexible. The good thing is that my fiancé is nice-looking! Others may think he's just average, but I think he is handsome!" Some women, such as in the case of Rita, stated that they were not looking for specific characteristics, that physical appearances were not fundamental to their search but that they were "lucky" enough to find someone who they felt attracted to.

Others, as in the cases of Viviana Morales (36 year-old) and Andrea Rueda (54 year-old), stated that physical traits are very important in their search process, however, they did not describe specific physical characteristics. Viviana for instance admits that if the man is not good looking "it won't work... No, no, no. First of all, I am not that type of person who would stay with a guy because he takes good care of me, no! If I don't like the guy there is nothing to do. I can't tell you that I could care less about my future partner's appearance. That would be a lie because I have to feel attracted to my 
partner. I can't be with someone just because he is nice and is offering a good future... sorry but I can't... It is very interesting, because sometimes what you find at the agency... No no no... They are ugly! Ugly! Ugly! And that is when you think, 'Well, no wonder they are still single!'[She laughs]."

Similarly, Andrea told me the story of her toothless boyfriend. "I have a boyfriend now who has come twice already to Colombia. When we met he was toothless and of course all his mouth was a disaster. So you can imagine he can't look right. ... As recommended by the agency's staff he is going to a dentist here in Colombia to have all his mouth fixed, but it is very difficult for me to think about him in a different manner. Though he has promised heaven and earth to me, I don't think it is going to work. All my friends here at the agency ask me all the time... Andrea, what's up with the toothless one? They even send me emails with cartoons of toothless people, can you imagine! He's a good person, we have had excellent conversations, he makes me laugh a lot, but I feel bad because I know he is really into me, but I just can't... I am waiting to see what happens after he is done with the dentist here, but I don't think I would be able to remove that image out of my mind..."

In contrast to the women whose expectations for the men's physical attractiveness is very general, men have in mind specific physical descriptions of the kind of woman they are looking for. Those mental ideals fit, in general, explicit standards--particularly for the weight and height of the women. Most of the interviewed men expressed admiration and thus expectations related to the "femininity" of Colombian women. Femininity is a code word about the care that 
women put into their overall appearance, constantly contrasting it to perceptions of American women being unkempt and letting go of their weight and overall appearance.

Nonetheless, in most of the cases high expectations about physical beauty were tightly tied to potential partners' ages and to high standards for women's “inner beauty." James Huppert, a 45 year-old insurance appraiser from North Florida, explained that he had to be totally attracted to a woman to step forward. "I am pretty picky; I am looking for a woman that looks more like a model. She has to be young, very beautiful but also sweet. You know, someone with a nice personality, somebody who becomes like a best friend. She has to be my best friend, I don't like somebody who becomes very confrontational and I don't like her to be loud. Basically I am looking for someone on the pleasing side, soft spoken. Obviously I want someone who likes to take care of her body, likes to go to the gym, eat healthy, be very health conscious, nonsmoking, non-drinking. All told, someone more focused on making her man happy..." Mark Douglas, a 37 year-old packing line employee, told me that "In the States women are too big. They do not take care of their bodies and after marriage they tend to gain weight." "See," he continued, "I don't like a woman who is too thin and not too big either. Her hair color is not important to me but it has to be pretty and shiny; her eye color is not important to me but I like the eyes and the way they look but not the color... I like average height because it will be awkward having somebody taller than me...5'2 $5^{\prime} 5$ will be OK... I don't know, to me it is important that she looks good but what is really important is how they are on the inside... Because you can have somebody really pretty, 
nice to look at but nothing else. So what do you have...? They could be really pretty but mean, demanding, you know... pretty but that is all..."

In addition to physical beauty, female and male IMB clients cite age as a critical criterion they take into account while searching for their mate. Men and women know and expect relationships in which the average age difference between partners will range between 15 to 20 years, women almost always being the younger partner. For instance, when I asked Rita Mendez about the age of her partner she responded, "There is a... you can say 'normal' age difference between us. To me it is not a huge difference, but it is for him... He is 45 and I am 31." I then asked why she considered that difference to be "normal" and she replied saying "I think that Latin women accept those age differences as normal perhaps because these men don't reveal their real age or... I really don't know... because with my ex-husband, when we got divorced he was 40 and I was $22 \ldots$ so go figure... Anyway, with my ex-husband I thought he was mature and serious enough at that age but I was wrong. I really don't know why I am always looking for older men... Funny, eh?"

Furthermore, the portrayal of age is an important part of the strategy of finding a partner as revealed in one interview in which both partners, Catalina and Johnny were present. When I inquired about their age differences, she said "See, the age thing is very complicated, because you would never guess the age difference between us... He is twice my age but he is very jovial and full of life..." At that comment, Johnny asked me how old I thought he was? My best guess was that he was not older than 58 to which he replied laughing and saying that he was 74 . Then he continued saying that he exercises 
often, that he goes out and walks every day and that he takes a 90 vitamin mineral capsule daily. "That has been my routine for 15 years and I have not had one cold in those 15 years," he explained. Feeling very proud of his physical appearance, he also revealed that Catalina had described herself as older in her online profile, Catalina then retorted by saying that she was receiving messages on the IMB site from "boys 18, 20, 24 years-old . So, I decided to put myself as older; instead of 36 I said I was 40, and it worked!" She continued, saying, "But don't let Johnny fool you, in his online profile he said he was 55 when he was 73 ! Can you believe that?"

Although some men feel attracted to the idea of a much younger partner, many also consider the levels of maturity and the expectations they might have, so they narrow their search to a more tight age differential. Matthew Goldberg, a retired 59 year-old, is a case in point:

Well I'll be 60 this year... I know I don't reveal my age here in Colombia. Here I seem to look younger! I live a healthy life. I am a half Italian and don't drink, don't smoke cigarettes, I exercise a lot, eat a lot of vegetables, a lot of fish and I don't eat too much red meat ... I got a little tiny paunch right [points to his stomach] here ... The good thing is that in Colombia you can find very young women interested in dating older men like me. I am here sincerely to find somebody to have fun with, with younger women it is very flattering too...I am not an old man, but I am older, OK? So usually you don't get to go out with 20 year-olds when you are in the U.S., so for a lot of men it is like a candy store here. They almost turn into the kind of man that the women here do not like, like the Colombian man who is a real womanizer. You have to have a lot integrity about what you are doing here. It all depends on the man! I want a real mate so I typically date women who are mature, see the youngest woman I dated here so far is 37 and the oldest was 55 . For me 50 and up is what I am looking for... 
Women of different ages revealed being pursued by men of all ages as in the cases of Catalina or the one of Laura from the beginning of the chapter. However, the age factor for Colombian women becomes very important when considering the difficulties that age imposes on their ability to socialize, get married and to find a job after they reach their 30s. The option of finding a foreign partner becomes a rational, as opposed to an emotional, strategy, one in which they are intentionally increasing their potential choices and opportunities no matter what the motivations and expectations are (companionship, marriage, migration, etc.). According to Buunk, et al. (2001) women prefer dating and marrying older males, particularly those who have already achieved the status of being able to provide resources because it is associated with their ability to be good providers. The Colombian women seek men who will be good providers even though, and somewhat ironically, most of the women are breadwinners in Colombia. However, the idea of marrying someone older gives them not only the option of being provided for, but also the impression of marrying someone mature and experienced enough to know exactly what he is looking for. The ideas of being provided for and maturity resonate with their motivations of finding someone who offers them the opportunity to be taken cared of as well as to feel secure about their partner's feelings and emotions.

Given the value of age as a marker of resources, it is no wonder that many IMBS post an age limit on their female clientele (usually no older than 45). Others, aware of the needs of their clients, have opted to develop distinctive subsections on their WebPages of what they usually call "Senior Colombian Girls." These senior "girls" 
subsections contain the pictures and profiles of women who typically are 45 and older. The fact that they are still called "girls" resonates with the IMBs' idea of offering younger women to their male clients. Many men, as in the case of Matthew, are truthful about their needs, expectations and what they can in reality offer a partner. Others feel especially attracted to the idea of dating or marring a younger woman. In many cases such attraction is related to their desire for starting a family, they are looking for women in their fertile years (not older than 40). Thus, one of the factors that motivate these age differences has to do with the idea of parenting, implying the need of female fertility resources that get exchange in marriage very often. Many of the women and men are looking for the fathers or mothers of their future or present children. Rita Mendez, for instance, states that "the difference in age between my fiancé and me is almost 14 years. One of the good things about it is that he does not want to have children. He does not have children and thinks that he is too old (44 yearsold) to have them now. Of course, he is willing to help me raise my daughter who is 9 years-old. I do not want to have more children because that would mean having to start all over again. But with him I am getting a great step-father for my child and a great husband for me. What else can I ask for?"

On the other hand, men like Alex look for younger brides because, as he admitted, "The truth is that I want children. So my partner has to be in a childbearing age. It's a matter of biology, as simple as that! Some people I know, friends of mine in the States, have been creating some rumors behind my back, rejecting the idea of me 
going to another country to try to find a woman much younger than myself. Maybe they are just jealous!

Many men, such as Albert Malik, were very reluctant in contemplating the idea to marry or even date single mothers. "I really have my mind frame set around finding a woman who does not have kids, I would like to have kids though, but I want them to be mine too... To be a father is a great deal, and I don't want to be involved in that if the child is not mine." However, many of the interviewed men stated that they would be willing to reconsider being step-fathers if their Colombian wife has a girl, claiming that girls are so much easier to raise than boys. When asked the reason for such a differentiation, they argued that boys are very jealous about their mothers while girls tend to be open to the idea of having a male role model and were easier to get closer to in a paternalistic way. Such is the case of Alex Silverman, 58 , who indicated that he is "looking for a 35 - 40 year-old woman, attractive looking, dark hair, able to have kids, and preferably if she is 'pure' still... but if she has kids already I don't see much problem. In that case I would prefer is she has a girl, I believe they are easier to raise than boys.

To this point I have been presenting the common qualities that both male and female IMB clients use to find mates. Though the qualities such as age, the desire to have children, and physical attractiveness are "common" in a broad sense, the data discussed above clearly show that men and women approach these qualities differently and in many cases imagine each other based on these qualities but in contrast ways. I will now extend this study by showing are the imagined ideals and motivations of men and women I interviewed and how much divergent they could be. 


\section{Gendered Motivations}

Although $100 \%$ of the women and men I interviewed joined the IMBs for the overall purpose of "meeting people with specific ideas of love and/or marriage," it is necessary to explore the complex and gendered meanings of "meeting people," "love," and "marriage." Two main tendencies were evident from the data (Table 5-1), those who enrolled in the IMBs in search of transnational companionship (19\%) and those who were looking for international marriage (81\%). These two tendencies will be explained and further elaborated by gender next.

Table 5-1: Motivational tendencies of enrollment in IMBs by gender

\begin{tabular}{|l|c|c|c|c|c|c|}
\hline & Respondents & $\%$ & Respondents & $\%$ & Respondents & $\%$ \\
\hline $\begin{array}{l}\text { Transnational } \\
\text { Companionship }\end{array}$ & 3 & $16 \%$ & 3 & $23 \%$ & 6 & $19 \%$ \\
\hline $\begin{array}{l}\text { International } \\
\text { Marriage }\end{array}$ & 16 & $84 \%$ & 10 & $77 \%$ & 26 & $81 \%$ \\
\hline
\end{tabular}

\section{What Motivates Men To Use The Services Of International Marriage Brokers?}

Don't want to be all by myself!

Andrew Raymond is a single 41 year-old casino manager living in Florida whom I met in May 2008 at an IMB agency in Bogotá. Four months before we met, he had to go to Colombia for business, and he used that opportunity to inquire about the services of a particular agency. On the suggestion of a close friend, he called the agency before his trip and explained them that he was not an "on-line" person, so the agency's representative gave him the details of their services and completed the registration 
process for him. This representative also sent him, via email, the direct link to the agency's women's profiles section, so Andrew only needed to navigate that page and write down the particular Member ID's of the women who he would like to meet. He then sent the list to the representative so she could set up the appointments. When I asked him what motivated him to do this, he responded, "I decided to join because I spend too many hours at work and I don't like to date people from work and I haven't been successful in finding someone." This was a frequent answer among other participants. As we continued talking he stated that this was his second trip to Bogotá and that he was planning on staying for a little more than two months. But he didn't want to be alone, "I want to do some sightseeing around here [Bogotá] and thought it would be nice if I killed two birds with one stone." He added that he wanted to explore the city and "enjoy the company of a nice Colombianita." However, soon after stating his need for company, he clarified that he was not looking for "an escort service" (although those services were readily available) and concluded that he "really would like to meet someone special." "But," he added, "I am not looking for someone to marry. It is complicated but it is true! You know...even if I do find someone special, I don't think I want to marry. I don't know if I ever want to get married but it is always nice to know that there is someone special thinking of you, someone to talk with and rely on... I wouldn't mind having to travel and stay here longer periods of time. I would love for that 'special someone' to be able to visit me in the States and why not, to travel with me around the world...I am hopeful, cautiously hopeful." 
This conversation with Andrew illustrates one the main motivations for using the services of a Colombian IMB I heard from men. That is the transnational companionship tendency in which twenty three (23) percent of the male interviewees envisioned a romantic, supporting and caring relationship but were not willing to commit to marriage. Clearly, they are looking for romantic companionships, a search for the support, care and sharing of experiences, but not necessarily cohabitation or marriage. They imagined a seasonal movement across borders, coupled with the continuous sharing of common goals and strong emotional ties. In most of the cases men use their superior economic position, their greater freedom to travel, and their generally freer lifestyles to their advantage. Such is the situation of Andrew who has a stable job, no other commitments (e.g., children, ill parents, etc.), is constantly traveling to Colombia and simply wants the company of a 'nice' Colombian woman. Not future-oriented, he enjoys the present and is trying to find a compatible woman to share life withcommitment free. These men use the IMBs as a pathway to transnational forms of companionship, an alternative to marriage in which men protect their independence and economic stability while enjoying a loving and stable transnational relationship.

Andrew was not the only male interviewee who stressed that he was not using the services of IMBs to find a prostitute. Such an emphasis merits exploration. Why would men be so careful to distance themselves from prostitution? It is well known that, globally, IMBs have been associated with prostitution and human trafficking networks (Pehar, 2003; Hughes, 2004; Chow-White, 2006; Newsome, 2006; Jackson, 2007; Plambech, 2008). Though the history of prostitution in Colombia has been well 
described since the 1960 s, only until the late 1990 s Colombian prostitution was

associated with the services of IMBs, particularly with the emergence of pre-paid prostitution $^{2}$.

Since IMBs introduce foreign men to local women, some assume that there is a possible connection to pre-paid prostitution. Several authors and human rights organizations (Pehar, 2003; Hughes, 2004; Chow-White, 2006; Newsome, 2006; Jackson, 2007; Plambech, 2008) argue that IMBs work as a façade for the offer and perpetuation of higher levels of prostitution and human trafficking. Men such as Andrew who use the services of IMB may receive criticism from their peers and human rights organizations if these relationships are perceived as supportive of international rings of prostitution that victimize women. The men can be further accused of considering only their own personal satisfaction. However, as the director of one such IMB stated, "It would be easier and cheaper for our male clients to access such services through the prohibited but well known sex tourism sites and networks." ${ }^{3}$ This is not to say that such a link does

2. Journalists have been the pioneers in the attempt to understand the 'pre-pago' phenomenon. However, they tend to be more descriptive than analytical (Arango-Posada, 2006) in their accounts of the phenomenon and short on exploring its roots and consequences. As a direct consequence of the cocaine trafficking sub-culture, pre-paid prostitution is a mode of prostitution in which men pay in advance for the companionship and sexual services offered by women who exclusively target clients from high economic strata, safely disguised within their academic or modeling/fashion environments (Arango-Posada, 2006; Bermudez-Pabon, et al., 2007). Often college students and fashion models, these women do not stand on the streets. Sex with them is negotiated through pimps or panderers who regularly charge remarkable amounts of money (the equivalent of $\$ 700$ or more for a few hours of their time). This guarantees total confidentiality and an exclusive clientele (Arango-Posada, 2006; Bermudez-Pabon, et al, 2007). Pre-paid prostitutes are thus not easy to identify; they have perfect bodies and expensive attire, and they are able to hide the nature of their employment behind flexible academic and work obligations.

3. For more information on sex tourism in Colombia see: Mayorga and Velásquez, 1999; Scoppetta DG and Rodríguez Cruz; 2006; Padilla-Diaz, 2008; ECPAT International, 2008; Instituto Colombiano de Bienestar Familiar (www.icbf.gov.co); Programa Presidencial de Derechos Humanos y Derecho 
not exist. I interviewed an American man who clearly explained that he was willing to pay the IMBs' joining fees and other expenses to get access to Colombian women who would have consensual sex with him but who do not do it as their "profession." This man, who asked not to be quoted, had traveled to Colombia numerous times just to enjoy the sexual services of Colombian women under false premises of love and commitment.

\section{All I want is a good wife!}

It is well known that American men have been using the services of IMBs as the channels to find "suitable" lifelong committed love partners overseas. As illustrated in Chapter III, American men have been at the heart of these connections for decades. Scholarly and popular literature explains that American men go overseas to find submissive and traditional wives and form controlling relationships that victimize the women. When studying the motivations of men using the services of IMBs, it is important to avoid over generalizing men as oppressors (as some of the sex trafficking authors portray all of them) and as engaging in relationships with disadvantaged women. They must also not be seen as violent predators who find their victims through IMBs. Although, as Nicole Constable (2003) states, one cannot negate the existence of men using the services that way, that is not the only side of story. Thus, there is the need to further explore their motivations and not just state that they have a need of 
power and socio-economic ability to submit foreign women to their will (Constable, 2003). While conducting interviews I heard men describing their willingness to expand their search overseas and try to find what most of them described as "true love." For instance, one of the men stated that "It is not that Americans are looking for submissive wives; it's that American women are too liberal. Plus Colombians are really beautiful!" Seventy-seven percent of the men I interviewed stated that their motivation for joining a Colombian IMB was "just to find a good wife." Such is the case of Bill Stephen, a 56 year-old psychiatrist who was widowed seven years ago. Two years after his wife passed, he went back to the dating scene. "I put an ad in the paper in Chicago, a personal column," he told me. The ad read: "widower: thoughtful, kind, knows how to make you feel like the most important lady in the world." He received over 500 replies to his ad, sorted them and even met some of the women who replied. However a very disappointed Bill declared that "out of those five hundred, I couldn't meet anybody that...I wanted." Bill said that he was deeply surprised about "how much women had changed" since he was imagining a "respectful, family-oriented, good listener, delicate and feminine woman" and the women he met were from what he termed as the "me, me, me generation." Disillusioned by American women, sometime after his newspaper ad fiasco he decided to use the services of Colombian marriage agencies. A friend of his who was married to a Colombian woman told him about these agencies and the opportunities he would have if he tried them. "I did [use the agency's services] and evidently I liked it, since this is my eleventh trip to Colombia," said Bill, laughing. 
Bill and most of the other interviewed men consistently stated that they were only looking for a "good wife"; when asked about the meaning of such statements, they mentioned their desire for a family-oriented woman with "strong values," who was willing to raise a family instead of pursuing a profession and one who would take care of herself, qualities they said could not find in American women anymore. In Bill's words, "I love the Latin culture because I think they tend to be very family-oriented and here in general the people are friendlier. In the U.S. it is not like that. Families are much more dispersed. When you come here [to Colombia] you can find a lot of people that have the values of $30,40,50$ years ago in the USA. This is the one positive thing... that women haven't been corrupted the way they were in the USA, and that means less familyoriented. The more professionally oriented say, 'Get a baby sitter.' They are looking to see if they can reach a better life status, checking how much money or how much property you have... Well, my family was always me, my wife, the kids and the three dogs. Nobody wanted to leave home. It was comfortable and everybody got along. There was almost no friction in the family, and that is what I like about Colombian women, they are very much family-oriented, like before in the USA."

The vast majority of the men interviewed for this study expect to find this type of woman in Colombia and to take her back to the U.S. where the men have their jobs and can offer the women economic stability. "I know this time [trip number 11] I am going to find her... and I will ask her to go with me to the USA. I don't think I will be able to stay here [in Colombia] permanently, because I can't make the same money here that 
I make there, see working a whole year here [in Colombia] will give me what I can make in two weeks over in the States."

These men also envision a transnational form of life, i.e., a regular rotation of residences between Colombia and the U.S. Bill is considering buying a house in Colombia too, "so we can come frequently. ... And yes, she will be coming and going with me. We will be living in the two countries, maybe the summers over there and the winters over here. Actually I am willing to move to a larger Latin/Colombian community or neighborhood in Chicago to help her to access her own culture, and I am also willing to move to a different state if the weather in Chicago is too cold for her."

A main reason Bill will go to such lengths to accommodate a Colombian bride is that he feels that Colombian women have not been "corrupted." He was not alone. Forty percent of the men interviewed and numerous narratives from the IMB websites attest to this gendered notion. Colombian women, as ideal wives, need to be protected from the corrupting ideas of liberalization and gender equality found in the U.S. so as to prevent them from becoming "Americanized" and can continue being the "perfect" wives the men are looking for. The men's fear goes beyond the courting stage and is also present after marriage and migration. Men hope that the values and beliefs of Colombian women (of all ages), will not change over time after being exposed to different family structures, values and ideologies in the U.S. James Huppert explained how "in a lot of the cases, you can start out with a great woman here, with a great heart and you bring her to the U.S. and if she develops good relationships with other good women there is a high chance of success, but if you have her be friends with other 
women who are sarcastic about relationships, start telling her of all the things she could take advantage of, you know? Probably it is not going to end up the way you want it to end up." He continued stating that he noted that Colombian women might be changing too. "Before when you visited an agency the girls were honored to have you coming to their country just by the fact you are here regardless of your lifestyle." However, in a very disappointing voice James admits that now Colombian women "are saying that they don't like how I look in the picture so they don't want to meet with me." He continues insisting that "there are a lot of bad traits from the States kind of washing their way to Colombia so a lot of the girls are getting spoiled! They want the same things American women have and more."

These motivations and apprehensions about finding and marrying a Colombian woman are constantly reinforced by the advertisement campaigns of Colombian IMBs and foreign brides' chat rooms (used by men) such as the following:

AllColombiaWomen.com - The people in Latin America are very warm and are much friendlier than even those in the United States. American women are very cold and not family-oriented by Latin standards

IntroductionsbyConsuelo.com - While they [Colombian women] have kept up with modern times and are empowered like western women, they have maintained the unique qualities of a Colombian woman: passionate, family-oriented, unselfish, strong traditional values, hard-working, respectful, ambitious and faithful. She will be the most loyal companion...a true-partner in life.

GoLatinNow.com - The Colombian women are much different than what you may be accustomed to. Unlike some American women who are more concerned with dating your checkbook and credit cards, the Colombian women are truly interested in you! 
LatinMatch.com - Latin women are looking for kind, thoughtful men who want a monogamous relationship in marriage. Most are conservative with a wonderful unspoiled attitude ready to devote themselves totally to marriage.

AmorDeCartagena.com - I cannot say that a Colombian woman won't change once she hits American soil but I can confidently state that with their indoctrination and inner fortitude based on the fundamentals of marriage and Christian principles, the relationship has a greater degree of probability for longevity and success than a normal marriage imitated from within the

US.

As explained in the previous chapter, IMBs are constantly feeding American men's imagination who in turn can act on their desires because they are socially, geographically and economically positioned with greater power (as related in Chapter I). Thus, the men I interviewed are using the IMBs as the channel that empowers them to imagine, and in the best of the cases to achieve, a partner with whom they can have the traditional, loving family they desire. They see this as natural, not an extension of patriarchy. Their imagining of a traditional woman and family is a step towards their goal of a life that would allow them to perform the role of breadwinner with its accompanying power inside the family that they were raised to perform and enjoy. Thus, they see a good wife as an excellent mother and a superior homemaker; it means being responsible for raising proper families and for performing "traditional" activities within the household. It means preferring domesticity to occupational achievement and this means that their principle role is the emotional support of their husbands and children.

However, this imagined "good" wife is not what they find in the U.S. So, enticed by the kind of woman advertised by Colombian IMBs, they seek their partner abroad. 
The men have the power to act on their desires; they can fly to Colombia without visas and they can afford the costs of the IMB memberships, the travel and the romancing abroad. It is clear that for those American men I interviewed, the most prominent motivation for participating and using the services of IMBs is finding abroad the characteristics they feel they cannot find in American women.

What about the women? What, do Colombian women imagine and strive for? Do they also seek "traditional" male partners? Do they want to turn the clock back to a time when man was man and woman was-his wife?

What Motivates Women To Use The Services Of International Marriage Brokers?

When Brian White, a 53 year-old computer systems analyst met Natalia Bohorques, "the love of his life," he believed he had found the traditional woman he could not find in the States but that had to go all the way to Bogotá Colombia to meet and fall in love with. However, Natalia, a 32 year-old business administrator and mother of a 6 year-old girl, did not consider herself to be "traditional." She admitted that "when I joined the agency, I wanted to find an American man, one of those that would respect my decisions, one that could help me professionally you know... I did not want one that would be all upset because I can possibly make more money than him, one that will help me around the house and with the kids. I wanted a real man, not like the ones we have in Colombia, men who believe that they are superior to women and want us to be working all day long, earning less than them of course. They want women responsible for the home, cooking, ironing, cleaning and taking care of the children." Natalia thought Brian was not only a very good man, but a "modern" man who loved her and 
her daughter and wanted nothing else but the best for the three of them. How could Brian feel he found a traditional woman who does not view herself as traditional at all? The great irony of my research is finding that American men go to Colombia seeking "traditional" wives and think they have found them when more often than not they actually attach themselves to women situated at the forefront of liberalizing gender norms in Colombia. As explained in Chapter III, the recent history of women's rights in Colombia had shaped Colombian women's perceptions and inspired them in various ways to take control of their destinies. These women, who are breaking out of "traditional" roles in Colombia, the women who complain about Colombian men, are so determined to leave this moniker behind that they are willing to appear traditional as a means of earning themselves a ticket to a land where they imagine gender roles as more modern - the U.S. These two desires cross in cyberspace, one headed backwards in time and tradition while the other headed forward. The illusion of better fit (the operative word here is better) motivates the fantasy even more. Indeed, the fantasy of finding "true love" sweetens the illusion all the more.

\section{All I want is love!}

Although I heard the statement "all I want is love" from $84 \%$ the women I interviewed (Table 5-1), early on I realized that I needed to further explore their definition of love, as it was clear that they used "love" in different ways. I found it easiest to convey by qualifying "love" in different ways: 1) the desire to be married, 2) being married to a "non-macho" man, 3) the attainment of a better social, economic and professional status, and 4) migrating to the U.S. 
All I want is love... and to get married!

For Colombian women in general and for my interviewees as well, marriage is understood as a social symbol that provides them with a certain degree of status and stability and increases their options for acquiring basic living resources. In Colombia, regardless of their educational level or their social stratum, women are expected to be married before they reach their 30 's. Pilar Rueda is a 39 year-old female art teacher and actress who became recently engaged to an American man. She recalls how the path she had to walk before meeting David, her fiancé, was full of disillusionment and frustration. "Just to give you an idea," she said, "I had a Colombian boyfriend for close to 10 years. We were planning to get married, but he was always between yes and no. He would decide to marry me and a month before the wedding he would chicken out and fly out of the country. Later he would come back and ask for forgiveness. He did that a couple of times... After that I had another boyfriend who was younger than me. After four years of that relationship he still claimed he was not ready to marry me or to have children.... He was the real love of my life so when it did not work, I felt like I was dying." After these disappointments Pilar decided to take some time off. She was invited by a close Colombian friend to visit the U.S. The friend was married to an American man and needed some help in the States. While helping her friend, Pilar used that time to rest and reflect on her life. "I had all those problems with men. And there was pressure I felt from my biological clock as, well as from my friends and family who continuously were telling me that I needed to get married, or to at least have a baby. They said that the train was leaving me, that I needed to remember that once a women 
turns 40 all the dreams of marriage and babies are gone." These pressures inspired her to think about a relationship but this time she imagined finding an American husband. She said she was looking to find a nice person, "not a Prince Charming but someone who was willing to commit, someone who wanted to share a lifelong project... I wanted to get married and have children." While narrating her story, Pilar repeatedly stated that she wanted to get married, that her biological and emotional clocks were ticking louder and louder. "There is an age in life where you cannot afford to continue waiting and exploring different relationships. I couldn't afford long relationships that were going nowhere, being heartbroken, alone and hopeless. No, no, no, I couldn't continue like that," she explained. When I met Pilar, her hard work had paid off as she was working on the last details of her wedding ceremony and celebration. The fact she was finally getting married radiated in her face. Her bridal blush, however, was tempered by recalling how on their first date, the man to be her husband told her that "the ideal stage of a human being is to be married. When you are married you are sharing, you are generous, and you can enjoy the everyday stresses of life together, men working and women taking care of the kids." Yes Pilar wanted marriage and yes she was getting that status but she revealed that "in many respects he was not the person I always dreamed about, you know... He is not very open minded, young or athletic as I would have liked for him to be." Pilar's dreamed partner was not ultimately the one she married, she had to give up part of the imagined husband, she gave up the ideal modern, young and athletic man in exchange of stability, commitment and the hope of a better future. Pilar is not the only one of my interviewees who had to internally negotiate the imagined 
ideal of a partner in order to achieve most of what that dream husband was all about. Several months after the initial interview I contacted Pilar and asked how her marriage was going. Very enthusiastically she replied that, "He has proven to be a great human being, very responsible, loving and above all very committed to me, to our relationship. Though I need to tell you that little by little he is opening to my lifestyle, though we are still negotiating me being able to work, he says that I need to concentrate on getting pregnant and not on finding a job! We'll see what happens, it is all in God's hands!" As illustrated by Pilar, many Colombian women, including those divorced, widowed and single, imagine themselves as married. According to the Colombian National Census of $2005,44.2 \%$ of women older than 10 years-old reported living with a partner whether in marriage or cohabitation (Dirección de Censos y Demografía, 2007). From such statistics and the narratives of the women interviewed, it appears that marriage is considered an important goal for women in Colombia. The women I interviewed consistently mentioned marriage; they viewed not being married as carrying a social stigma. And they also did not see mere cohabitation as part of their imagined futures. Cohabitation was viewed by them as lacking commitment, as not a real option when dealing with children and the desire for a stable future. However, their imagining of marriage was of a companionate marriage not a traditional one. Hence, what Schaeffer-Grabiel (2004) and Rodriguez Salazar (2001) point out about Mexican women can be applied to Colombian women as well. These authors state that for women in their late 20s and older, marriage tends to signify success, desirability, opportunity, happiness, achievement, advancement, and fulfillment while on the 
contrary being single or an uncommitted relationship at that age is stigmatized as failure, stagnation, desolation, loneliness and ugliness, and thus rejection.

Marriage is not the same social status for men and women. Being single is more accepted for men than for women. Women feel socially expected to marry en route to social acceptance and status (Palma, 1986) even with the increasing acceptance of cohabitation and divorce (Fuentes, 2002; Garcés de Eder, 2002, Murdock, 2008). For many of the interviewed women, being married is a life strategy that includes commitment, love, sex, children and companionship, and that guarantees economic survival, allows the attainment of social status and prestige, etc. The characteristics of these life strategies are fluid and vary in different social contexts and with different personal aspirations, as in the case of Pilar, but in most of the cases the strategies include the imagining of getting married, motherhood, and feeling emotional and financially supported by a truly committed partner. For the interviewed women, the imagining of love not only represented getting married, it also included a foreign partner. Foreigners represent, at least in their imagination, a different kind of man from those they are able to find locally. This is what is illustrated next.

All I want is love... and get married but not to a Colombian!

Up to this point it has been understood that a common goal of my Colombian women interviews is a marriage. This desire would appear to make them seem traditional, particularly vis-à-vis their American counterparts. However, they also made clear to me that they did not want to get married to just anyone. As in the case of American men, Colombian women search for an imagined partner whose personal and 
social characteristics differ dramatically from those of Colombian men. Many women believe that getting married to a foreigner will mean greater parity in their relationship. They expect to find in the foreign partner someone who views them as an equal, not someone peering at them through a machista lens. Colombian women constantly compare an idealized image of love against their unpleasant, lived realities with the Colombian men. The positive depictions of American men image are largely broadcast by the IMBs and various media outlets and thus feeding the imagining of Colombian women engaging in these relationships.

Patricia Novoa is a 51 year-old woman who has worked more than 27 years at a renowned hair salon as a stylist in order to live well including paying for her child through a bilingual private school. She, like many other Colombian women, is completely disillusioned with Colombian men and decided to join an agency in hope of finding the American of her dreams:

I started with the agencies right after I got divorced five years ago. I did it because my two previous relationships, my ex-husband and the father of my child,...were very bad partners. Although they were nice people, they were liars, cheaters and very mean... I always heard that American men are very caring, generous and that their wives are treated as queens! To be honest, I really don't want to know anything about Colombian men. All the girls at the agency are looking for an American [man], because they are much more giving. They want to fall in love and commit to a person for life, and that is exactly what we don't get here from Colombian men.

Patricia clearly summarized what many of the interviewed women agreed on: that Colombian men are unfaithful, dishonest, and very stingy. These are thus opposite qualities from what Colombian women are looking for in a partner and expecting to find 
in an American. Additionally, Colombian men are constantly seen as lacking the desire to commit to the long-term relationship Pilar Rueda spoke of previously, and what Rita Mendez describes as follows:

I have met different American men through the agency, and I can tell you that you cannot compare American and Colombian men. Ah...I had many relationships here with Colombian men, from different parts of the country. Those relationships were long... more than a year each... But all of them ended because of infidelity. So I believe that it is a cultural issue, not only in Colombia but in all Latin America. The cultural issue is the long accepted practice of unfaithfulness. A man, a Colombian man, will only commit while he is feeling satisfied, then simply loses interest and instead of finishing the relationship, he finds another woman. There is no honesty here. There is no commitment... unless all of the ones that I had relationships with, and the ones my girlfriends had relationships with, are a simple coincidence... What do you think?

The behaviors that Pilar, Patricia and Rita complain about as inherent in Colombian men, motivates them to search for foreign partners. The behavior of these women's partners is something that many other interviewees complained about. The infidelity is just one marker of the dominant status of Colombian men. Clearly, and as stated in Chapter III, the legal structures and cultural traditions in Colombia have permitted the development of such behavior, particularly the lack of commitment and unfaithfulness. However, beyond the cultural understanding of Colombian men's behavior, it is important to point out that this type of behavior is not unique to Colombian nor to Latin men. Perhaps these male dominated gender roles are stronger in Latin American countries, but they are not too different from the ones once encountered in the U.S. (Marx Ferree, 1990; Thompson, 1993; Levant, 1997; Kelly, 2001; Newsome, 2006; Jackson, 2007; Kabeer, 2007). In fact, they are quite in alignment with 
the gender roles remembered as normative in "traditional" families by the American men using the IMBs. American men who search for Colombian wives, seek a return to this ideal and imagine Colombians as ideal partners. Meanwhile and ironically, Colombian such as Pilar, Patricia and Rita use the services of IMBs in their search of more modern, less traditional (patriarchal) spouses. They want to be partners in relationships, not subordinates.

American men, however enjoy more privileged social locations over Colombian women so they can better set the terms of the relationships bargains. Colombian women have to play a very traditional sounding game to fuel American men's desires but to achieve what the women want--more equal relationships than in Colombia. All I want is love... and get married, but not to a Colombian, to an American, well to a supportive American!

Colombian women seek foreign partners in pursuit of more companionate marriages but they also seek support financially. The women I interviewed not only complained about macho unfaithful Colombian male partners, but also of these partners as not helping them with the household finances. It is not that the women seek to be taken care of, to be financially dependent, but that they want to share the financial responsibilities. Patricia, for example, told me that she was tired of being a single mother, that she was envisioning a partner who would help her financially. She explained that "...I have been working more than 27 years at the hair salon, Monday through Sunday. I am killing myself in this place because I have always been the one putting food on the table. Even while I was still married, I had to buy groceries and pay 
the mortgage. My husband did not help at all. Because I wanted the best for my child I enrolled him in a private school that is very expensive. I AM TIRED! So I want to find a good man who will take care of me and would help me pay for my child's schooling. He wants to be a pilot and that is very expensive you know." Patricia clearly wants help financially; she is not looking to become a free loader: "I would like to work over there [in the U.S.] as well. I know that I could work less and get more money doing what I am doing here... I want to be blessed by not having to work if I don't want to, and still have food and a roof to enjoy."

While Colombian women I interviewed expressed their willingness to do their fair share, they also idealize American men as being affluent and generous. This is not a hard target for the women to hit since the poorest men cannot pay the IMB fees or travel cost to visit overseas romantic interests. In on-line dating, it is the men who usually pay the basic subscription fees to be able to chat with women. Colombian women tend to interpret that as a sign of affluence and equate it with ideals of prosperous futures, free of living paycheck-to-paycheck. They imagine lives of economic stability, of having the option of working or not working based on their own personal motivations and not on the need to feed the family or pay the rent. Some women hope that after marrying U.S. men, they would be able to join the labor force in the professional sectors they have been trained for as well.

Like Patricia, many women are tired of being the providers; they would like to be able to rely on someone, not necessarily to find someone to take charge and entirely support their families, but someone to share life with, to have the choice of not having 
to work if they so choose to without having to worry about their futures as they do day after day in Colombia. Many dream of migrating, studying English and, after some time adjusting, going back to work and feeling productive again. To a certain degree they are willing to perform traditional sex and gender roles in exchange for escaping the bleak realities they experience in Colombia.

Clara Garcia, 31, is engaged to an American citizen and planning to get married soon. She is also highly motivated by the opportunities she imagines she will encounter professionally once in the U.S. On our interview, she discussed being an occupational therapist with a specialization in sensorial integration. She hoped that finishing another specialization in occupational safety and health would open many doors in the occupational therapy field in the States. "In the U.S. there is a high demand for professional occupational therapists, so I will be able to find a great job, the kind of job that I wouldn't be able to find here, with decent pay." She and her fiancé have talked about wanting babies often, she said, "But that has not stopped him from somehow encouraging me to finish school and dream of a bright career."

Although American men are searching for traditional wives, in many cases education is seen by them as a way to compromise, to show how "modern" they can be. However as stated earlier in this chapter, education does not necessarily have to translate into professional development. Clara is certainly convinced that her husbandto-be is all she had imagined an American man would be: "see what they say about American [men] is all true. They are really supportive of women working and being 
mothers. With that attitude I could really support my family from over there." Clara is just waiting for her dream to take flight. First she must get a visa.

All I want is love... and get married, but not to a Colombian, to an American, well with a supportive American and of course... to move to the United States!

In addition to the previous motivations, the common incentive these women shared was the underlying desire for living outside Colombia. These women's faces glowed as they imagined their lives in the U.S. Though conscious of some of the difficulties they could encounter, their hope for a brighter future sharpened their pursuit of this goal. In most of our conversations, the idea of going to the U.S. was a given; not much thought was given to it, since it was implicit in their decision to join an IMB. Thus, underlying their relationship strategies via the IMBs was the pursuit of international migration. Colombian women use the services of IMBs as a tactic to migrate.

Over three fourths of the women I interviewed imagined the U.S., like Patricia, as a country with "nice houses, with everything being very organized, [where it is] easy to find a job and with plenty of places and activities to enjoy the weekends." As she thought about how to migrate the trepidation and excitement became increasingly noticeable in her voice and tone. "Of course I want to go over there without any problems with my papers," she stated. "I want to get there legally, so I don't have to be scared about the police or anybody. If I have my fiancée visa I have nothing to fear. Besides, if something wrong happens between my future husband and me, I do not want to have to go through a nightmare, like the ones we hear about all the time. I 
know that right after marrying I can get my papers, I can work, I can travel and that will be perfect!" Patricia's imagined life did not anticipate trouble. She was not expecting to wait for her work permit, did not know that she needed to obtain a hair dresser license, that she would not get a permanent residency card right away, etc. In general, the women I interviewed lacked a thorough understanding of what being an immigrant entails. As in Patricia's case, these women were imagining a bright future and eschewing the legal and social obstacles all immigrants face.

While migrating for women was a dream, for the men it was an expected fact that reinforced their idealized view of Colombian women, that they would follow their husbands. A few of the men I interviewed considered migrating to Colombia, most of them were envisioning a life in the U.S. with their Colombian wives, but many of them quickly abandoned the idea.

Company, just company...

While the overwhelming majority of the Colombian women I researched fit the category or categories just described, I would be remiss to my data if I were to leave out the few "outlier" cases in which women were seeking "just company." Much as in the case of men, there are also women who seek no long-term relationship. One such example is that of Laura Torres, a 63 year-old, divorced mother of two, who has been using the services of IMBs since 1999. After having survived cancer and preparing to retire, she was introduced to the on-line world by one of her co-workers who encouraged her to use IMBs to meet some new people. As a 32-year veteran and top Colombian manager for a Dutch multinational company, she had not needed to learn 
about computers or the Internet, as her secretaries and assistants did everything for her. So when her friend told her about the IMBs, she hired a personal instructor who taught her all the basics. "That young man taught me everything from where to turn on the computer to how to do web surfing," she remarked. When I asked her why she decided to learn computers and join the IMBs she explained that she wanted to "meet a lot of people, to explore that world that seemed very intriguing and promising." She was emphatic that she was not looking for a husband. Once connected, Laura met a lot of men, mostly American, and even started some romances. Interestingly, many of the men with whom she established relationships were much younger than she. This "was good because it has helped me to be more sensible and realize that I can't expect anything from these relationships. I do not want to get married; I have been very honest with them." When I met Laura, she was involved in two different romantic relationships with American men. She had visited her noviecitos (boyfriends) several times and they had visited her as well. However, she insisted, "I am much older than they are and I have been very clear to tell them that I do not want to get married or anything like that. They know about my having two relationships. They understand it. ... I just want to have nice conversations, enjoy myself when I am with them and that's it!" Laura has a very busy life as a retiree. She exercises, plays cards, paints, visits with her girlfriends and family, and spends a lot of time chatting with her friends on-line, traveling and visiting with them when they come. She feels very content with her lifestyle and romances but knows that this type of relationship is hard on those days when she "feels like needing a hug." When I asked her what her real motivation was for having these types of 
relationships she said that "The nice thing about these relationships is that I feel loved and feel companionship. But, if it becomes suffocating I can turn off the computer, or take 'vacations' from them if I want... I don't think I would be able to do that if I were to get married. Besides, I am too old for that [she laughs] Let me tell you, Kevin [one of her boyfriends] really fantasizes about living here with me, but I don't think it will work; we are fine as we are right now..."

Laura's story is not unique, but it is not typical either. Of all the women I interviewed $16 \%$ (Table 5-1) of them were using the services of IMBs hoping for a romantic relationship, wanting to feel love and companionship without having to get married, to perform the implied domestic duties, or to give up or reduce their existing social and recreational activities. These women are very clear about their ultimate goals while using the services of IMBs. They want to establish romantic relationships with foreign partners that allow them to travel and enjoy the benefits of a transnational relationship while at the same time are very careful about maintaining their independence and economic stability.

What sets these women apart? They enjoy financial resources that allow them to retain their independence. They thus occupy a similar socioeconomic position of advantage as the American men but, unlike the men, do not translate that into finding a marriage partner because this would bring into their worlds expectations for domesticity that these high status women easily avoid in Colombia. Such is the case of Laura, who is retired, has no financial constraints (because she has multiple pension and retirement benefits), can travel freely, and has the emotional and economic support of 
her adult children in addition to a well nurtured social network. This select group of women is socially located where they can do what American men can do, so they do not have to just be content with imagining but can act (traveling, initiating relationships, etc) and can most certainly dictate the terms of the relationships. These women are clearly different from what most American men are seeking, rather than being their dream they could be their nightmare.

\section{Recapitulating}

This chapter sought to answer several questions: What is motivating Colombian women and American men to join the IMBs? What are they expecting to achieve through these relationships?; and Are these motivations/expectations the same for women and men? It is clear from the data that the IMB clients' expectations and motivations, while in some ways overlapping, are significantly and differentially gendered. Women and men use IMBs looking for idealized, imagined forms of companionship and/or marriage. The IMB provides a marketplace for active and deliberate interaction without much investment. Each brings a gendered set of resources to exchange but, in almost every case, women are at a disadvantage. They also seek to do more through the relationship - migrating and increasing their socioeconomic status in particular- than men so they have greater pressures to work toward achieving their goals.

What emanates from these people's experiences going into courtship via IMBs is the role of the imagination in shaping their behaviors and romantic decisions. Imagination here needs to be understood not as a fantasy, but as the largely intentional 
product of IMBs' marketing and, more generally, the global media. These communicate the lifestyles of the imagined "other" a cognitive invention of foreigners as fitting what is unattainable in their own countries. The sales pitches are carefully crafted using the age-old and effective tool -- gender.

Thus, through media images, the rhetoric of IMBs, and word of mouth transmission, these women and men are articulate and absorb complex ideas of what specifically they are looking for in a partner, the type of relationship they are seeking, and the kind of future they want for themselves and, in many cases, for their families. Women and men exert different and contrasting levels of agency, power and control at the crucial moments of interaction and having to make decisions about their futures and their romantic lives. They are not socially located as equals despite frequently asserting their desire for great parity. They rarely, if ever, perceive that these social locations will matter; they are too caught up in their imagined lives to come. But what do they find? 


\section{CHAPTER VI - IMAGINATION INTO ACTION: THROUGH ROSE COLORED LENSES (THE EXPERIENCES OF COLOMBIAN WOMEN AND AMERICAN MEN)}

The previous chapter explored the primary expectations and motivations of Colombian women and American men who use the services of IMBs. This chapter follows them as they move from imagination into action and it explores their experiences. These are both stories of dreams fulfilled and disappointed. The chapter opens with my analytic lens focused on interviewees working the IMB system to find a mate. Later the lens shifts to the lives they encounter once they meet their potential mate.

\section{Playing the field}

At first, men like Peter O'Brien, the 55 year-old salesman, joined an IMB out of curiosity, not with the goal of finding a partner. For many, IMBs are ways of meeting women. Of the men I interviewed, 53\% stated that they were curious about what it was like to have an online relationship or to travel and meet an "exotic Latina." For instance, when I asked Peter about his subscription to the IMB he told me that it all started because of curiosity that one of his best friends married a Colombian woman and they had a really good relationship. "She is a great woman and I wondered for a long time if I could possibly meet someone just like her," he told me. Peter then decided to join not one but three different Colombian IMBs to increase his chances of meeting his dreamed-of Colombian wife. Such word-of-mouth advertising helped drive demand for 
IMBs. They met the demand and more women and men started participating, driving competition for both seekers and providers. Tania Rodriguez, a 33 year-old financial assessor, frequented two different IMBs, because, she said, "I want to have more options, be able to show myself off in as many places as I could. You never know where the love of your life might be." The fact that people enroll in multiple IMBs shows their strategy for augmenting their opportunities to find their ideal partners, as also expressed in the following quotes.

The owner of this agency used to have a physical location in the States. After a while I started looking for it but found the website instead. I studied the idea for a few years and decided to check it out, out of simple curiosity...
Well, I didn't have any luck there [in the U.S.]. You know, I did the whole online dating over there but just didn't have enough luck. Well, I already know how American women are and I just wanted to try it here in Colombia, I heard a lot of things about Latin women, I was very curious...

It was also curiosity, because I wanted to meet some people, I wanted to practice my English... Online you can meet some of them, but when they come to Colombia to visit you that is really nice, I never thought it could be possible. 
I mean, it could be the Internet fever. Everyone is online, meeting people, establishing relationships. Someone told me "Look I met someone online" so I wanted to do the same thing, to have that experience. Why not maybe meet someone really special? And then you leave the country and have a family, the world is waiting for you...

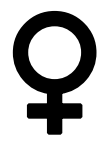

I was very curious; at the beginning it was pure curiosity. Of course it was also a lot of incredulity, because I couldn't imagine how a relationship would work... if they [women] are there and we [men] are here [the U.S,], but I joined the agency and it is been great!

Now, if you ask the majority of girls if they have a boyfriend, they say yes... but on the Internet!

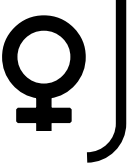

Once enrolled, the core tools that men and women have in the mate selection process are the pictures and profiles individuals use to represent themselves. When I asked IMB representatives about the enrollment process, they all agreed that the most important part of the process was the selection of good pictures and a clear and comprehensive profile. The IMBs instruct women, and to a lesser extent men, on the type of clothing they should wear, the poses they should assume and the general attitude they need to portray through the posted pictures.

By the nature of their business, IMBs are highly involved and interested in the quality of the pictures and the overall content of these profiles. Hence, individuals are 
regularly advised by IMB representatives about the kind of pictures they should use and the essential personal information they should share on their profiles to increase their chances of meeting their dreamed-for partners. For instance, one of the IMB representatives stated "the profiles are very personal so we do not get too involved in that but we do help a lot with the pictures. See, right now we are asking [the women] to go to a photographer who gives them a special discount if they are referred by us. He tells them what to wear, how to pose, everything...It is not very expensive, he does the final touch-ups to the pictures so they look really pretty and gives them a CD with all the pictures and sends us the best three via email so we can post them on our website." Another IMB representative stated that they offer a photo studio and profile advice as part of the enrollment package. "We bring a make-up artist, a hairdresser, and ask them to bring at least three different outfits, so the photographer takes 50 to 60 pictures from which we select four and those are the ones we upload. We also sit down with each of our clients and discuss the expectations they have, what they are looking for, how they see themselves in one, three and five years and with that information we help them write their profiles." Another representative stated that they allow their clients to post their own profile and pictures. However, the IMB owner was clear in stating that "as our clients have the freedom to post their own pictures, we watch over every single picture and profile that gets posted. That way we can advise a client in case their profiles are not complete or comprehensible or in case one of the pictures does not really complement her inner self or if the pictures are not appropriate in terms of quality. And you know they could be too revealing or heavily sexual." 
International Marriage Brokers, as explained in Chapter V, are almost exclusively focused on the posting of pictures and profiles of women; however they are much relaxed about their male clients' pictures and profiles, as men's pictures are not required and/or supervised. The profile "guidance" they offer to their male clients is presented as part of their services, but clearly the IMBs are more concerned about marketing women. This differential treatment serves as evidence of the gender asymmetries that are at work under these portrayals of the self under the clear guidance and influence of IMBs' recommendations and requirements.

When I asked women about their pictures and how they decided on what kind of pictures to post, they often recognized pictures and profiles as the way to best project femininity and sexuality, the characteristics they imagined would best attract the type of men they were looking for and at the same time would reflect their personalities. For instance, Rita Mendez described the process she went through with her pictures: "First I posted a normal picture of myself; a picture a friend of mine had taken one day we were out at a picnic. I know that is the reason why I did not receive as many invitations to go out from the agency or to at least chat online, so after a while I decided to pay the photo-studio and it made a big difference. When they posted my new pictures, I started to receive invitations to meet the guys [through the agency], and online winks and nudges I did not receive before. Good pictures really make a difference."

Colombian women I interviewed consistently repeated the popular saying "todo entra por los ojos" [A picture is worth a thousand words]." What did this mean? When I asked Clara Garcia about the pictures on her profile, she immediately opened her wallet 
and took out three pictures and explained, "See, these pictures were taken by the agency's photographer. The day they took them was crazy because I had to do my hair and make-up four times. You know, I wanted the best pictures! I wanted to look beautiful and sexy, I wanted to show a bit of my skin but not too much so I wouldn't give the wrong impression. Do you understand what I am saying? It is like a game, you need to look as sexy as a lingerie model but at the same time you need to portray your moral values. It is tricky, very tricky!"

Viviana Morales told me how she struggled with how her photo should be done. She was able to visit the IMB site and check out what other women's photos looked like. Laughing, she remarked that "Some pictures were super erotic, showing cleavage, almost with no clothes and with highlights in their profile saying things like 'chica ardiente busca Americano' [hot woman looking for an American man]. I thought it was like a meat market, a place to show and sell yourself to the best bidder." She felt uncomfortable. "Then I also saw some pretty pictures of less exposed but yet not prudish women and thought I could do something much more like me and not like those who thought they were in a swimsuit contest... I decided to pay for the studio [to do my photo] and not show as much [skin] as the majority of the women do."

While women enter the IMB market after (with the help of the IMBs) carefully cultivating an image somewhere along the vixen-virgin scale, men pay much less attention to own pictures and profiles. When I asked them about their pictures, $58 \%$ told me they did not have a picture posted. They did not consider it important because they had "pretty good descriptive profiles" that conveyed more than what a picture 
could. The other $42 \%$ said that even though they have some pictures posted, they did not put much effort into their own pictures. In fact, the pictures they usually post are, in general, very casual. In contrast to the women's studio shots, the men's pictures are amateur shots of them around their homes, in sporting events with friends and family, etc. As influenced by the IMBs both women and men present themselves in what they are told increase their chances to find their imagined mate. The asymmetry, once again, is the reflection on the influence that specific messages and ideals created and used by the IMBs, affect the imaginings and corresponding actions of their clients.

Regardless of the effort and cost they put into their posted pictures and profiles, clients use them as the tools to attract one another, as the means of inviting or accepting an invitation to start an online conversation, a date, or simply to be added to their list of potential candidates. Of the interviewed women, $55 \%$ stated that they use these systems to actively search for, select, choose, express interest in, initiate conversations with or just wink at those they imagine as potential partners based on their profile characteristics and/or pictures. Nonetheless, $45 \%$ of the interviewed women, such as Patricia, stated that they do post their pictures, but they do not actively look at the pictures of males in search of the most attractive. "Of course you can actually look [at men's pictures] and write to them, but I almost never sit in front of the computer to search for a man. To me that's like showing I am desperate for a man. So no... I wait for them to write to me, and they do... a lot!"

Why do women wait for men to take their bait? Why do not hunt actively? The answer, like the whole IMB process, is a mix of economics and psychology. With online 
dating sites women have to pay a fee to be able to start conversations with men.

Additionally, IMBs promote "traditional" women - women who will follow men. Women are very strategic both in taking care to not appear "aggressive" by initiating conversations and also in the way they portray themselves in order to increase the number of chat invitations - the first step toward getting married and migrating. How is this done? Viviana Morales explained it as being like "the prettiest woman in the party. Everyone would naturally notice you and want to talk to you! Simple, don't you think? The prettiest at the party is never chasing around a guy. On the contrary she has the opportunity to choose from all the ones who want to talk to her."

If women (in concert with IMBs) deliberately seduce with their images, the question must be asked: How easy are men to trick? Bill Stephen, the 56 year-old psychiatrist for instance, insisted that there were several problems with the pictures. "I have been consistently disappointed" he told me. "The pictures lie. When you meet [Colombian women] there are many differences, particularly between the weight they post and the real one... When you are far away it is always difficult [to judge]. The pictures can be distracting. For instance, there was a woman who in her picture looked great but when I meet her she had about 20 pounds more than the picture in her profile. ...There was one that I would never choose from the pictures on the website, but when I saw her interviewing with someone else in the agency, she looked really great. So the process is very difficult." Men complained of being accused of going just for "looks" but stated that pictures were the only tool they really had. "You need to approach it with an open mind," said Alex the 58 year-old astrophysicist. "You see nice 
pictures but sometimes the pictures are not really accurate, sometimes they look so much better than the picture and sometimes they are not that good." Men consistently stated that beyond the pictures, "which all of us know can be altered," women needed to work more on their profiles. "See, these profiles don't have enough information about the women, on their likes, wants... They need a deeper description of the person," James Huppert told me. "I need more about what they are looking for, their plans and all that stuff."

In sum for both men and women, pictures and profiles are tools of the online mate marketplace. However there are big discrepancies in what they both invest into and realize from these tools. Women invest heavily in seduction and the distance afforded by the Internet gives them greater power than a face-to-face encounter would. Men, though clearly seduced sexually, are wary enough to ask for more "realistic" information on personality traits, life goals, etc. They can afford to be choosey and demanding without revealing much; they know that they have disproportionate power to choose over the women yet it is also interesting and important to note here that though they are clearly disillusioned with U.S. women as too liberal, the men avoid choosing Colombian women solely on face value. Meanwhile Colombian women, who express "modern" values, play decidedly old games on the Internet.

\section{Partner Selection Process}

The process of selecting a partner is initially based on the pictures and profiles women and men post in the websites of the IMBs, as explained above. However, one of the most interesting factors to explore in these relationships are the multiple 
approaches used by these individuals in the process of choosing a partner "on-line."

While I was interviewing Mark Douglas, the 37 year-old packing line employee, we were at the computer lab of one of the agencies in Bogotá; I inquired about his own method of selecting the women he would like to date or initiate conversations with. He instantly signed logged on the IMB's website and started showing me some of the pictures of women explaining that it was primarily on the pictures that he based his selections. He then said very loudly, "When reviewing pictures if the women look too dark I just don't like them." As he spoke, three other men, who did not want to be interviewed, got closer to the computer screen and one of them commented that he did not agree with Mark, that he did not care about skin color; the other one commented that he actually liked the woman who was on the screen. Mark ignored them and continued saying, "If they look too sexy on the picture, you know, showing lots of cleavage or sexy looks, then you can guess she is probably too easy." To this the other men agreed: "And if she is too built, then I feel like she could beat me from here to Pittsburg!" The other three men laughed while agreeing with Mark, and then one of them suggested that they could show me a picture of "normal looking women." While in the process of finding the picture, they explained that they understood how glamour shots were common in these websites. However, they were very quick to affirm that they knew each woman was free to decide the kind of pose that she wanted to adopt for each picture, so as one of the men told me, "If she looks like a hussy, chances are she is a hussy...You know if you want someone like that you can easily get her in the States. Women think that posing extremely sexually will attract more of us, but that is not true. Well not [those of us] 
with the right intentions..." Then one of the men continued, saying, "The selection of clothes is also very important, you look at the color and how much they show; it is simple, if they show now they will show always and that is something I may not like once she is my wife." These men agreed on saying that discrete clothing, "not too revealing but also not too formal" was very effective. They continued showing me pictures of the women and decided that even though they had different tastes, in general they were looking for nice-looking, feminine and delicate women, ones who would inspire them to protect them while at the same time be physically attractive. Other men stated that many pictures were too sexual, like those in which the women were in swimsuits, pole dancing, laying in bed with pouty poses, etc. These led to the men's assessment of poor judgment on the part of the women, who were portraying themselves as mere "eye candy" rather than potential partners. Men sought in-depth profiles and personality descriptions to improve their partner selection.

It was not surprising that men were focused on the pictures to perform their initial partner selection. However, contrary to what IMBs usually portray, and men believe, women do also base their initial selection on the pictures they are able to see through the websites or through the requested oral descriptions of the men given by agency staff. When I asked interviewed women the same question (the method of selecting a partner) the responses were remarkable. For women using the services of online dating sites, it was very important to be able to see pictures of the men they would show interest in. Although the pictures were very casual, women would not express interest if they did not feel attracted to them--even if their profiles were 
describing the person they were really looking for. For instance, according to Victoria Echeverry a 46 year-old nail stylist, "Although many men do not even have pictures posted, I browse through all the pictures of the men, looking to see if someone appears handsome and interesting. Then I send him a nudge or an email saying that I would like to know more about him." However, acknowledging that although her English is not perfect, she could read their personal profiles and found that "many men write as if they were perfect human beings. Others are more modest. You know, many times while I am reading I see a man who is exactly what I am looking for. However, if they don't have a picture or if they look very unattractive then I do not do anything [she laughs] I don't feel bad; I know they do the same thing, so why should I feel bad about not talking with unappealing guys?"

Many IMBs do not post pictures of the men, so when their representatives call women who were chosen by visiting men to set up initial appointments, these woman often ask for some type of description of the man who they are calling to set up the appointment with. The representative of one of the agencies in Bogotá told me, "You know there are two types of female clients. The large majority of them want to know everything about the guy before they meet him. For instance, I call a woman and tell her that 'Joe Brown' wants to meet her, and ask when she is available to have a cup of coffee with him. Before they answer, they ask everything: How old is he? Is he good looking? Where does he live? Is he working? You know these women want to know it all before telling me if they are available or not... Of course there are other women that are much more humble, that do not ask many questions about the man. On the contrary, 
they thank me for keeping them in mind. They truly enjoy the opportunity of meeting a new guy. They value the process."

When enrolling with IMBs, women and men both have the general hope that it will be a fairly simple process. They think internationally they will find someone with the characteristics they are looking for but cannot find locally. In reality, the process is not nearly as simple as they initially thought, nor as straightforward as the IMBs claim it to be, nor as quick as they hope it might be. However, these women and men embark on the process always hoping to find that imagined person. Soon after joining they realize that they need a strategy for attracting potential partners which they craft through their pictures and profiles. However, they also need a strategy to hook the one out of many in the sea who will be right. The initial selection process then turns into narrowing the field and preparing the right bait.

\section{Flirting}

According to the clients I interviewed, the entire process of searching for a dream husband or wife is very stimulating. However the stage when they flirt with each other through instant messages, email, or video conferences, was repeatedly described as one of the most exciting and influential stages of the relationship. Flirting becomes a game in which each individual plays and decides whether or not the game is on or over. For many of them the stress of having to approach or wait to be approached is relieved by the knowledge that all the people on the sites are playing the same game. "It is like a level playing field," explained Rita Mendez. "We all are here looking for the same thing. We know what we want, we want to succeed. So being able to relate to the other 
person is so easy. It flows so much easier and feels so much better, regardless of whether you are being pursued or if you are pursuing someone." Women and men feel empowered by the fact they are part of a system that opens new opportunities and new experiences and at the same time encourages them to continue the not-so-easy task of finding the "one."

Male interviewees frequently used words such as "flattered" and "grateful" to describe their feelings when they are being, directly or indirectly, pursued by Colombian women, even more so if those women are significantly younger than themselves. For some, these interactions mean that the hard job is already done-breaking the ice and starting a conversation. Through agency events or the online chat rooms they feel less anxious, because they are able to engage in easy conversation. When talking about the flirting process with Tom Connor, the 43 year-old self-employed publicist, he said that he was "grateful... grateful because I believe we [men] feel so much confidence [online]. I do feel free to express my feelings and emotions knowing that even though I could be rejected, at least I had the chance to establish some contact to express myself without restraint. And you know what? Women like that; women like to hear they are pretty. They like to know that you notice what they said, or how they say it... And then they also give you the sweet talk and it works... It is really nice to be able to flirt with someone without having to worry about the women's willingness or their reaction!" Similarly, Matthew Goldberg, the retired 59 year-old, shared how he felt in the process of dating and courting Colombian women: "It is very flattering you know, I am not an old man, but I am older, OK? So usually I don't get to go out with 20 year-olds or 30 year- 
olds on a date as I do here in Colombia, so can you imagine how we men feel? Now imagine how nice it is when you find a gorgeous young woman, when you seem to understand each other, sex is great and everything is so perfect... It is a remarkable feeling; I truly can't describe it..."

Women claim to enjoy the flirting process as much as men do. Juana Gomez a 36 year-old events coordinator said that "it is thrilling to know you have so many admirers. It makes you feel pretty, young, confident." Women told me that flirting online was so much easier than flirting with someone at a social event, a party or a bar. Juana continued, saying, "You know the online dating sites are a great way to establish conversation and to express your real self without thinking 'What is he going to think?' without being concerned with coming across as being too needy or giving the wrong impression of just wanting to go to bed... If you are honest to yourself and you know what you want it is great... you can say it exactly as it is, what you want and how you want it... If he doesn't like it... well it is OK... There are more men... millions more... [She laughed]."

Similarly, Clara Garcia the 31 year-old occupational therapist told me that "what really called my attention was the adrenaline I felt when I would wonder about what this guy is going to say. Is this other one going to reply? Did he like what I said? You know what I mean. ... It is like the sensation of being in contact with these men and trying to uncover their needs and see if those needs pair up with mine. That constant give and take is so addicting. ... I loved it until I found the one, my fiancé. Then it was just pure love..." When talking with Pilar Rueda the 39 year-old female art teacher, she 
was very open and candidly said "there is a clear advantage with on-line dating... you will never be bored! Of course, if we are honest, the flirting game is really pleasant, they tell you nice things, and you say nice things and the fact that there will always be someone wanting to talk with you it is so fun."

Evidently, through matchmaking, women and men are constantly excited by the fact that they feel pursued and liberated in terms of the openness to pursue another person without much social pressure or shame. Thus, flirting is an important process that both women and men experience and enjoy. However, more than that, it is a motivation for the continued use of the services of IMBs regardless of the fact that not all the experiences of women and men using these services are entirely positive or lead to real matches. The flirting process, however, can be frustrating and disappointing. For example, Constanza Hernandez, a 44 year-old dental assistant, remembers "I started flirting with multiple people, trying different strategies, tried and tried and tried but it is like if those relationships started to dilute little by little. And at the end I felt like not talking or dating anyone ever again. It was so frustrating that out of so many people I could not find the right one for me."

These flirting and courting processes have interesting implications in terms of real commitment. A total of $80 \%$ of all my interviewees agreed that the level of commitment does not change whether one is establishing a relationship face-to-face through traditional means or through an IMB. However, $72 \%$ of the interviewed individuals agreed that using an IMB and being able to flirt in a more relaxed and anonymous setting (such as the through email, instant messaging, or phone calls) was a 
good tool for predicting the success of the future relationship, particularly with respect to the levels of commitment of the people involved. Men and women described the advantages and disadvantages of on-line flirting. For instance Viviana Morales explained how for her it was advantageous to meet people and flirt with them online because "if it does not work, or if you feel like that person really doesn't fill your expectations it is so much simpler to call the relationship off. In fact you don't have to say anything if you don't want to talk with him or her anymore you simply block that person from your list of contacts or tell the personnel at the agency that you don't want to date that person anymore. So there is no room for explanations or 'I'm sorrys'..." She was referring to the simplicity of breaking up with people online. This "advantage" clearly has two sides, one for the person who does not want to talk to the other person anymore, and the one for the person who is left without explanation. Andrea Rueda the retired 59 year-old, told me "I was falling in love, this man was so special although now I can see he had a lot of issues.... The point is that he lied to me. I knew he almost had a heart attack, he was really sick and had to stay for a couple of days at the hospital so he gave me his cell phone number. I called him to know how he was doing and everything... But one day he disappeared without any reason and I thought he had died... I was very sad about it; he would not answer my emails or my phone calls. I persisted, thinking some family member would pick up or something but no, nothing. A week or so after a friend of mine from the same website told me that she had seen him online the day before... I thought it was weird and tried to contact him again but nothing. So I asked my friend to call him and tell him that I was looking for him. She did and he answered the phone... 
Can you believe that? When she told him that she was calling on my behalf he hung up the phone and since then I haven't learned anything else... I understand if he did not want to know anything about me anymore, but I was worried he had died. It was not fair. He could have been more honest about it, don't you think?"

On the other hand, Andrew Raymond, the 41 year-old casino manager, thought that if a couple can survive an on-line or long distance relationship for a while the couple was meant to be together: "Flirting, then, is the possibility of keeping the feelings alive, to realize if that person is the one for you." By the same token, James Huppert, the 45 year-old insurance appraiser, stated that, "Flirting, once you meet them here [Colombia] could be difficult. You start a relationship with different women trying to figure out who could be the one. Everywhere people lie and women can be saying something on the phone or in an email but doing something completely different." He also admitted that the process could be rewarding and life changing.

The flirting process feeds the imagination work of the people using the services of IMBs. Although many times confronted by reality, the idea of feeling pursued inspires them to continue the search for the "special one." The levels of commitment of these relationships makes them very fluid, short and even snappy but "always instructive; there is always something to learn." Women and men interact under their own perceptions, motivations and expectations. They feel empowered by their own interaction and the "control" they have, particularly when contrasted with the implicit and explicit limitations that need to be overcome to achieve the same type of relationships in their own countries and cultures. 


\section{Filtering}

Once IMB clients decide to whom they would like to talk to or to meet, they use a filtering process to decide with whom to attempt to establish a relationship. They call it "filtering" because they start with myriad choices and little by little they screen through the possibilities, discarding those who no longer meet their expectations. The most common way of filtering initial contacts is to establish person-to-person communication, whether through email, instant messaging, video conferencing, or faceto-face meetings. Physical attraction, not surprisingly, is one of the most common criteria in the process of filtering. For both women and men physical attraction filtering is the easiest step in the process. It is a simply a subjective matter of feeling attracted or not. The cases of Victoria, detailed above, and Viviana Morales, the 36 year-old jewelry designer, are illustrative. "The men write a lot to me," explained Viviana. "I receive emails and nudges (a feature used in online social networks to call the attention of others) all the time, so what I do is to check the profile of the men that write to me; if I like them sometimes I write them back; if I don't, then I just ignore them." Such is also the case of Brian White, a 53 year-old computer systems analyst who showed me his online-dating email account with more than 280 messages from Colombian women showing interest in getting to know him. "I replied to one or maybe two of those messages. Many of those women I did not feel attracted to when I saw their pictures and profiles, and there were others who did not even have a picture in their profile so I could not make an informed decision!" 
Nevertheless, there is a strong influence from the IMB staff to push their clients to explore beyond looks and give opportunities to people they do not feel $100 \%$ attracted to. Patricia Novoa remembered how the director of one of the agencies she was registered with once told her, "Patricia what are you waiting for? You have met a lot of men and you have not liked any of them so far. Think about Ryan, he is going to treat you like a queen! Please... what are you thinking?" Patricia confided that she did not like Ryan, that there was no physical attraction but the agency director continued, "You can change his looks. He needs a new hair style so that is easy. If it is because of his glasses then you can ask him to have laser surgery. In fact, you can have your eye surgery done at the same time! I believe you should marry him. He is all you have been looking for... and what he is not, you can easily change. So what do you think?" Patricia did not marry Ryan, but when I interviewed her, she did admit to the importance of looking beyond the initial impression.

During the process of filtering, in addition to the physical aspects, women and men investigate the various characteristics they are looking for in a person. They evaluate the responses to key questions they ask and to comments a prospective mate makes about day-to-day happenings and issues. Colombian women I interviewed also filtered their choices based (among other things) on their perceptions of men being economically and emotionally stable as reflected in the following quotes:

Most of the Americans I have met through this agency have a clear disadvantage, on the one side they are very stingy, and they do not want to spend money. They have very tight budgets. On the other side most of them are already divorced. They have many problems... psychological problems, personal problems, emotional problems that is why they are alone and 
single. So you really have to search hard to find one that is generous and normal without so much conflict in their lives. (Juana Gomez)

I have what I need but I would love to meet someone to share my life with. However I don't want to meet someone who I have to pay for the movies or invite him to dinner because he did not earn enough that month. I talked with an American once. He complained a lot about money so I decided not to talk with him anymore. And another time, I met one here at the agency, he told me that he usually buys his clothes in thrift stores or that he preferred to do many things by himself even if he did not know how, just because people sometimes charge too much for basic services. (Andrea Rueda)

I was starting a really nice relationship with a wonderful man, he was very very special. However he had too many "family issues." His children were going through a rebellious phase, his ex-wife was suicidal, his mother was very sick. So, many times it does not work because of other factors, things way out of your control! (Laura Torres)

I really did not look for men, they looked for me all the time. If the person was kind of interesting, I would continue talking with him. I have to turn down offers from men who seem kind of weird, men that were always talking about their problems, and how their friends and families were worried about them... Those I block from my page, I really like when I can have a nice conversation with a man, when they make me laugh, but there are some that are just drama and I really don't want that for my life. (Tania Rodriguez)

The process of filtering for those men that use the services of marriage and introduction agencies and travel to Colombia to meet the women is best explained by Albert Malik, the 44 year-old investment manager: "I would say the best is to get a package [with one of the marriage and introduction agencies] and meet as many ladies as possible. I don't recommend just finding one and going for her fairly quickly ... It is better to meet many ladies which will help you form a better judgment... Spend more time with a few more, and then choose two or three, and try to identify one afterwards... I need to tell you that I always have a sort of backup just in case, because 
my time in Colombia is very limited... I have to have a plan B just in case... In the case it doesn't work with the one in the first place. That's how I do it and I think it is working." The men I interviewed filtered possible matches initially based on the Colombian's pictures. In addition to physical attraction they also take notice of day-to-day manners, spending patterns, communication factors, family structures, and sexual behaviors. Here are some sample quotes:

While in the process of screening I always question myself after every date or outing. Does she really likes me or is it that she likes the idea of having an American husband? So if it is the latter I don't ask her out anymore, but if I think she likes me as I am and I am still also interested in her, then I continue going out with her... I guess the only way to get to this is to be friends first... (Bill Stephen)

...So you have to meet them and have an open mind, for the initial contacts go for coffee next door... just to find out if you like her, so the first meeting has to be a cup of coffee and take it from there... Meet a good number of them and talk honestly about what you do, what you are interested in and what they are looking for... (Peter O'Brian)

Sexual intercourse soon is a big sign, especially if it is unprotected... As in the U.S., women can use pregnancies as a way to force a relationship... I know of two cases of friends of mine... Last time I was in Medellin, there were some younger women that in the first date wanted to sleep with me... I thought it was because they wanted to "seal the deal" so to speak, which I am not interested in. I am here sincerely to find somebody... (Matthew Goldberg)

In one of my trips, I had finally selected the last two women I wanted to spend time with. One of them, a very attractive lady, told me that someone in her family had died but that she did not have money to buy clothes to go the funeral... I did not have enough pesos to pay for her outfit so I reached for my wallet in front of the cashier. My date looked at my wallet and said you can use that... pointing to what she believed was a credit card, in reality it was a library card, but she knew what she was looking for... At that moment I realized the garments she was buying were not very appropriate to go to a funeral, they were all black but not appropriate, so now I know that I have to be careful and attentive to those signs. (James Huppert) 
The other thing I look for when I am filtering my dates is the level of education of these women; you know I learned that if they are professional they tend to be very choosy and picky... I imagine that is because of the Colombian society. They believe they deserve more if they are educated and because men here [Colombia] do not treat women with respect, so they have to earn it through education... (Alex Silverman)

Women and men participating in these processes are looking for a partner who corresponds directly to their expectations and motivations (Chapter V). Claudia Rojas, a 37 year-old linguist, thought "The process is not simple; people get really 'naked' and tell you everything about their lives so it is your task to catch the inconsistencies, to see the red flags and not fall that easy." Donald Brown, a 49 year-old business owner, concurred with what Alicia stated when he said, "In my case I am not that gullible but you really need to pay attention to what they say; analyze the whole situation and of course have fun. It is not easy in person, so what makes you think it will be easy on line or long distance? But it is possible... I will find my wife this way, I know it!" What happens during the filtering process is the pairing of what people say and how they act and what the others are looking for in them. In other words the filtering process is the stage in which men and women exert their power to choose based on their own needs, wants and overall requirements.

\section{Cyber-chemistry and the not so rose colored lenses}

Many of my interviewees said that attraction, whether face-to-face or through long distance communication, was like a blast of adrenaline-a brain and heart rush. They expressed this feeling as "cyber-chemistry." For instance, Rita Mendez described her story as a "cyber-fairy tale." Alicia Hernandez explained it as "pure computed 
chemistry." Tom Connor recalled it as "a magic online connection, an indescribable feeling" and Johnny Adams believed it was "a divine cyber-explosion of beautiful feelings." "Cyber" is often part of the of the expression they use because, whether or not they started their relationship online, in one way or another they communicated and courted using the Internet and its multiple channels (email, chat rooms, video calls, or computer-basedphone calls, or texting). For some, such chemistry was both instant and long-lasting. Carmen Gonzales, for instance, told me, "Since the first moment there was chemistry. When he contacted me through the agency's website I knew something good was going to happen but I wasn't too hopeful. When he came to visit me it was a big surprise. You know what I am saying? I was hoping for something good, but when I saw him it was even better than in the pictures [she laughs]. We are getting married next month, I will move to the States with him, we will have at least two children and he will help me find a good job... I can't wait!"

Alicia Hernandez, the 38 year-old jewelry designer, who met her fiancé online, radiated chemistry when she said "If one is destined to have a soul mate, I found it!" She started using the services of an online IMB in late December 2007. After a week she met Jerry Simon. The first week of February he traveled to Colombia and after meeting face-to-face they became engaged. When I asked Alicia if she thought it was a bit hasty, she responded saying "Everyone asked me that... In fact I even talked about it with Jerry. What I am going to tell you is not the 'in love' side of me speaking. The thing is that at my age, I am 39, with two previous marriages and with a daughter; I needed to be very careful; I knew what I wanted. I needed to be sure and feel inside that he was 
the right person, because I was letting him enter into my life, into my house, into my family. You know? Talking with my mom about all of this, I told her, 'Look, it is not as unreasonable as it might seem, it is real, meaningful, and it has everything. There is love. It is perfect and it all happened in a matter of a week!'” They married five months after they met; at the time of this writing they have been married for over a year. I contacted Alicia again and she stated that their marriage was great, that he continued being a "prince charming." Her daughter was doing great, she was still trying to get pregnant but had a good job, she said that although she was still getting used to her new life in the States, she would do it all again without thinking twice.

The pace of these cyber-relationships is an important characteristic to highlight. Eighty three percent (83\%) of both female and male respondents revealed that these relationships, whether initiated online or face-to-face through an IMB, progressed at a rapid pace and increased intensity compared to the relationships established through traditional means. "It was amazing. We met the first time in March of 2007, by the end of May of the same year we were already married and living together...I don't think it would have been the same if we had not met on-line," said Catalina Ortiz. "You know, I liked him so much, but he was very timid. So I started saying nice things to him and he felt so good that he started saying them back to me. Then after two months of chatting and seeing each other in the camera I invited him to come visit me in Colombia. He agreed so he came, let's say,... three and a half months after we met. And we got married a month after. So, it was only a matter of almost 5 months that we got married. After three years of being married, I do not regret it!" 
Talking about the pace of the relationships with Peter O'Brian, he stated that men and women using the services of introduction and marriage agencies were in a difficult situation. "You see, most likely we [men] come here for two or three weeks in which we are supposed to meet as many women as possible and hope for the best [and] find the one you think is the right for you. It seemed easy when I first saw that Colombian women are so beautiful, but then you think twice. It is very difficult... Look, the first time I was here was to find a 'novia,' (girlfriend) and I did find one but it only lasted 9 days, 5 days here and 4 days over there [in the U.S.]. I wrote some letters; she didn't write back. She had some issues. She had some emotional instability issues. Beautiful woman, hard working business woman, but I saw some red flags and I ignored them. This time I am not ignoring any red flags, and I would recommend any person in the agency not to rush. Now, my plan for these five weeks is to develop a group of 8 to 10 women that when I come back in September, if they are still available, I will spend some time with. I'll take my time to do it... I am not rushing anymore. My heart has been broken many times. It is my fault because as the song says, you can't hurry love!" In many other cases, however, the initial cyber-chemistry between the two people was tainted by circumstances that did not allow the relationships to flourish. Such was the case of Patricia Novoa, the 51 year-old stylist, who once was engaged to a 56 year-old mechanical engineer from Boston. "He was so nice! We were preparing everything for the wedding when he became ill. That was in December and he died in February. He had stomach cancer and he did not know. So in two months he was gone... I was very sad because I was not able to go take care of him or be with him." 
For others the chemical reaction was probably too explosive, due to the increasing demand for virtual sex. Improved communication systems allow men and women to talk and see each other through instant messages and video calls. However those same mechanisms that allow communication are being used to initiate virtual sex experiences that the majority of the interviewed women disapproved of and found disrespectful:

A lot of people contacted me with the idea, many more than what I expected, of having sex... through the web-cam and the chat... They begin to communicate in lewd, crude and socially unacceptable language that can only lead towards a virtual sexual encounter... That's through the chat, and then they ask if you have a web-cam and to tell you something like "Why don't you show me this or that?" or "Why don't you get naked?" and things like that... It is amazing because I am in my sixties and they still want to do those things... It is really revolting... (Andrea Rueda)

There is always the one insolent and rude person telling you things like I want to do this and this with you... and touch you here and there... So you really have to be careful; it is not like you can chat with everyone... (Pilar Rueda)

Those pages never lack the one guy who thinks that it is a porno site... the worst that has happened to me was one time that I was chatting with this guy from Chicago, and we had chatted already for about a week and one day he asked me if I wanted to see him through the video, so I said yes and when I saw him, he was completely naked with a whole set of paraphernalia ready to masturbate with himself...I swear it was horrible... (Constanza Hernandez)

As women and men motivate each other to subscribe to and use the services of IMBs they are, with the same intensity, warning their friends and acquaintances about these types of issues. They often recommend to others that they be careful and be aware of all the possible obstacles and to be very selective in their choices while chatting and video-calling in these systems. 
For others the initial cyber-chemistry lost its potency little by little leaving participants disappointed, though never completely dashing their hopes of finding the right person. Christian Cook is a 38 year-old who has been working in a supermarket in Kansas City for the last 22 years. During his first trip to Colombia he met Mary, a beautiful 30 year-old business administrator. When I interviewed him in Colombia, he looked very sad. I asked him if he was feeling okay and he responded saying "Oh... I am OK... Well, my body is OK... I need to be honest with you at this point I am just bewildered... See this is my second time here, in Colombia. I have been here before with this agency already once. I met Mary last time I was here, and then I came back this time to visit her. Things did not work out. I stayed at her house actually for about three days, almost three days... Things didn't work out... I don't know how to explain it. It's very complicated. I am meeting with you because I need to let it all out. ... I didn't expect to be here at the hotel. I was thinking I would be at her house. Last time I was here she said 'Next time you come to Colombia you're staying in my house.' But I came to the hotel yesterday because I couldn't stay at her house anymore. Things just changed, she changed a lot since the last time I saw her. I can't believe how much she changed actually. People at the agency tell me that it is a good thing that I realized who she really was before getting more serious... But you know what? It was already serious, so it hurts... When I was here two months ago everything was just right. Well, I really thought she was the one for me... On that plane [back to Colombia] I thought she was the one... But when I arrived I noticed something weird and after the first day I figured it out. Things were not going well. I saw her acting really different to the last time I saw her. 
She was much more aggressive in the way she spoke. She was so much sweeter when I was here before. This time she was much more demanding, more strong-willed, and the weight of problems in her own life was making her a different person. I thought all of that was coming out from inside her, her real self! On the second day I felt that she was not what I wanted, and it worried me. Then, when I mentioned that maybe it was best for me to stay in the hotel, she said that she agreed and that she did not want to see me ever again." I saw Christian almost a week after the day of the initial interview. He told me that he decided to stay in Colombia for two weeks as planned and that contrary to what he initially thought he started to go out with other women. "I am trying to look and think forward, to learn from my mistakes" he said. "It is hard to learn from your mistakes because sometimes you repeat them... I guess I rushed that relationship [with Mary] and all the chemistry and feelings disappeared in two days. But Colombian women are fascinating and I know I am going to meet the one for me, probably not this time but I know I will."

The story of Christian and Mary is far from unique. Good, lasting cyber-chemistry is hard to find. Viviana Morales, the 36 year-old actress, explained that "Regardless of all the people I have met, I can't tell you there was even real chemistry with even one of them. At the beginning of each relationship I always felt like 'This is the one' but after I met them or became more familiar with their lives, I was disappointed. That is incredible. ... Maybe it is me, I don't know."

Similarly, Albert Malik, the 44 year-old investment manager, repeatedly stated that he has been very frustrated because when he finally meets the women face to face 
they "do not look as they do in the pictures, as I had imagined them. When you look into some of their eyes they reveal an overconfident, arrogant, full-of-themselves person and I really don't like that. So I have come to the realization that if I want to succeed I need to look deeper and take it easy... I guess it will take longer than what I envisioned."

Others interviewed said that even though there was initial "cyber-chemistry" with different people they met through the IMBs, many times their expectations were too different from reality, from the ideal person they sought in a relationship. Such is the case of Hilda Cardenas, a 30 year-old accountant and business owner, who also told me that she met once "a very handsome and attractive man who was very generous. He gave me money to pay for my 'lipo' [liposuction]; he also sent me money every month like $\$ 1,000$ saying that it was just to pamper myself. That lasted like 5 months. When he came the second time he invited us to go to Cartagena. He was very generous. But the problem was that he got sick, he had arthritis and I thought, 'What am I going to do with a sick person?' No, no, no! I understand that if I am going to have a family, I will have to take care of my husband. But it is not like I am a nurse, so it didn't work out. What a shame he was very handsome and wealthy!"

Another similar case was the one of Peter O'Brian, the 55 year-old salesman, who had established a relationship with, in his words, a "highly educated woman through an online dating site. I wrote the lady everyday for 5 months and it became a romance, a long distance romance. So I thought to myself, 'Let me go to Colombia.' We had a fantastic weekend out in the mountains close to Medellin, and I thought very 
seriously about taking her back. But I just wasn't ready, I started that relationship not taking it really serious, I was not ready to commit. I didn't... Next time I was going to come we were going to meet in Cartagena like five months later. I knew that I had to start doing the visa paperwork but I didn't. I know I disappointed her, I disappointed her... I think she was hoping..."

Bill Stephen, the 56 year-old psychiatrist, started his interview telling me that the path to find the right person was long and that "you need to be very careful... After eleven trips to Colombia I know now that approximately ten to twenty percent of the women in the agencies just want the visa and the money or one of the two. So yes, you have to pick and choose and take some time..." In the same way Donald Brown, the 49 year-old businessman, told me the story of a very close friend of his who was "bamboozled by a Colombian woman from Barranquilla... she used all kinds of tricks in the book to get her own way particularly about money, she would ask him for so much money and he would always send it to her... She asked him to invite her to Miami, but he had to pay for her tickets and the ones of her son and her niece. Once in Miami she told him that she would marry him and moved to Reno with him if he also paid for her son, her sister and her niece to move to the States... at the end his children, who were all grownups, had to intervene because he was sending ridiculous amounts of money, presents, paying for trips and surgeries but she never committed. She only wanted the money, she did not want to be a wife she was just taking advantage of my friend."

Women also tell stories of disillusion, Constanza Hernandez a 44 year-old divorced dental assistant, explained how she felt so disheartened by American men. "I 
don't know if I am sending the wrong message but all they want with me is sex. I am sorry to put it so bluntly but it is true. Last year I met this great guy from one of the agencies. After a couple of dates here in Bogotá he invited me to go to Isla Palma which is an island close to Cartagena. It was very romantic and intimate, we had a great time. He promised me lots of things and of course I believed him, but nothing was real. He was actually married and not planning on leaving his wife. He only wanted company to spend his time with while in Colombia..." Constanza reported him to the agency and he was barred from using their services. Erika Sanchez, a 45 year-old spa manager also recalls how disappointing her experience has been with the men she has been introduced to by the agencies. "I thought it was the agency's fault. But now I believe the agencies can't do anything about it. What happens is that most of the men, well at least the ones I have been with, are here but not with serious intentions. They are here just to see what they can get away with! The sad part is that many of the women they go out with think they are serious and telling them the truth. But this has not been the case in most of my dates or the dates of my close friends... I don't know how American women are, but I am not used to sleeping with anyone on the first date and that is what the men all want. They invite you to go out and to go to places just expecting you to return the favor in bed... I think I will have to find my way to the States first and then try to find the right man for me over there."

These stories of dashed dreams from women and men abound. They are not the fairy tale endings participants imagined through the "rose colored lenses" clients typically wear when they begin their IMB-mediated dating games. On the contrary, they 
show how difficult the process of finding the "one," the cyber-alchemy, is. It is important to note that the women and men I interviewed felt confident about knowing when to report those clients whose behaviors were considered "inappropriate," resulting in the banning of those members from using the services of these IMBs.

Of course, the "right person" has different meanings to different people and varies according to his or her ultimate motivations, expectations and social locations. There is not an easy formula. For some, the result is love and happiness. For others the alchemy does not appear. While talking about these disparities with Victoria Echeverry, the 46 year-old nail stylist, she candidly offered her own analysis of these bad experiences and poor chemistry, saying, "The problem is that you enroll in these agencies thinking you are going to find an ideal person. In my own case, I clashed with some men; others are just good friends, and still others I really felt in love with. But once you start a relationship the utopian dream of the Prince Charming that you will meet online disappears and you need to confront someone real, someone tangible, someone with his own history, probably with some baggage. And it is not the same. The dream becomes real and in many cases, as in mine so far, it is not the dream I have been imagining. When you have that person in front of you, and you can touch him and see him face-to-face, things change a lot. The breathtaking feeling and butterflies in your stomach disappear and then you have to deal with a real person and with the lack of chemistry and physical attraction you think you felt before. When you realize they are not immune to unfaithfulness and they are expecting you to be at home, limiting your options to grow as a person, it becomes an obvious mismatch. You know Colombian 
women are really family-oriented. That is true, but it does not mean that we don't have other aspirations. We could be successful mothers, wives and workers all at the same time, and we need open-minded men who understand and support this, knowing that for us our families will always be our number one priority."

For James Huppert the secret recipe for this type of relationship is the correct combination of chemistry, self knowledge and timing. "A lot of guys from the States can't find the women in their life and they come to Colombia and the first girl who gives them some attention they fall in love and they marry and that is something I would not advise. Instead, I would say you need to know yourself well enough to know exactly what you are looking for in a woman, what you are willing to give up and what you are capable of offering. Then come [to Colombia], take your time and observe and come back multiple times. Think about it. Now...really scan out what you are looking for, instead of just coming and the first girl that meets you and sits in your lap and says I love you... you marry her. It's too fast, it doesn't work! First you need to feel real chemistry, you need to feel inside that she is the one, not only because you feel attracted to her but because you feel compatible with her culture, her family, her hopes, dreams, etc. ... And you need to spend time with that person. You need to invest. If you are going to invest in bringing that woman back to the States, [you've] got to invest time in getting to know her, not three months, two months. I would say a year coming back and forth and back and forth. It is a plus if she has a tourist visa. That is the best because she can go [to the U.S.] and you can come [to Colombia]. That is the best way to truly find the girl of your dreams!" 


\section{Additional Barriers}

The women and men I interviewed narrated their experiences and stories which were filled with hopeful imagination work of their futures. They frequently interpreted mishaps through the rose-colored glasses of imagined bliss as part of the 'normal' disappointment found in the dating process. However there are real barriers to bicultural relationships that increase the potential for problems. These barriers include aspects such as different languages, countries of origin, legal restrictions, socio-cultural misunderstandings and particularly gendered misunderstandings. I turn to these now.

Communication difficulties are always at the core of these relationships. Only $23 \%$ of the men interviewed reported being fluent in Spanish while $28 \%$ of the women interviewed reported being fluent in English. The reminding $77 \%$ and $72 \%$ stated they needed an interpreter or were barely functional in the other's language. Not being able to communicate in the other's language was stated as the most common barrier for the development of these relationships. However it was seen as a barrier easily surpassed. Therefore it was not uncommon to see clients walking around the corridors of the agencies with electronic translators, dictionaries, or hiring independent translators to help them with their individual appointments. Patricia Novoa, the 51 year-old stylist, for instance, confided that she always took her 17 year-old son to first dates so he could translate for her. Peter O’Brien the 55 year-old salesman, stated that he learned Spanish during the three months prior to his first visit as a sign of real interest and commitment to his online - international dating success. 
Legal restrictions prove a bigger and more revealing barrier. The difficulties of acquiring a tourist visa for Colombian women to visit the U.S. was mentioned by both male and female respondents. Catalina Ortiz the 36 year-old homemaker, recalled how she could not be with the man she called the "love of her life" because her tourist visa was denied four times to go and visit him in Anchorage, Alaska. She explained that "the people at the embassy kept repeating that I was a single mother, without a stable job and with too many good reasons to try to stay in the U.S. illegally. They not only denied my visa but also the chance I had to be happy." When I asked her why he did not visit her, she explained that he had some sort of illness that prevented him from travelling long distances. "After that, you know, the distance, the time and the inability to be together destroyed our four year long on-line relationship."

Colombian women's difficulties obtaining visas were often met with skepticism on the part of men. The men frequently did not see how their nationality gave them privileges versus the woman. They interpreted women's need for help obtaining visassuch as the men filing for a fiancé visa-as the possibility that women were using them "just to obtain legal migration papers and then disappearing." Although this skepticism was consistently addressed by the IMBs who tried to explain restrictive U.S. immigration laws, $85 \%$ of the men mentioned "green card marriage" skepticism in some form during their interviews.

\section{Recapitulating}

People using the services of IMBs put their imaginations into action. They do imagination work. As documented in this chapter searching for a partner via IMBs and 
overseas travel involves devising and deploying multiple strategies to entice, find and hook "the one." With the help of IMBs, particularly their grooming of female clients, men and women craft their selling and searching strategies by the selection of pictures and the assembly of their descriptive profiles, filtering through contacts and flirting online and face to face. Although they use similar tactics, they do not come to the mate market with equal resources. Men are clearly in the better position and take advantage of this; women however are far from passive. They know what they want too and pursue it vigorously. A match is their sought-for ticket to a better life-and hopefully a happy relationship. The cyber-chemistry and the stories seen through the not-so-rosecolored lenses show that regardless of the outcome and difficulties of each person's experience, these people do not easily give up. On the contrary they continue hoping, expecting, dreaming and imagining that person who will fit their own ideals and help achieve all the dreams they have of a foreign partner. 


\section{CHAPTER VII - CONCLUSION}

This dissertation was designed to investigate the agency of Colombian women and American men who pursue romantic courtship through the services of IMBs from the "Gendered Geographies of Power" (GGP) framework of analysis. The GGP framework of analysis developed by Mahler and Pessar was presented from a theoretical perspective. Within this dissertation I applied it to the concrete case of international courtship, exploring and documenting the utilization of social locations, the negotiation of geographic scales and, most importantly, the role of the imagination in social agency of both women and men in the pursuit of an international partner and migration.

The study of international courtship as seen through the GGP framework turned out to be much more than the simple pursuit of "love." In fact, beyond the idea of finding a mate and migrating, these individuals are engaged in the processes of negotiating and strategizing gender.

\section{A fluid game of give and take}

This dissertation goes beyond seeing international courtships as straightforward arrangements between powerful men and weak women - the story that emanates from previous iterations of cross-border romantic relationships in the forms of Picture Brides, War Brides and Mail-Order Brides. Although there still exist ample asymmetries in the relationships documented in this dissertation, they are counterweighted to a large 
degree by women's empowerment through the Women's Movement, Internetmediated communications, the role played by IMBs and globalization. The result is greater gender parity and more informed choices in the romance marketplace. Rosa and Kenneth's story presented in the introductory chapter show for instance, how Rosa renounced her ideal of finding a young, attractive, schooled partner in exchange of what she perceived to be a committed, faithful and economically stable partner. In a similar vein, Kenneth renounced to the ideal of a childless stay-at-home woman and proposed to Rosa who was already a mother and had high expectations of working. They clearly did not attain the partner they had imagined, but they were able to hold internal and external negotiations between the dream and the reality, to develop strategic self presentations and to use the confluence of external supra-individual factors and agents that facilitated and solidified the entire process. It is precisely in the confluence of the components of the GGP (geographic scales, social locations and agency-imagination) that women and men use the power to better present themselves and assess and negotiate their opportunities.

The analysis of the geographic scales and social locations is very revealing, though, as expected, the scales and locations constantly overlap and complement each other at the same time. Through the preceding chapters I have shown how diverse scales of analysis are needed to examine the interaction of these individuals within the IMB business and the courtship process in general from a larger social science perspective. 
A typical example of these negotiations, overlapping and complementing interactions between geographic scales and social locations is the intersectionality of nationality, household dynamics, education and marriage. Nationality or country of origin (a geographic scale with power geometry implications), for instance, is seen among my informants as a characteristic that gives men a relative advantage in the negotiation. American men understood that their citizenship places them in advantageous position since they can offer women the opportunity to legally move to the U.S. However, Colombian women understand that at another geographic scale, the household, they can enhance their disadvantaged social location if they align their selfmarketing with males' gendered ideals for mates. Thus, women exchange realizing the men's desired family life for the men's offer of the better lives in the U.S. the women seek. This is then a win-win situation, in which both women and men use their resources to level power asymmetries. Another example is seen in education. In most of cases, the educational level of the women interviewed was higher than that of the men, and it seems as if women were dating or marrying down. However, an analysis of these same women makes it clear that although an educated woman in Colombia tends to have a higher social position (compared to uneducated women); it also implied, for multiple reasons, a lower chance of getting married and sharing financial responsibilities with her partner. Alternatively American men, commonly with lower education levels than the women they were courting, constantly reassured women that they could offer a stable and faithful relationship, economic stability and could open opportunities in the U.S. In this case, women trade their higher education social location for more stable 
relationships, families and migration that offers greater professional opportunities for their educational status. Men may understand that their lower levels of education are inconvenient, if not a disadvantage, but not one precluding them from effective bargaining with the women since they still can trade their social location in the U.S. and other characteristics known to be much appreciated and requested by women. Women and men then negotiate past the asymmetries in their social locations in large part because they are fueled by gendered imagination work. They seek in each other and across international borders the gendered ideal mate they feel precluded from at home.

With respect to theory, there has been more attention paid to identifying and explaining the structures and historical contexts which shape migration than to examining the actual agency of the people as they transform themselves into migrants. Many theories of international migration treat migrants as if they were pawns of larger socioeconomic forces (microeconomic theory and the historical-structural school in particular). While these theories have proven important to predicting migrations, they do little at household and family scales of analysis to shed light on how people transform themselves into migrants and how they migrate as well. When my interviewees considered courting and migration using the services of the IMBs, they clearly used their social locations and negotiated their geographical positions in the pursuit of their imagined future with their "ideal" partner. Thus, courting and migration in these cases is not simply the result of economic cost-benefit analyses, networking or supra-individual structural factors. Yes, these are important, but they underestimate the role of people's agency. In this study agency, often referred to as imagination work, is 
deeply gendered but also highly strategic. From their asymmetric social locations, IMB clients-female and male--position themselves and maneuver their way toward their objectives - their dreams and their idealized relationships.

This dissertation has shown the complex elaboration of the imaginative work involved in the pursuit of an international partner and, for the women, migration overseas. This study includes a discussion of the clash between expectations and realities and the comparative analysis of potential migration and love. Traditional migration theories have not included the gendered processes of idealizing, longing and imagining that this study analyzes. Yet these gendered processes certainly shed light on why and how some people migrate. While authors have noted how women are active participants in negotiating relationships that enable them to migrate (e.g., Constable, 2003; Brennan, 2004; Constable, 2005; Schaeffer-Grabiel, 2004; Thai, 2008), such studies have not taken imagination work as their central concept.

This study makes a strong contribution to the GGP framework, particularly in applying it and further developing the critical role of imagination work. Men and women imagine their ideal mates in similar, gender-specific and sometimes contradicting and ways. Through their imaginations they construct these potential mates as the "other." The "other" represents a positive image and contrasts against what the participants perceive of as the norms in American women and Colombian men. What they imagine and how they imagine as well as what they present for others to imagine are all carefully crafted by themselves but also with the expertise and watchful eyes of the IMBs. As with most fantasies, these gendered ideals work well in the "cyber chemistry" 
world but must, at some point, be grounded in the "real" world. Thus, while gendered ideals drive many of the romancing strategies and decisions, they do not yield consistent results.

Imagined ideals often differ from that which is achieved. We know this to be true even before chronicling the lives of modern-day Shangri La seekers. The value added in the current analysis is not that reality differs from the dream, the goal of imagination work, but, rather, the detailed investigation of how gendered differentials in men's and women's imagination work create an alchemy with their social locations that yields realities not too distant from those imagined. It is convenient to think that in the imagination people are liberated from the axes of differentiation that constrain their "true" lives; but this study documents that imagination work, itself, is subject to the very axes of differentiation people hope to escape.

Another asymmetry addressed in this dissertation and inculcated in the gendered imagination work of my interviewees is that between the "traditional" and the "modern." American men eschew "modern" American women as mates and seek "traditional" Latin ladies. Ironically, the "traditional" women they find are, in their own societies, very "modern" yet articular "traditional" values as they seek "modern" men, the opposite of "traditional" macho Colombian males.

Men search for Colombian women who are more traditional than American women in order to buttress the masculinity they feel has eroded in American households. Women, on the other hand, search internationally for the modern men they cannot find in their homeland, someone who embodies progressive ideas of 
equality, democracy and freedom and is willing to practice them at the household as well as the societal level. From the reader's perspective it is hard to understand that these men and women do not recognize the very irony of their criss-crossed longings. Instead their imaginations ignite the agency that propels them in real ways across real borders, cultural as well as political. How can this happen? An individual's imagination, fueled by IMB marketing, creates idealized fictions of the "other" that feed emotional needs which overwhelm rationality. Moreover, Colombian women strike a type of bargain with themselves: they see in American men mates who are more in line with their ideals than Colombian men will ever be and recognize that in order to take a step closer to their ideal mates-and many steps toward greater occupational and economic opportunities - they must play the game necessary to secure their man. That said, I do not mean to say that Colombian women merely talk the talk; they do subscribe to more traditional sex roles for women than many if not most American women of the same social strata. The operative word here is "more." Men and women find more of what they are looking for, not necessarily all.

Clearly, the imaginative processes experienced by clients are fed and supported not only by themselves, but also by IMBs, whose objective is to profit from these interactions. Agency is not the dominion of those seeking mates. IMBs develop tailored, deeply gendered sales tactics, open doors to what is perceived as a less restrictive means of courtship (with respect to tradition and social norms) and promote "achievable ideals" through the use of their services. In effect, IMBs serve as cyberspace counterparts to the more commonly known coyotes, smugglers who spirit migrants 
across barricaded borders. Each is paid for facilitating migration though the transit means and medium varies. Yet, while there is ample literature on smugglers the work of the IMBs is, correctly and intentionally, less well known. Nonetheless, in a dissertation aiming to bring to the fore neglected forms of agency, the IMBs' activities have merited much attention.

\section{The Contributions}

The contributions of this dissertation are specifically towards the application and expansion of the Gendered Geographies of Power framework and the marriage-based migration literature. Even though the GGP framework was extensively elaborated by its authors in three different academic articles, they did not apply it to their own research. In this dissertation, as explained above, I applied the GGP framework, carefully emphasizing the interaction of each of its components. In that process, I was also able to expand the framework since I researched the imagination component that the authors had only highlighted as needing further consideration. Imagination as the process leading to agency is understood as the ability of and effort expended by individuals to visualize their future in terms of dreams, expectations, beliefs, and overall fantasies nourished by the experiences of others and the influence of "accredited" institutions, social institutions, the media, cultural myths, etc. Through the pages of this dissertation and particularly in Chapters Five and Six, I was able to demonstrate its importance not only as a personal attribute that propels agency but also in its ability to be translated into realities and as a mechanism that supports individuals when faced

with adversity. 
Another contribution this dissertation makes is to the literature on marriagebased migration. In recent years, scholars have widened academic perspectives on international marital relationships and how women seek and achieve migration abroad through marriage (Kendall, 2002; Constable, 2003; Wang and Chang, 2003; SchaefferGrabiel, 2004; Johnson, 2007; Thai, 2008). This study extends that widened view even further by revealing how men and women imagine and embellish both their own characterizations (as more traditional or more modern) as well as those of the "other" in their courtship rituals. It includes the work of IMBs in these international relationships and migrations. The IMBs play significant roles as intermediary agencies. This has been studied by other scholars, but this dissertation goes beyond documenting how the IMBs should be understood as part of the migration industry.

This dissertation has also expanded the understanding of international gender relations through the influence of the intertwined social locations, geographic scales, agency and imagination. Evidently the fluidity of gender interactions and the continuous adjustment to the realities that each individual goes thru become a contribution itself to the study of gender theory. Though my informants are immersed in the inequalities and discrepancies of their geographic scales and social locations, they demonstrated to be constantly challenging such inequalities and discrepancies and assuming fluid meanings of their actions and dreams. Thus, in the process of international courtship described in this dissertation, women and men are far from constrained within gender roles and gender expectations, on the contrary these women and men are using imagination work 
and strategizing to be able to influence their negotiation power, and constantly (re)defining their own behavior to achieve their own goals.

The specific effect of the Women's movement, Internet-mediated communications and globalization has shown to be a catalyzer as well as a window for many women in their development of transnational feminism. The idea of a transnational feminisms, as evident in this dissertation, need to seen not as a global - all encompassing ideal, but the need to see women's struggles in relation to their own historic, economic, political and cultural circumstances. Through imagination work and the negotiation of "womanhood" meanings, women across the planet procure their own advancement while fighting to balance gender inequalities. This dissertation illustrates how Colombian women are constantly compared and contrasted to American women, and how the existing inequalities (which are also circumstantial) in the romantic courting negotiations are understood and negotiated differently by women at the international scale. This dissertation shows how the ideals of Transnational Feminisms are not constant or fixed, but they should be understood as a continuum that allow women to rise their overall expectations and experiences as women, by altering gender boundaries and utilizing them to be able to thrive and adapting within new circumstances and environments.

\section{The future of gender international relations studies}

Certainly, the centrality of international courtship is part of a much broader social construction of the family through migration. This study focuses, as a first step, on courtship processes. Courtship leading to marriage is, of course, not synonymous with 
studying marriages. Thus, it is necessary that future studies study actual marriages of couples who meet and marry this way. Such studies should aim to contrast spouses' imagined futures with their current realities using the GGP framework as a way to analyze their agency and imagination work knowing that their social locations and geographic scales change with marriage and migration.

Another limitation to this study and one indicated in my introductory chapter is bringing race into the study. Although in my research I began to encounter a racial asymmetry at play in addition to the others discussed, I did not have enough data to expand the analysis in terms of race. That is, I saw some indication of a pattern in African-American men seeking Colombian women, but I would have had to change my data collection strategy very significantly to pursue this connection and without the guarantee of achieving enough data for analysis despite these efforts. Inter-racial international courtship exists and marriages are established; the work of Denise Brennan features race (2004). Future studies need to consider race perceptions, explore possible stereotypes of blacks or other minorities within the use of the IMB systems and international courtship in general. It could be pertinent as well to explore multiracial international couples in relation to assimilation and acculturation processes and kinbased networks.

Finally, while in the process of analyzing the data, I realized that children of both women and men play a key role in the courtship process and imaginings of future families. Concern for children's wellbeing and futures often motivates Colombian women's actions. At the same time, according to many accounts of my informants, 
children have an important role in the actual development of these relationships: some serve as interpreters, others screen the future potential partner during casual encounters (face-to-face or web-based) and others are considered an "obstacle" in the relationship and migration process. I am certain that studies that concentrate on the role of children in migratory processes within transcultural, international (and many times blended) families is needed to enrich the literature of migration and family. I see this as a fruitful future direction for my own research. 


\section{REFERENCES}

Allgeier, E. R., and N. W. Wiederman

1991 Love and mate selection in the 1990s. Free Inquiry 11:25-27.

Antin, Mary

1912 The Promise Land. New York: Penguin Books.

Appadurai, Arjun

2003 Modernity, Globalism, and Diaspora. In Theorizing Diaspora. J.E. Braziel and A. Mannur, eds. Bodmin, Cornwall: Blackwell Publishing.

Bales, Kevan

2003 Because She Looks like a Child in Global Woman: Nannies, Maids, and Sex Workers in the New Economy. B. Ehrenreich and A.R. Hochschild, Eds. New York: Metropolitan Books.

Barnett, Larry D.

1963 Interracial Marriage in California. Marriage and Family Living 25(4):424427.

Baxandall, Rosaline, and Linda Gordon 1995 America's working women: a documentary history 1600 to the present. New York: W.W. Norton \& Company.

Boyd, Monica

2006 Women in International Migration: The context of exit and entry for empowerment and exploitation. In Commission on the Status of Women, Highlevel panel on "The Gender Dimensions of International Migration". New York: United Nations.

Boyd, Monica, and Elizabeth Grieco

2003 Women and Migration: Incorporating International Migration Theory. In Migration Fundamentals: Migration Information Source.

Brennan, Denise

2003 Selling Sex for Visas: Sex Tourism as a Stepping-Stone to International Migration. In Global Woman: Nannies, Maids, and Sex Workers in the New Economy. B. Ehrenreich and A.R. Hochschild, Eds. New York: Metropolitan Books. 
2004 What's love got to do with it? : Transnational desires and sex tourism in the Dominican Republic. Durkham: Duke University Press.

Brettell, Caroline B., and Patricia A. DeBerjeois

1992 Anthropology and the Study of Immigrant Women. In Seeking Common Ground: Multidisciplinary studies of immigrant women in the United States. D. Gabaccia, ed. Pp. 41 - 63. Westport, Connecticut: Greenwood Press.

Bunagan, Mae

2002 Cash on Delivery: the mail-order bride industry exploits women.

Perspective, Harvard-Radcliffe's Liberal Monthly (November, 2002).

Cañizares Molina, Anita

1995 Women's Voices and Institutional Discourses: The Social Construction of Gender in Colombia: Syracuse University.

Castles, Stephen, and Godula Kosack

1973 Immigrant Workers and Class Structure in Western Europe. New York: Oxford University Press.

Castro, Max, Ed.

1999 Free Markets, Open Societies, Closed Borders? Trends in International Migration Policy in the Americas. Miami: North South Center Press, University of Miami.

CEPAL

2001 La Migración International y el Desarrollo de las Américas. In Simposio sobre la Migración Internacional en las Américas. San José Costa Rica: CEPAL.

Chai, Alice Yun

1992 Picture Brides: Feminist Analysis of Life Histories of Hawaii's Early Immigrant Women from Japan, Okinawa, and Korea. In Seeking Common Ground Multidisciplinary Studies of Immigrant Women in the United States. D. Gabaccia, ed. Westport, Connecticut: Greenwood Press.

Chin, Ko-lin

1994 Out-of-Town Brides: International Marriage and Wife Abuse among Chinese Immigrants. Journal of Comparative Family Studies 24(1):53-69.

Chow-White, Peter 
2006 Race, gender and sex on the net: semantic networks of selling and storytelling sex tourism. Media, Culture \& Society 28(6):883-905

Cohen, Erik

1986 Lovelorn Farangs: The Correspondence between Foreign Men and Thai Girls. Anthropological Quarterly 59(3):115 - 127.

Cohen, Lucy M

2001 Colombianas en la Vanguardia. Medellín: Editorial Universidad de Antioquía.

Constable, Nicole

2003 Romance on a Global Stage: Pen Pals, Virtual Ethnography and "MailOrder" Marriages. Los Angeles: University of California Press.

2005 A Tale of Two Marriages: International Matchmaking and Gendered Mobility. In Cross-Border Marriages: Gender and Mobility in Transnational Asia. N. Constable, ed. Pp. 166 - 186. Philadelphia: University of Pennsylvania Press.

2006 Brides, Maids and Prostitutes: Reflections on the Study of 'Trafficked' Women. Portal, A Journal of Multidisciplinary International Studies 3(2):2-25.

Curren, Sara R., et al.

2006 Mapping Gender and Migration in Sociological Scholarship: Is it Segregation or Integration? International Migration Review 40(1):199 - 223.

Davis, Kathleen

2006 Brides, Bruises and the Border: The Trafficking of North Korean Women into China. SAIS Review XXVI (1):131-141.

di Palma Castiglione, G.E.

1905 Italian Immigration into the United States 1901-4. The American Journal of Sociology 11(2):183 -206.

Dumont, Louis

1957 Hierarchy and Marriage Alliance in South Indian Kinship: Royal Anthropological Institute of Great Britain and Ireland.

Ehrenreich, Barbara, and Arlie Russell Hochschild, Eds.

2003 Global Woman: Nannies, Maids, and Sex Workers in the New Economy. New York: Metropolitan Books. 


\section{Espiritu, Yen Le}

2003 We Don't Sleep Around Like White Girls Do": Family, Culture, and Gender in Filipina American Lives In Gender and U.S. Immigration Contemporary Trends. P. Hondagneu-Sotelo, ed. Pp. 263 - 284. Los Angeles: University of California Press.

Ewen, Elizabeth

1989 Immigrant Women in the Land of Dollars: Life and Culture on the Lower East Side: 1890-1925. New York: Monthly Review Press.

Fawcett, James, and Fred Arnold

1987 The Role of Surveys in the Study of International Migration: An Appraisal. International Migration Review 21(4, Special Issue: Measuring International Migration: Theory and Practice):1523-1540.

Flores, Juan

1999 Pan-Latino/Trans-Latino: Puerto Ricans in the "New Nueva York." In Identities on the Move: Transnational Processes in North America and the Caribbean Basin. Liliana Goldin, ed. Pp. 107-132. New York: Institute for Mesoamerican Studies, University at Albany.

Foner, Nancy

2003 Introduction: Anthropology and Contemporary Immigration to the United States - Where We Have Been and Where We Are Going. In American Arrivals: Anthropology Engages the New Immigration. N. Foner, ed. Pp. 3 - 44. Santa Fe: School of American Research Press.

Fuentes, Lya Yaneth

2002 El Origen de una Política: Mujeres jefas de hogar en Colombia 1990-1998. Bogotá Colombia: Facultad de Ciencias Humanas, Universidad Nacional.

\section{Gabaccia, Donna}

1992 Introduction. In Seeking Common Ground Multidisciplinary Studies of Immigrant Women in the United States. D. Gabaccia, ed. Westport, Connecticut: Greenwood Press.

1994 From the Other Side: Women, Gender and Immigrant Life in the U.S., 1820 - 1990. Bloomington: Indiana University Press.

Garcés de Eder, Elena 
2002 The Construction of Radical Feminist Knowledge: Women in Colombia as an Example: Columbian College of Arts and Sciences - George Washington University.

Garcés de Eder, Elena, and Adriana Marulanda Herrán

2005 You Forge your Path as you Walk. In Female Well-Being toward a Global Theory of Social Change. J. Mancini Billson and C. Fluehr-Lobban, eds. Pp. 133158. New York: Zed Books.

Gardner, Martha

2005 The Qualities of a Citizen: Women, Immigration, and Citizenship, 1870 1965. Princeton: Princeton University Press.

George, Sheba Mariam

2005 When Women Come First Gender and Class in Transnational Migration. Los Angeles: University of California Press.

Georges, Eugenia

1992 Gender, Class, and Migration in the Dominican Republic: Women's Experiences in a Transnational Community. In Towards a Transnational Perspective on Migration: Race, Class, Ethnicity, and Nationalism Reconsidered. N.G. Schiller, L. Basch, and C. Blanc-Szanton, eds. Annals of the New York Academy of Science, Vol. 645. New York: The New York Academy of Sciences.

Gibbs, Terry

2007 Women and the Struggle for Social Change in Colombia. Colombia Journal Online Publication (www.colombiajournal.org).

Glick Schiller, Nina, Linda Basch, and Cristina Blanc-Szanton 1992 Towards a Definition of Transnationalism: Introductory Remarks and Research Questions. In Towards a Transnational Perspective on Migration: Race, Class, Ethnicity, and Nationalism Reconsidered. N.G. Schiller, L. Basch, and C. Blanc-Szanton, eds. Annals of the New York Academy of Science, Vol. 654. New York: The New York Academy of Sciences.

Glick Schiller, Nina, Linda Basch, and Cristina Blanc-Szanton 1992(b) Transnationalism: A New Analytic Framework for Understanding Migration. In Towards a Transnational Perspective on Migration: Race, Class, Ethnicity, and Nationalism Reconsidered. N. Glick Schiller, L. Basch, and C. BlancSzanton, eds. Annals of the New York Academy of Science, Vol. 645. New York: The New York Academy of Sciences. 


\section{Goldman, Emma}

1931 Living My Life. New York: Dover Publications Inc.

González, Yolanda

1995 Movimiento de Mujeres en los Años 60 y 70s. In Las Mujeres en la Historia de Colombia Tomo I Mujeres, Historia y Política. M. Velásquez Toro, ed. Pp. 258-278. Bogotá Colombia: Grupo Editorial Norma.

Gordon, Melanie

2006 Matchmaker Matchmaker... Online. Women's League Outlook 76(3):3236.

Gouveia, Lourdes 2005 Divergent Origins, Converging Destinies? Venezuelans, Colombians and Mexicans in the Heartland. In Immigration to the United States: New Sources and Destinations.

Grieco, Elizabeth, and Monica Boyd 1998 Women and Migration: incorporating gender into international migration theory (working paper): Center for the Study of Population. Florida State University College of Social Science.

Hart, John

2002 Stories of Gay and Lesbian Immigration: Together Forever?: Harrington Park Press.

Haus, Leah

1999 Integrated Issues: Migration and International Economic Interdepence. In Free Markets, Open Societies, Closed Borders? M. Castro, ed. Miami - Florida: North-South Center Press

Hernández-león, Rubén

2005 The Migration Industry in the Mexico-U.S. Migration System. In On-Line Working Paper Series - California Center for Population Research.

2008 Metropolitan Migrants: The Migration of Urban Mexicans to the United States. Los Angeles: University of California Press.

Hing, Bill Ong

2004 Defining America through Immigration Policy. Philadelphia: Temple University Press. 

Holt, Martin
2004 'Marriage-like' or Married? Lesbian and Gay Marriage, Partnership and Migration. Feminism \& Psychology 14(1):30-35.

Homeland Security Department

2006 Yearbooks of Immigration Statistics (1999 - 2005) Vol. 2005:

http://www.dhs.gov/ximgtn/statistics. .

Hondagneu-Sotelo, Pierrette.

1992 Overcoming Patriarchal Constraints: The Reconstruction of Gender Relations among Mexican Immigrant Women and Men. Gender and Society 6(3):393-415.

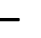

1994 Gendered Transitions: Mexican Experiences of Immigration: University of California Press.

1999 Introduction: Gender and Contemporary U.S. Immigration. The American Behavioral Scientists 42(4):565 - 576.

2000 Feminism and Migration. The ANNALS of the American Academy of Political and Social Science 571(1):107-120.

2003 Blowups and Other Unhappy Endings. In Global Women: Nannies, Maids, and Sex Workers in the New Economy. B. Ehrenreich and R. Hochschild, eds. Pp. 55 - 69. New York: Metropolitan Books.

2003 Gender and Migration: A retrospective and Introduction. In Gender and U.S. Migration Contemporary Trends. P. Hondagneu-Sotelo, ed. Pp. 3 - 19. Los Angeles: University of California Press.

Hondagneu-Sotelo, Pierrette, and Cynthia Cranford 1999 Gender and Migration. In Handbook of the Sociology of Gender. J.S. Chafetz, ed. New York: Plenum Publishers.

Houstoun, Marion F., Roger G. Kramer, and Joan Mackin Barret 1984 Female Predominance in Immigration to the United States since 1930: A First Look. International Migration Review 18(4 Special Issues: Women in Migration):908 - 963. 
Ichioka, Yuhi

1980 Amerika Nadeshiko: Japanese Immigrant Women in the United States, 1900-1924. The Pacific Historical Review 49(2):339-357.

Immigration and Naturalization Services (INS)

1998 International Matchmaking Organizations: A Report to Congress. Immigration and Naturalization Services, Ed: U.S. Department of Homeland Security.

Johnson, Ericka

2007 Dreaming of a Mail-Order Husband Russian-American Internet Romance. London: Duke University Press

Joppke, Christian

1999 Immigration and the Nation-State: The United States, Germany and Great Britain. New York: Oxford University Press.

Kaufman, Michael

1999 Men, Feminism and Men's Contradictory Experiences of Power. In Men and Power. J.A. Kuypers, ed. Pp. 58-83. Halifax: Fenwood Books.

Kimura, Yukiko

1957 War Brides in Hawaii and Their In-Laws. The American Journal of Sociology 63(1): 70-76

Laughlin, Mel

1997 Foreign Affairs to the Satisfied Customers of Fort Lauderdale's Latin Life Mates, Marrying a Total Stranger Who Barley Speaks Your Language Is Not As Crazy As It Sounds. The Miami Herald: November 16

Lee, Everrett S.

1966 A Theory of Migration. Demography 3(1):47 - 57.

Lee, Gary, and Lorene Stone

1980 Mate-Selection Systems and Criteria: Variation according to Family Structure. Journal of Marriage and the Family 42(2):319-326.

Lee, Sharon M

1996 Issues in Research on Women, International Migration and Labor. Asian and Pacific Migration Journal 5(1):5-26. 
Leeds, Anthony

1976 Women in the Migratory Process: A Reductionist Outlook.

Anthropological Quarterly 49(1):69-76.

Levine, R., et al.

1995 Love and Marriage in Eleven Cultures. Journal of Cross-Cultural

Psychology 26(5):554.

Levitt, Peggy

2001 The Transnational Villagers. Berkeley: University of California Press.

Levitt, Peggy, Josh DeWind, and Steven Vertovec

2003 International perspectives on transnational migration: an introduction. International Migration Review 37(3):565 - 576.

Lim, Lin Lean

1990 The Status of Women and International Migration. International

Migration Policies and the Status of Female Migrants. Proceedings of the United

Nations Expert Group Meeting on International Migration Policies and the Status of Female Migrants, San Miniato, Italy, 1990, pp. 29-55. United Nations.

Luibhéid, Eithne

2002 Entry Denied: Controlling Sexuality at the Border. Minneapolis: University of Minnesota Press.

Madrid, Gilma, and Terry Lovell

2007 Working with Flowers in Colombia" the 'Lucky Chance'? Women's Studies International Forum 30(3):217-227.

Mahler, Sarah J

1999 Engendering Transnational Migration: A case study of Salvadorans. The American Behavioral Scientists 42(4):690 - 719.

Mahler, Sarah J., and Patricia R. Pessar

2006 Gender Matters: Ethnographers bring gender from the periphery toward the core of migration studies. International Migration Review 40(1):27 - 63.

Massey, Douglas

1987 The Ethnosurvey in theory and practice. International Migration Review 21(4, Special Issue: Measuring International Migration: Theory and Practice):1498-522. 
1999 Why Does Immigration Occur? A Theoretical Synthesis. In The Handbook of International Migration: The American Experience. C. Hirschman, P. Kasinitz, and J. DeWind, Eds. New York: Russell Sage Foundation.

Massey, Douglas, and Rene Zenteno

2000 A Validation of the Ethnosurvey: The Case of Mexico - U.S. Migration. International Migration Review 34(3).

Meertens, Donny

2001 Victims and Survivors of War in Colombia: Three Views of Gender

Relations. In Violence in Colombia 1990-2000 Waging War and Negotiating

Peace. C. Bergquist, R. Peñaranda, and G. Sánchez, eds. Wilmington, Delaware:

Scholarly Resources Inc.

Moore, $\mathrm{C}$.

2004 Stories of Gay and Lesbian Immigration: Together Forever? The Australian Journal of Politics and History 50(3):464-465.

Morokvasic, Mirjana

1984 Birds of Passage are also Women... International Migration Review 18(4):886 - 907.

Murdock, Donna F 2008 When Women have Wings: Feminism and Development in Medellin, Colombia: University of Michigan Press.

Navarrete, Hector Gabriel

2006 My Latin Bride. Antípoda 2:315-326.

Obeyesekere, G.

1963 Pregnancy Cravings (Dola-Duka) in Relation to Social Structure and

Personality in a Sinhalese Village. American Anthropologist 65(2):323-342.

Oishi, Nana

2002 Gender and migration: An Integrative Approach, Working Paper 49: The Center for Comparative Immigration Studies. University of California, San Diego.

Pallitto, Christina, and O'Campo Patricia 
2005 Community Level Effects of Gender Inequality on Intimate Partner Violence and Unintended Pregnancy in Colombia: Testing the Feminist Perspective. Social Science and Medicine 60(10):2205-2216.

Paradise, Viola

1913 The Jewish Girl in Chicago. Survey 30:700-713.

Parreñas, Rachel Salazar

2001 Servants of Globalization: Women, Migration and Domestic Work. Stanford, California: Stanford University Press.

Pedraza, Silvia

1991 Women and Migration: The Social Consequences of Gender. Annual Review of Sociology 17:301-325.

Pehar, Julie

2003 E-brides: the mail-order bride industry and the internet. Canadian Women Studies 22(3/4):171.

Pessar, Patricia R.

1984 The Linkage between the Household and Workplace of Dominican Women in the U.S. International Migration Review 18(4, Special Issue: Women in Migration):1188 - 1211.

2003 Anthropology and the Engendering of Migration Studies. In American Arrivals Anthropology Engages the New Immigration. N. Foner, ed. Pp. 75 - 98. Santa Fe: School of American Research Press.

2003 Engendering Migration Studies: The Case of New Immigrants in the United States. In Gender and U.S. Migration Contemporary Trends. P. Hondagneu-Sotelo, ed. Pp. 20 - 42. Los Angeles: University of California Press.

2005 Women, Gender, and International Migration Across and Beyond the Americas: Inequalities and Limited Empowerment. In Expert Group Meeting on International Migration and Development in Latin America and the Caribbean. Mexico City: United Nations.

Pessar, Patricia R., and Sarah J. Mahler 2003 Transnational Migration: Bringing Gender In. International Migration Review 37(3):812-846. 
Portes, Alejandro

1995 Economic Sociology and the Sociology of Immigration: A Conceptual Overview. In The Economic Sociology of Immigration: Essays on Networks, Ethnicity, and Entrepreneurship. A. Portes, Ed. New York: Russell Sage Foundation.

1999 Immigration Theory for a New Century: Some Problems and Opportunities. In The Handbook of International Migration: The American Experience. C. Hirschman, P. Kasinitz, and J. DeWind, Eds. New York: Russell Sage Foundation.

Portes, Alejandro, and Robert L Bach 1985 Latin Journey: Cuban and Mexican Immigrants in the United States. Los Angeles: University of California Press.

Portes, Alejandro, and Min Zhow 1993 The New Second Generation: Segmented Assimilation and its Variants. Annals of the American Academy of Political and Social Sciences 530(Nov):74-96.

Ravenstein, Ernest George

1885 The Laws of Migration. Journal of the Statistical Society of London 48(2):167-235.

Reyes Cárdenas, Magdala, and Magdala Velásquez Toro 1995 Proceso Histórico y Derechos de las Mujeres años 50 y 60. In Las Mujeres en la Historia de Colombia Tomo I Mujeres, Historia y Política. M. Velásquez Toro, ed. Pp. 229-257. Bogotá Colombia: Grupo Editorial Norma.

Rodríguez Salazar, Tania

2001 Las Razones del Matrimonio: Representaciones, Relatos de Vida y Sociedad. Guadalajara: Universidad de Guadalajara.

Rossiter, Marian J 2004 International Correspondence Marriages: The Slavic Connection: Prairie Centre of Excellence for Research on Immigration and Integration.

Saenz, Rogelio, Sean-Shong Hwang, and Benigno Aguirre 1994 In Search of Asian War Brides. Demography 31(3):549-559. 


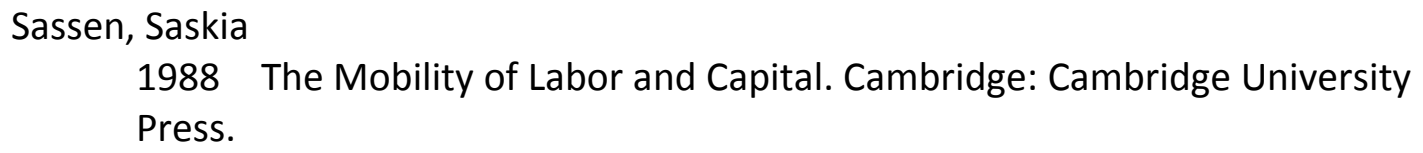

1999 Transnational Economics and National Migration Policies. In Free Markets, Open Societies, Closed Borders? Trends in International Migration and Immigration Policy in the Americas. M. Castro, ed. Miami: North South Center Press, University of Miami.

1999b Guests and Aliens. New York: New York Press.

2000 Women's Burden: Counter-Geographies of Globalization and the Feminization of Survival. Journal of International Affairs.

2002 Women's Burden: Counter-Geographies of Globalization and the Feminization of Survival. Nordic Journal of International Law 71:255-274.

2003 Global Cities and Survival Circuits. In Global Women: Nannies, Maids, and Sex Workers in the New Economy. B. Ehrenreich and R. Hochschild, eds. Pp. 254 274. New York: metropolitan Books.

2003(b) Strategic Instantiations of Gendering in the Global Economy. In Gender and U.S. Migration Contemporary Trends. P. Hondagneu-Sotelo, ed. Pp. 43 60. Los Angeles: University of California Press.

Schepp, Gerald, and Agnes Masato Yui 1955 Cultural and Marital Adjustment of Japanese War Brides. The American Journal of Sociology 61(1):48-50.

Scholes, Robert, and Anchalee Phataralaoha 1999 Appendix A: the Mail-Order Bride Industry and its Impact on U.S. Immigration. In International Matchmaking Organizations: A Report to Congress. I.a.N. Services, Ed.

Schaeffer, Felicity 
2001 Surfing the Internet for Love and Brides: Nationalism and Desire between the Boundaries of Latin America and the U.S. In Raizes e Rumos: Perspectivas Interdiciplinares em Estudos Americanos. S. Torres, ed. Pp. 305-312. Rio de Janeiro: Viveros de Castro Editora.

Schaeffer-Grabiel, Felicity

2004 Cyberbrides and Global Imaginaries: Mexican Women's Turn from the National to the Foreign. Space \& Culture 7(1):33-48.

2006 Planet-Love.com: Cyberbrides in the Americas and the Transnational Routes of U.S. Masculinity. Signs: Journal of Women in Culture and Society 2005 31(2):332-356.

Sigal, Janet, and Mauren Nally 2004 Cultural Perspectives on Gender. In Praeger Guide to the Psychology of Gender. M. Paludi, ed. Westport, CT: Praeger Publishers.

Simon, Rita

1992 Sociology and Immigrant Women. In Seeking Common Ground:

Multidisciplinary studies of immigrant women in the United States. D. Gabaccia, ed. Pp. 23 - 40. Westport, Connecticut: Greenwood Press.

Simon, Rita, and Caroline B. Brettell

1986 International Migration: The Female Experience. New Jersey: Rowman and Allanheld.

Simpson, J. A., B. Campbell, and E. Berscheid

1986 The Association between Romantic Love and Marriage: Kephart (1967)

Twice Revisited. Personality and Social Psychology Bulletin 12(3):363.

Sprecher, S., et al.

1994 Love: American style, Russian style, and Japanese style. Personal Relationships 1(4):349-369.

Strauss, Anselm

1954 Strain and Harmony in American-Japanese War-Bride Marriages. Marriage and Family Living 16(2):99-106.

Stychin, Carl. F.

2000 'A Stranger to its Laws': Sovereign Bodies, Global Sexualities, and Transnational Citizens. Journal of Law and Society 27(4):601-625.

Sutton, Constance R. 
1992 Some Thoughts on Gendering and Internationalizing Our Thinking about Transnational Migrations. In Towards a Transnational Perspective on Migration. N.G. Schiller, L. Basch, and C. Blanc-Szanton, eds. Annals of the New York Academy of Sciences, Vol. 645. New York: The New York Academy of Sciences.

Tambiah, Stanley

1965 Kinship Fact and Fiction in Relation to the Kandyan Sinhalese. The Journal of the Royal Anthropological Institute of Great Britain and Ireland 95(2):131-173.

Taraban, Svitlana

Upcoming 2007 The Internet Bride: Ukranian Women in Virtual Space. In Living Gender after Communism. J.E. Johnson and J.C. Robinson, Eds.

Thai, Hung Cam

2003 Clashing Dreams: Highly Educated Overseas Brides and Low-Wage U.S. Husbands. In Global Women: Nannies, Maids, and Sex Workers in the New Economy. B. Ehrenreich and R. Hochschild, eds. Pp. 230-253. New York: Metropolitan Books.

Thomas, William, and Florian Znaniecki

1919 The Polish Peasant in Europe and America. Boston: The Gorham Press.

Torado, Michael, and Lydia Marussko

1987 Illegal Migration and US Immigration Reform: A Conceptual Framework. Population and Development Review 13(1):101 - 114.

Tyner, James

2003 The Global Context of Gendered Labor Migration from the Philippines to the United States. In Gender and U.S. Immigration Contemporary Trends. P. Hondagneu-Sotelo, ed. Los Angeles University of California Press.

Tucker, Joe $A$

1989 Assimilation to the United States: A study of the adjustment of status and the Immigration Marriage Fraud Statutes. Yale Law and Policy Review 7(2): 20100

\section{U.S. 19th Congress}

2005 International Marriage Broker Regulation Act of 2005.

United Nations

1948 Universal Declaration of Human Rights.

http://www.unhchr.ch/udhr/lang/eng.htm, Ed, Vol. http://www.unhchr.ch/udhr/lang/eng.htm. 
2005 - 2004 World Survey on the Role of Women Development. New York: United Nations Population Fund.

2006 State of World Population 2006 A Passage to Hope Women and International Migration. New York: United Nations Population Fund.

Uribe, Martha Lucia

1995 Mujeres y Violencia. In Las Mujeres en la Historia de Colombia Tomo I Mujeres, Historia y Política. M. Velásquez Toro, ed. Pp. 348-361. Bogotá Colombia: Grupo Editorial Norma.

Velásquez Toro, Magdala

1995 Aspectos de la Condición Jurídica de las Mujeres. In Las Mujeres en la Historia de Colombia Tomo I Mujeres, Historia y Política. M. Velásquez Toro, ed. Pp. 173 - 182. Bogotá Colombia: Grupo Editorial Norma.

Waldinger, Roger, Howard Aldrich, and Robin Ward

1990 Ethnic Entrepreneurs: Immigrant and Ethnic Business in Industrial Societies. Newbury Park, CA: Sage Publications.

Wallerstein, Immanuel

2004 World-Systems Analysis: An Introduction. Durham, North Carolina: Duke University Press.

Weinberg, Sydney Stahl

1992 The Treatment of Women in Immigration History: A Call for Change. In Seeking Common Ground: Multidisciplinary Studies of Immigrant Women in the United States. D. Gabaccia, ed. London: Greenwood Press.

Whiteford, Michael

1978 Women, Migration and Social Change: A Colombian Case. International Migration Review 12(2):236 - 247.

Withshire, Rosina

1992 Implications of Transnational Migration for Nationalism: The Caribbean Example. In Towards a Transnational Perspective on Migration: Race, Class, Ethnicity, and Nationalism Reconsidered. N.G. Schiller, L. Basch, and C. BlancSzanton, eds. Annals of the New York Academy of Sciences, Vol. 645. New York: The New York Academy of Sciences.

Yalman, Nur. 
1962 The Structure of the Sinhalese Kindred: A Re-Examination of the Dravidian Terminology. American Anthropologist 64(3):548-575.

Zinn, Maxine Baca

2000 Feminism and Family Studies for a New Century. The ANNALS of the American Academy of Political and Social Science 571(1):42-56.

Zlotnik, Hania

1995 The South-to-North Migration of Women. International Migration Review 29(1, Special Issue: Diversity and Comparability: International Migrants in Host Countries of four Continents):229 - 254.

2003 The Global Dimensions of Female Migration. In Data Insight - Migration Information Source. 
JASNEY E. COGUA-LOPEZ

2010

Program Evaluator - Adult Drug Court Specialized

Treatment for Women. 11th Judicial Circuit of Florida

2008

Teaching Assistant - Sociology and Anthropology

Department. Florida International University

$2005-2007$

Research Assistant \& Program Evaluator - Sociology and Anthropology Department. Florida International University

April 2006

M.A. Comparative Sociology - Florida International University. Miami, Florida

$2003-2004$

Assistant - Director Middle America Area. Compassion International. Deerfield Beach, Florida

December 2003

M.A. Sociology - University of Nebraska at Omaha. Omaha, Nebraska

$2002-2003$

Teaching Assistant - Sociology and Anthropology

Department. University of Nebraska at Omaha

$2001-2002$

Research Assistant - Sociology and Anthropology

Department. University of Nebraska at Omaha

August 2000

Bachelor's In Public Accounting - Universidad Central.

Bogotá, Colombia

\section{PUBLICATIONS AND PRESENTATIONS}

Cogua-Lopez, Jasney. "Through the prisms of Gender and Power: Agency in International Courtship between Colombian Women and American Men" Presentation, Florida International University, Women Studies Conference, Miami, FL. March 2008

Eisenhauer, Emily, Barclay Brianne, Cogua-Lopez Jasney and Angee Alejandro. 2007.

"Community Knowledge and Attitudes toward Refugees and Asylees in Miami-Dade and Broward Counties: An Analysis for the International Rescue Committee." In National Association for the Practice of Anthropology Bulletin, May 2007, Vol. 27, No. 1, pp. 224-236. 
Cogua-Lopez, Jasney. "Plan Colombia's Program of Eradication Illegal Crops and Their Effects on Rural Communities" Presentation, Florida International University, Graduate Students Association 2005 Scholarly Forum, Miami, FL. March 2005

Eisenhauer, Emily, Barclay Brianne, Cogua-Lopez Jasney and Angee Alejandro.

"Community Knowledge and Attitudes towards Refugees and Asylees in Miami-Dade and Broward Counties" Presentation, International_Rescue Committee in Miami, FL. August 2005

Gouveia Lourdes; Carranza Miguel and Cogua Jasney. 2005. "The Great Plains Migration: Mexicanos and Latinos in Nebraska." In New Destinations: Mexican Immigration in the United States, edited by Victor Zuniga and Ruben Hernandez-Leon. Russell Sage Foundations, New York.

Cogua-Lopez, Jasney. Plan Colombia: Whose Plan is it Anyway?" Presentation, North Central Council of Latin Americanists. Omaha, NE. October 2003

Cogua-Lopez, Jasney. "Plan Colombia: The last gasp of rural development? Vision and alternatives" Presentation, Midwest Sociological Society Annual Conference. Chicago, IL. May 2003

Gouveia Lourdes; Carranza Miguel, Cogua Jasney and Katrina Ondracek-Sayers. 2002. The Integration of the Hispanic/Latino Immigrant Workforce - Final Report. Submitted to the State of Nebraska Mexican American Commission and Task Force on Productive Integration of the Immigrant Workforce Population.

\section{AWARDS}

- Dissertation Year Fellowship (Spring 2009 - Fall 2009) Florida International University; 2009

- National Association for the Practice of Anthropology Student Achievement Award Competition 2005. Second Place: "Community Knowledge and Attitudes towards Refugees and Asylees in Miami-Dade and Broward Counties" Authors: Emily Eisenhauer, Brianne Barclay, Jasney Cogua-Lopez, and Alejandro Angee. December, 2005

- Florida International University, Graduate Students Association 2005 Scholarly Forum. Second Place: "Plan Colombia's Program of Eradication Illegal Crops and Their Effects on Rural Communities" March, 2005

- University of Nebraska at Omaha in-state tuition scholarship award, May 2001

- University of Nebraska Scholarship - Scholarship award August 2000

- Universidad Central - Colombia: Thesis Special Mention. Contabilidad Cultural 2000 